Prepared in cooperation with Sauk-Suiattle Indian Tribe

\title{
Skagit River Coho Salmon Life History Model—Users' Guide
}

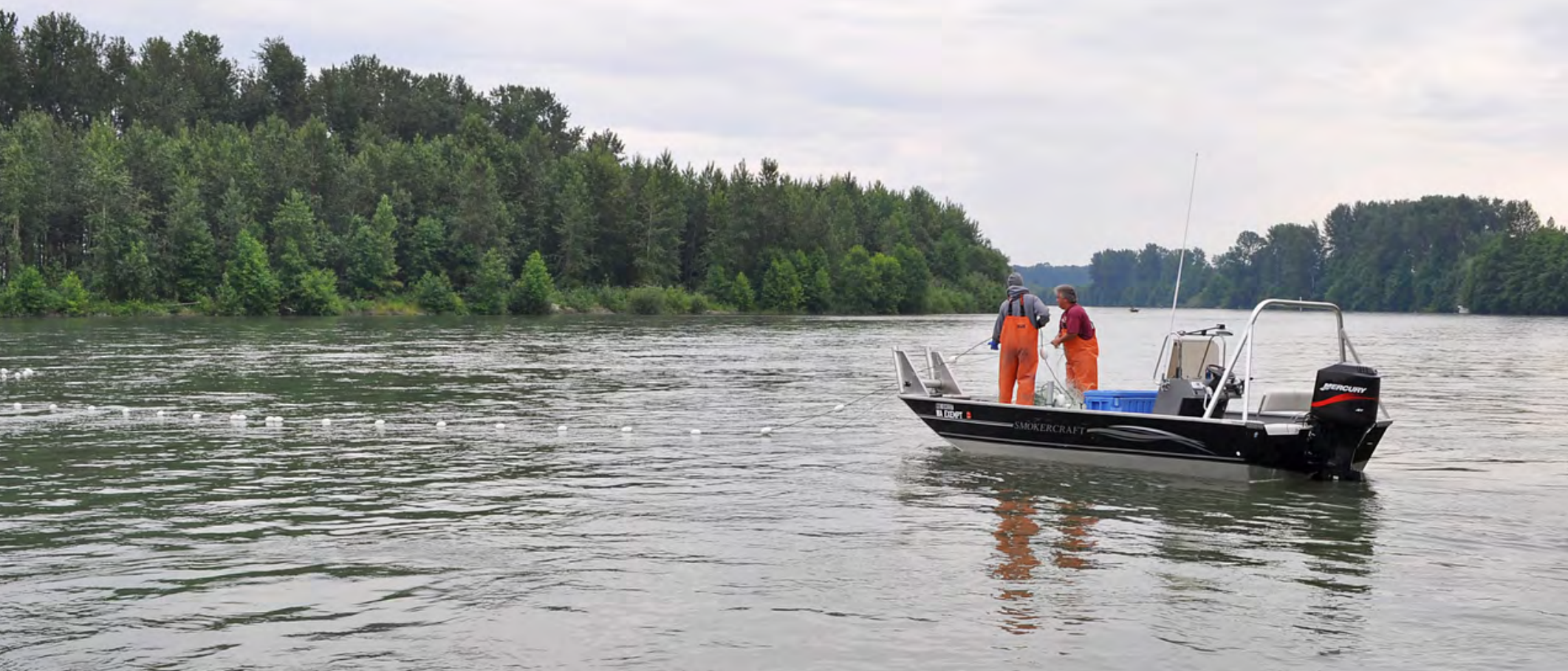

Open-File Report 2017-1125

U.S. Department of the Interior

U.S. Geological Survey 
Cover: Photograph showing Tribal fishers in the lower Skagit River, Washington, June 2011.

Photograph from Sauk-Suiattle Natural Resource Department. 


\section{Skagit River Coho Salmon Life History Model—Users' Guide}

By Andrea Woodward, Grant Kirby, and Scott Morris

Prepared in cooperation with Sauk-Suiattle Indian Tribe

Open-File Report 2017-1125

U.S. Department of the Interior

U.S. Geological Survey 


\section{U.S. Department of the Interior \\ RYAN K. ZINKE, Secretary}

\section{U.S. Geological Survey \\ William H. Werkheiser, Acting Director}

U.S. Geological Survey, Reston, Virginia: 2017

For more information on the USGS-the Federal source for science about the Earth,

its natural and living resources, natural hazards, and the environment-visit

https://www.usgs.gov/ or call 1-888-ASK-USGS (1-888-275-8747).

For an overview of USGS information products, including maps, imagery, and publications, visit https:/store.usgs.gov.

Any use of trade, firm, or product names is for descriptive purposes only and does not imply endorsement by the U.S. Government.

Although this information product, for the most part, is in the public domain, it also may contain copyrighted materials as noted in the text. Permission to reproduce copyrighted items must be secured from the copyright owner.

Suggested citation:

Woodward, Andrea, Kirby, Grant, and Morris, Scott, 2017, Skagit River coho salmon life history modelUsers' guide: U.S. Geological Survey Open-File Report 2017-1125, 57 p.,

https://doi.org/10.3133/ofr20171125.

ISSN 2331-1258 (online) 


\section{Contents}

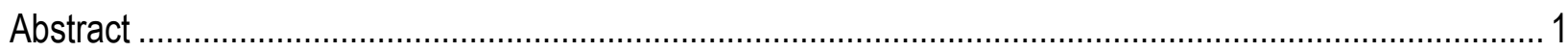

Introduction

Purpose

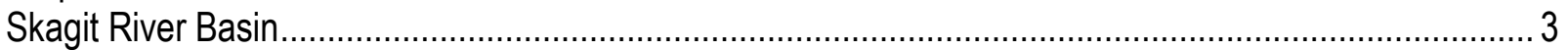

Sauk-Suiattle Indian Tribe ..................................................................................................... 3

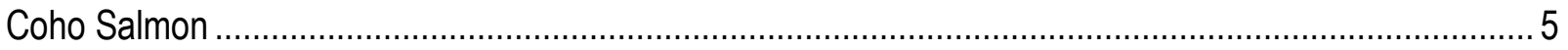

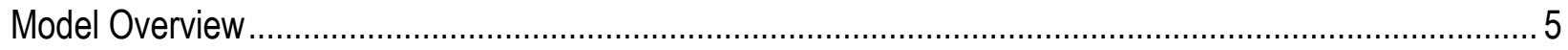

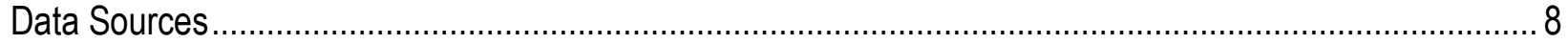

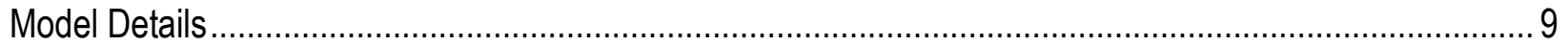

Modeling "Predicted Smolts" .................................................................................................

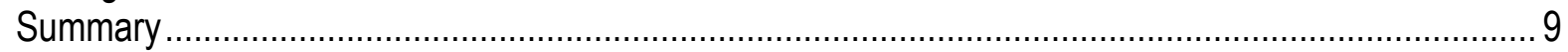

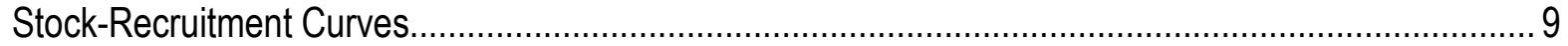

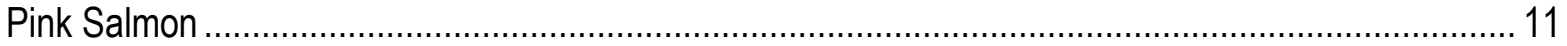

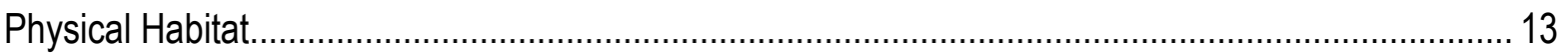

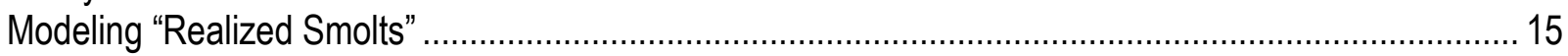

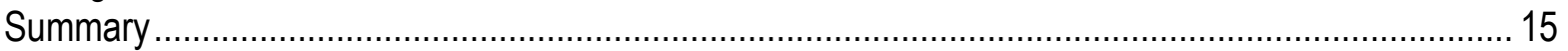

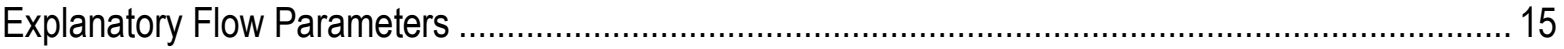

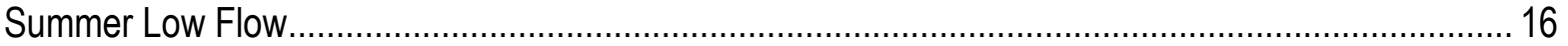

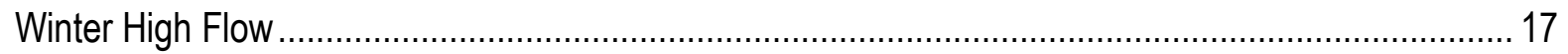

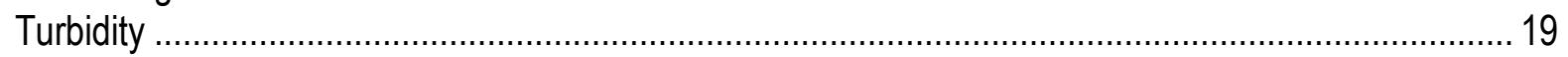

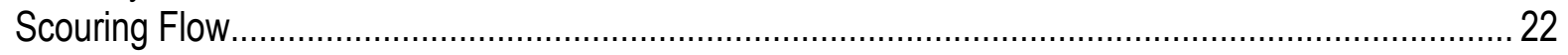

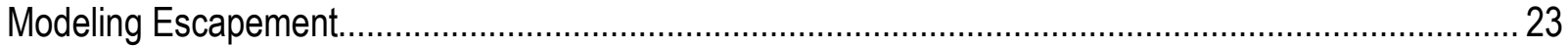

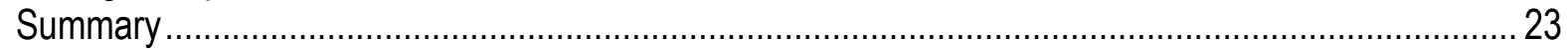

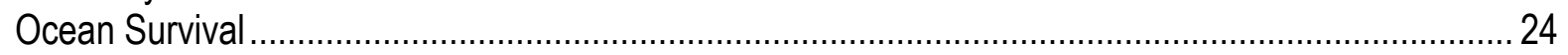

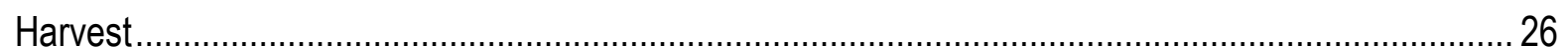

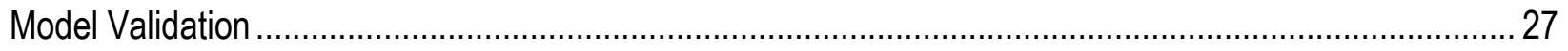

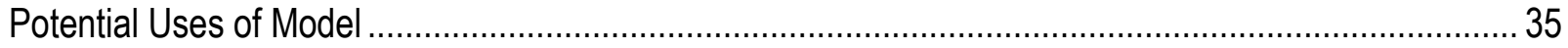

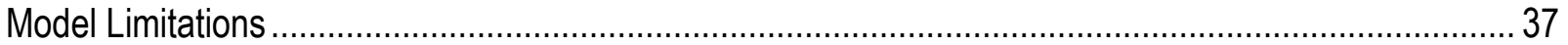

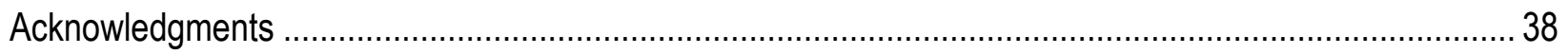

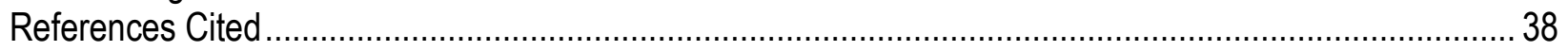

Appendix A. Definitions of Model Terms ....................................................................................... 48

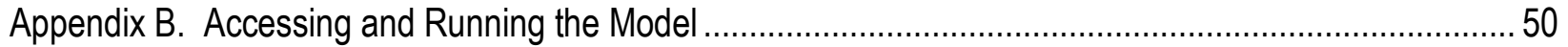

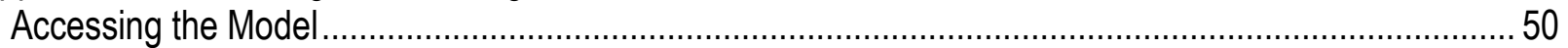

Running the Model............................................................................................................ 50

Appendix C. Skagit Salmon Co-Managers Data Used in Model Development .......................................... 55

Appendix D. Model Equations ………………................................................................................ 56 


\section{Figures}

Figure 1. Map showing Skagit River Basin, northwestern Washington .................................................. 4

Figure 2. Schematic diagram showing Skagit River coho salmon life history mode.................................. 6

Figure 3. Ricker stock-recruitment curve calculated from smolt and spawner data collected on the Skagit River, northwestern Washington, brood years 1989-2012. 10

Figure 4. Comparison of smolt recruitment curves expected in years with and without spawning pink salmon, brood years 1989-2012

Figure 5. Comparison of Ricker stock-recruitment curves calculated for early and late in the period of record, brood years 1989-96 and 2006-12, respectively.

Figure 6. Regression showing fraction of smolt prediction from Ricker curve actually realized owing to summer flow conditions measured at Sauk River streamgage (USGS 12189500).

Figure 7. Graph showing effect of high flow during juvenile rearing period on residual deviation of smolt production from Ricker-based prediction after accounting for the effects of summer flow measured at Sauk gage (USGS 12186000).

Figure 8. Regression showing relation of number of days with turbidity greater than $(>) 30$ Nephelometric Turbidity Units during the freshwater life stages of coho cohorts (February following spawning through April of following year) with residual deviation of actual from predicted smolts after summer low flow is accounted for

Figure 9. Comparison of model results with estimated number of smolts from counts at smolt trap when each year is initialized with estimated number of spawners (escapement), 1989-2012

Figure 10. Comparison of model results for estimated escapement predicted using Pacific Decadal Oscillation and smolts compared with data-based estimates when each year is initialized with estimated number of spawners (escapement), 1989-2012.

Figure 11. Comparison of model results for estimated escapement predicted using North Pacific Gyre Oscillation and chlorophyll-a compared with data-based estimates when each year is initialized with estimated number of spawners (escapement), 2001-12.

Figure 12. Comparison of model results with estimated number of smolts based on counts at smolt trap when the first 3 years of the model run are initialized with estimated number of spawners (escapement) and subsequently by model results.

Figure 13. Comparison of model results for estimated escapement predicted using Pacific Decadal Oscillation and smolts compared with data-based estimates when the first 3 years of the model run are initialized with estimated number of spawners (escapement) and subsequently by model results

Figure 14. Comparison of model results for estimated escapement predicted using NPGO and chlorophyll-a compared with data-based estimates when the first 3 years of the model run are initialized with estimated number of spawners (escapement) and subsequently by model results 


\section{Tables}

Table 1. Data sources used to develop Skagit River coho salmon life history model................................. 8

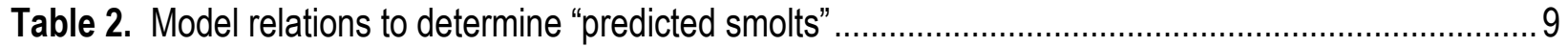

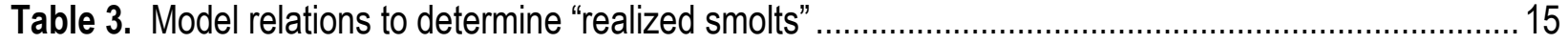

Table 4. Best-ranked multiple regression models explaining smolt production ........................................16

Table 5. Model relations to determine "escapement" ....................................................................... 23

Table 6. Indicators of ocean condition determined to be associated with ocean mortality of coho salmon in geographic areas near to or including the Skagit River, northwestern Washington....................25

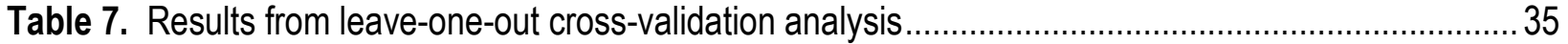

\section{Conversion Factors}

U.S. customary units to International System of Units

\begin{tabular}{|c|c|c|}
\hline Multiply & By & To obtain \\
\hline \multicolumn{3}{|c|}{ Area } \\
\hline acre & 4,047 & square meter $\left(\mathrm{m}^{2}\right)$ \\
\hline acre & 0.004047 & square kilometer $\left(\mathrm{km}^{2}\right)$ \\
\hline \multicolumn{3}{|c|}{ Flow rate } \\
\hline cubic foot per second $\left(\mathrm{ft}^{3} / \mathrm{s}\right)$ & 0.02832 & cubic meter per second $\left(\mathrm{m}^{3} / \mathrm{s}\right)$ \\
\hline
\end{tabular}

International System of Units to U.S. customary units

\begin{tabular}{|c|c|c|}
\hline Multiply & By & To obtain \\
\hline \multicolumn{3}{|c|}{ Length } \\
\hline centimeter $(\mathrm{cm})$ & 0.3937 & inch (in.) \\
\hline $\operatorname{meter}(\mathrm{m})$ & 3.281 & foot $(\mathrm{ft})$ \\
\hline kilometer $(\mathrm{km})$ & 0.6214 & mile (mi) \\
\hline \multicolumn{3}{|c|}{ Area } \\
\hline square meter $\left(\mathrm{m}^{2}\right)$ & 10.76 & square foot $\left(\mathrm{ft}^{2}\right)$ \\
\hline square kilometer $\left(\mathrm{km}^{2}\right)$ & 247.1 & acre \\
\hline square kilometer $\left(\mathrm{km}^{2}\right)$ & 0.3861 & square mile $\left(\mathrm{mi}^{2}\right)$ \\
\hline
\end{tabular}

Temperature in degrees Celsius $\left({ }^{\circ} \mathrm{C}\right)$ may be converted to degrees Fahrenheit $\left({ }^{\circ} \mathrm{F}\right)$ as follows:

$$
{ }^{\circ} \mathrm{F}=\left(1.8 \times{ }^{\circ} \mathrm{C}\right)+32 \text {. }
$$




\section{Datums}

Vertical coordinate information is referenced to the North American Vertical Datum of 1929 (NAVD 29)].

Horizontal coordinate information is referenced to the Datum of 1983 (NAD 83)].

Elevation, as used in this report, refers to distance above the vertical datum.

\section{Abbreviations}

$\begin{array}{ll}\text { AICc } & \text { Akaike's Information Criterion for small sample } \\ \text { BY } & \text { brood year } \\ \text { CI } & \text { confidence interval } \\ \text { ENSO } & \text { El Nino Southern Oscillation } \\ \text { LOOCV } & \text { leave-one-out cross-validation } \\ \text { MWMT } & \text { maximum weekly maximum temperatures } \\ \text { NPGO } & \text { North Pacific Gyre Oscillation } \\ \text { NTU } & \text { Nephelometric Turbidity Unit } \\ \text { ONI } & \text { Oceanic Nino Index } \\ \text { PDO } & \text { Pacific Decadal Oscillation } \\ \text { r }^{2} & \text { coefficient of determination } \\ \text { R2 } & \text { coefficient of multiple determination } \\ \text { SST } & \text { sea-surface temperature } \\ \text { TOCAS } & \text { Treaty Online Catch Accounting System } \\ \text { USGS } & \text { U.S. Geological Survey } \\ \text { WDFW } & \text { Washington Department of Fish and Wildlife } \\ \text { WY } & \text { water year }\end{array}$




\title{
Skagit River Coho Salmon Life History Model-Users' Guide
}

By Andrea Woodward ${ }^{1}$, Grant Kirby², and Scott Morris²

\begin{abstract}
Natural resource management is conducted in the context of multiple anthropogenic stressors and is further challenged owing to changing climate. Experiments to determine the effects of climate change on complex ecological systems are nearly impossible. However, using a simulation model to synthesize current understanding of key ecological processes through the life cycle of a fish population can provide a platform for exploring potential effects of and management responses to changing conditions. Potential climate-change scenarios can be imposed, responses can be observed, and the effectiveness of potential actions can be evaluated. This approach is limited owing to future conditions likely deviating in range and timing from conditions used to create the model so that the model is expected to become obsolete. In the meantime, however, the modeling process explicitly states assumptions, clarifies information gaps, and provides a means to better understand which relationships are robust and which are vulnerable to changing climate by observing whether and why model output diverges from actual observations through time. The purpose of the model described herein is to provide such a decision-support tool regarding coho (Oncorhynchus kisutch) salmon for the Sauk-Suiattle Indian Tribe of Washington State.

The Skagit coho salmon model is implemented in a system dynamics format and has three primary stocks - (1) predicted smolts, (2) realized smolts, and (3) escapement. "Predicted smolts" are the number of smolts expected based on the number of spawners in any year and the Ricker production curve. Pink salmon (Oncorhynchus gorbuscha) return to the Skagit River in odd years, and when they overlap with juvenile rearing coho salmon, coho smolt production is substantially higher than in nonpink years. Therefore, the model uses alternative Ricker equations to predict smolts depending on whether their juvenile year was a pink or non-pink year. The stock "realized smolts" is calculated based on the expected effect of streamflow conditions to alter the productivity predicted by the Ricker curve. Adverse conditions include scouring flow events that occur when redds are present; high-flow events during winter on juveniles, which can cause fish displacement and adverse water turbidity; and extremely low flows in summer. The stock "escapement" represents the fish remaining after accounting for ocean mortality and harvest. Ocean mortality has been linked with indices of ocean conditions, which are related to ocean biological productivity. Ocean survival also may have a density-dependent component such that lower survival is associated with higher numbers of smolts. The model allows the user to change certain model parameters and inputs, and choose among alternative predictors for certain modeled relations.
\end{abstract}

\footnotetext{
${ }^{1}$ U.S. Geological Survey.

${ }^{2}$ Sauk-Suiattle Indian Tribe, Darrington, Washington.
} 


\section{Introduction}

\section{Purpose}

Natural resource management is conducted in the context of multiple anthropogenic stressors and is further challenged owing to changing climate. Experiments to determine the effects of climate change on complex ecological systems are nearly impossible. However, using a simulation model to synthesize current understanding of key ecological processes through the life cycle of a fish population can provide a platform for exploring potential effects of and management responses to changing conditions. Potential climate-change scenarios can be imposed, responses can be observed, and the effectiveness of potential actions can be evaluated. This approach is limited owing to future conditions likely deviating in range and timing from conditions used to create the model so that the model is expected to become obsolete. In the meantime, however, the modeling process explicitly states assumptions, clarifies information gaps, and provides a means to better understand which relationships are robust and which are vulnerable to changing climate by observing whether and why model output diverges from actual observations through time. The purpose of the model described herein is to provide such a decision-support tool regarding coho (Oncorhynchus kisutch) salmon for the Sauk-Suiattle Indian Tribe of Washington State.

Coho was selected as a candidate salmonid species for this modeling exercise because of life history attributes, distribution, and ongoing efforts. Coho life history provides a level of simplicity to the model because on average 97 percent of recruits return to the river as 3 -year-olds. Therefore, the model does not have to account for variable life cycle lengths within cohorts as with most other salmon species, and whereas coho life history may become more complex in the future, we do not attempt to model potential changes. Coho also have the largest spatial distribution among salmon species in the Skagit River system. Coho spawning occurs in low-gradient conditions throughout the watershed, including urban drainage ditches, main-stem side channels, small and large tributaries, and low-gradient spawning habitat within high-gradient mountain streams. Fry to juvenile fish rear in main-stem fringe habitat, streams, wetlands, beaver ponds, and lakes. This extensive distribution will help with assessing effects of climate as variable changes are observed among habitat types. With ongoing and future coho habitat restoration planned (in particular, Barnaby Slough and culvert replacement), the model will serve as a tool to assess success. Additionally, we did not want to select a species that would duplicate the efforts of others. Presently (2017), much research and data compilation are being conducted regarding Skagit Chinook salmon (Oncorhynchus tshawytscha) and steelhead (Oncorhynchus mykiss) because both species are listed as threatened under the Endangered Species Act of 1973 (16 U.S.C. § 1531 et seq.). Coho are not considered threatened or endangered in Puget Sound; however, there has been a steady decline in ocean survival of coho originating in the Salish Sea (Puget Sound, Strait of Juan de Fuca, and Georgia Strait) over several decades (Beamish and others, 2010; Zimmerman and others, 2015). 


\section{Skagit River Basin}

The Skagit River Basin covers $8,270 \mathrm{~km}^{2}$, including the $1,849 \mathrm{~km}^{2}$ Sauk-Suiattle watershed, and drains the North Cascades Mountains of Washington and British Columbia. The Skagit River is the largest river between the Fraser River in British Columbia and the Columbia River, and it is the largest tributary to Puget Sound. The Skagit River Basin has a steep elevation range, from marine waters to $3,275 \mathrm{~m}$, and a steep annual precipitation gradient from $90 \mathrm{~cm}$ at sea level to $460 \mathrm{~cm}$ near Glacier Peak (Beechie and others, 2005). The river flows from the subalpine fir (Abies lasiocarpa) vegetation zone at high elevation, through the Pacific silver fir (Abies amabilis) zone, to the western hemlock (Tsuga heterophylla) zone in the lowlands (Franklin and Dyrness, 1973). Land uses and ownership include the State of Washington or private owners (19 percent), protected areas (44 percent), managed national forest (24 percent), and the Province of British Columbia (13 percent) (Beechie and others, 1994).

Steep elevation gradients and a maritime climate mean that the Pacific Northwest has wet winters and dry summers, with winter precipitation falling as snow at high elevations, mixed snow and rain at mid-elevations, and rain in the lowlands. Peak flows in snow-dominated areas occur in spring, owing to snowmelt, whereas peak flows in rain-dominated areas occur in early winter, owing to winter storms. Mixed areas, also known as the transient zone, have intermediate hydrographs (Beechie and others, 2006). Hydrologic patterns are predicted to shift as snow-dominated areas become transient and transient areas become rain-dominated because of climate change (Mantua and others, 2010). Pacific Northwest climate varies in concert with the El Nino Southern Oscillation (ENSO; period 2-7 years) and Pacific Decadal Oscillation (PDO; period of several decades) patterns of sea-surface temperature anomalies. Warm phases of each pattern are associated with warm and dry winter and spring weather, whereas cool phases are associated with $1^{\circ} \mathrm{C}$ lower average temperature and 20 percent higher precipitation (Mote and others, 2003).

\section{Sauk-Suiattle Indian Tribe}

The Sauk-Suiattle Indian Tribe historically occupied the Sauk, Suiattle, and Cascade River watersheds, tributaries of the Skagit River in western Washington (fig. 1) with seasonal villages extending downriver to the marine nearshore. The main part of the Sauk-Suiattle Indian Reservation covers 28 acres in the flood plain of the Sauk River, about $10 \mathrm{~km}$ north of Darrington, Washington. Traditionally, Sauk-Suiattle Tribal members subsisted as fishers, hunters, and gatherers, and traveled downriver to Puget Sound by the Skagit and Stillaguamish Rivers to harvest fish and shellfish; to the mountains for food, herbs and other materials; and to eastern Washington on horseback for trade. The Tribe's continuing interest in fish for commercial, subsistence, and ceremonial purposes is subject to the 1974 Boldt Decision ${ }^{3}$, which reaffirms the reserved right of Tribes to co-manage (along with the State of Washington) fisheries and hatchery programs in Washington State, and allocates one-half of the harvestable surpluses of fish runs to Tribes. Specifically, the Sauk-Suiattle, Swinomish, and Upper Skagit Indian Tribes are co-managers of Skagit salmon with Washington State. As such, they have input into management decisions regarding ocean fisheries made by the Pacific Fisheries Management Council and regarding Puget Sound fisheries.

${ }^{3}$ United States v. Washington, 384 F. Supp. 312 (W.D. Wash. 1974), aff'd, 520 F. 2d 676 (9th Cir. 1975). 


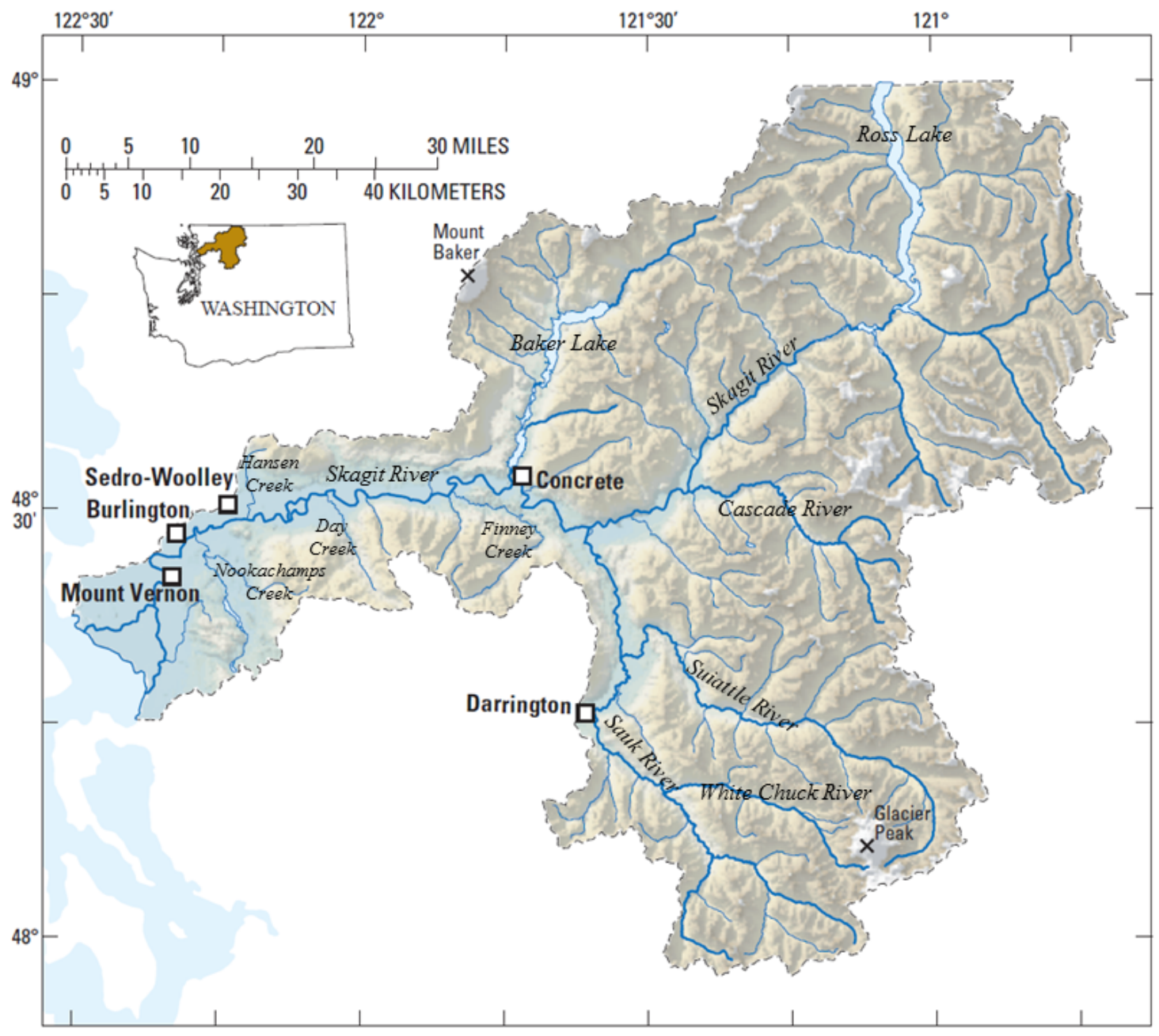

Figure 1. Map showing Skagit River Basin, northwestern Washington. (Source: USGS; horizontal datum, North American Datum of 1983). 


\section{Coho Salmon}

Coho salmon in the eastern Pacific Ocean range from northern California to Alaska including the Skagit River system, where they are present from the river mouth to the Gorge Dam, which is their native range. They have a 3-year life cycle that begins when coho spawners return from the ocean to freshwater and arrive at spawning grounds, typically between late November to early February, when they build redds, lay eggs, and expire in smaller tributaries (Sandercock, 1991; Beechie and others, 1994; Lestelle, 2007). Eggs hatch into alevins and emerge as fry in spring. Juveniles grow in the freshwater habitat through summer, autumn, and the following winter until they smolt in spring and migrate to the ocean, although small fish may remain in freshwater for another year (Seiler and others, 2001). After 18 months in the ocean, they return to freshwater as spawners to repeat the cycle (Groot and Margolis, 1991). However, some return after a few months in the ocean and others may remain in the ocean for 30 months (Shapovalov and Taft, 1954; Gallagher and Wright, 2012).

Although Puget Sound coho salmon are not currently (2017) considered threatened under the Endangered Species Act, all salmonid populations on the Skagit River are subject to a number of anthropogenic disturbances. Flow regimes, including summer low flows (Mathews and Olson, 1980; Quinn and Peterson, 1996), winter high flows (McMahon and Hartman, 1989; Shirvell, 1990), and scouring flows during spawning (Seiler and others, 2003) explain much of the variation in coho smolt production. Climate change also is a potential threat to Skagit River Basin coho (hereinafter "Skagit coho") because flow amount and timing as well as water temperature are expected to be altered by climate change (Mote and others, 2003; Mantua and others, 2010). Moreover, ocean conditions, including sea-surface temperature, upwelling, and other climate-related parameters are associated with ocean survival for coho salmon (Scarnecchia, 1981; Nickelson, 1986; Beamish and others, 2010; Zimmerman, 2012). The purpose of this coho salmon life history model is to integrate the various factors hypothesized to affect coho survival and to enable managers to investigate how changes predicted because of climate change and potential management actions may affect the Skagit River coho population.

\section{Model Overview}

The Skagit coho salmon life history model was built using a system dynamics format (Ford, 1999), which consists of three basic elements: stocks, flows, and converters. Stocks are measurable quantities that can change over time, such as numbers of animals in populations. Flows are any processes or conditions that change the quantity in a stock over time and are expressed in the model as a rate of change. Converters are processes or conditions that change the rate of flows. Anything that influences the rate of change such as different environmental conditions, other external factors, or feedbacks from other stocks or flows, is modeled as a converter. For example, the number of fish in a population is appropriately modeled as a stock. Mortality is modeled as a flow because it is a rate of change over time that determines the number of fish in the population. The effect of flow regime is an example of a converter because it influences the rate of mortality. Together, the flows and converters change the number, or stock, of coho. The instructions embedded in the stocks, flows, converters, and the linkages among them are processed by the simulation software. Unfortunately, the standard terms used for system dynamic models can be confusing when used regarding fisheries, where the terms stocks and flows have other meanings. 
The Skagit coho salmon model is implemented using Stella Architect ${ }^{\circledR}$ version 1.1.2 system dynamics software (http://www.iseesystems.com, accessed September, 2017) and has three primary stocks, (1) predicted smolts, (2) realized smolts, and (3) escapement (fig. 2). "Predicted smolts" are the number of smolts expected based on the number of spawners in any year and the Ricker production curve. Pink salmon (Oncorhynchus gorbuscha) return to the Skagit in odd years, and when they overlap with juvenile rearing coho salmon, coho smolt production is substantially higher than in non-pink years (Michael, 1995; Zimmerman, 2012; Nelson and Reynolds, 2014). Therefore, the model uses alternative Ricker equations to predict smolts depending on whether their juvenile year was a pink or non-pink year. Ricker curves include parameters describing the non-density dependent productivity and carrying capacity of system. The model allows the user to modify the baseline carrying capacity to account for positive or negative changes in habitat availability owing to processes such as restoration, aggradation owing to mass sediment deposition, and unsuitable water temperatures.

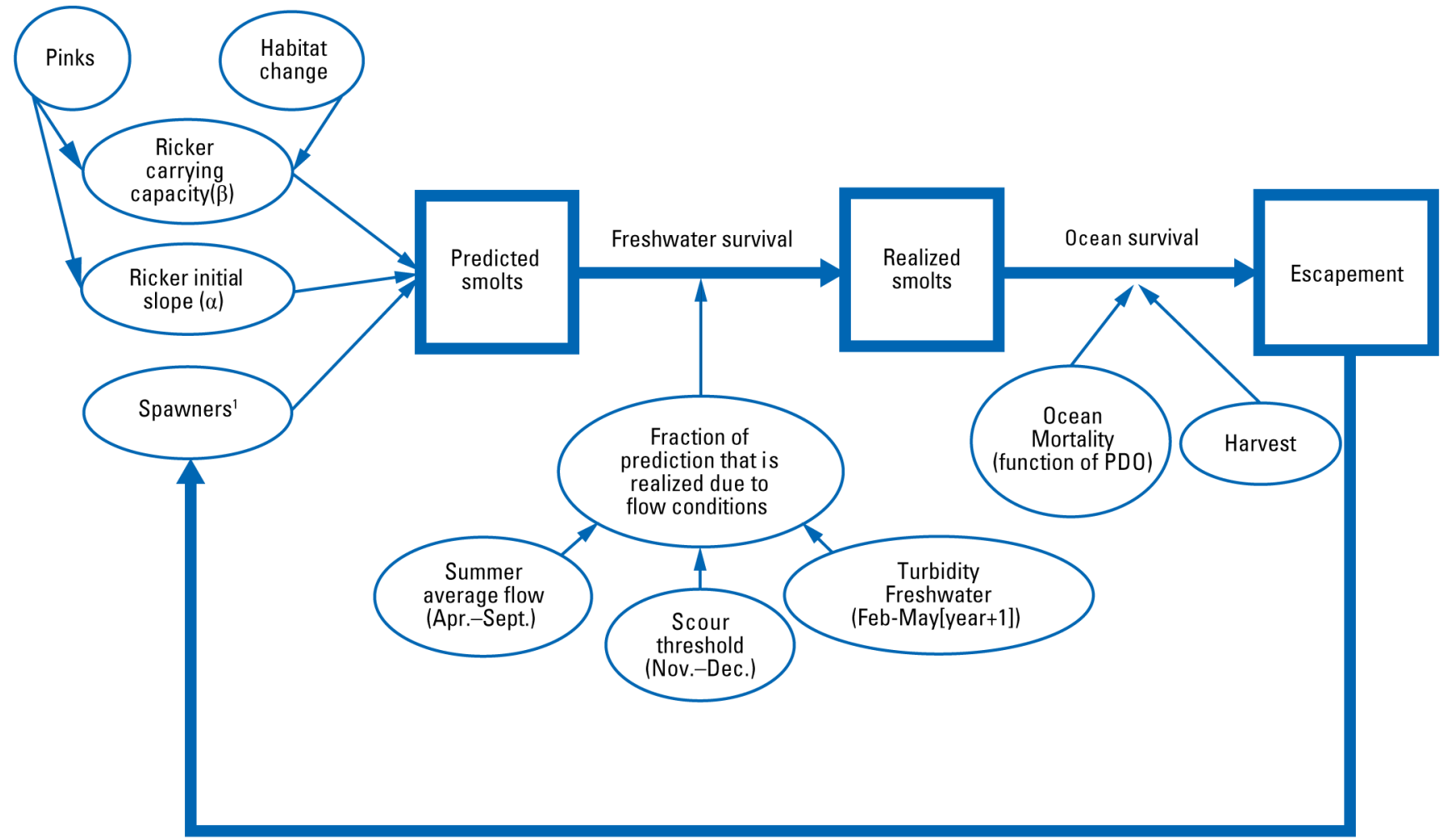

1 "Cycle" model version: spawners equal escapement after intial year for cohort "Non-Cycle" model version: spawner numbers are input for each year

Figure 2. Schematic diagram showing Skagit River coho salmon life history model. 
Streamflow conditions at various fish life stages have been identified as the major environmental conditions affecting coho freshwater productivity (Mathews and Olson, 1980; Quinn and Peterson, 1996; Seiler and others, 2003). The stock "realized smolts" is calculated based on the expected effect of streamflow conditions to alter the productivity predicted by the Ricker curve. Adverse conditions include scouring flow events that occur when redds are present (Seiler and others, 2003); high-flow events during winter on juveniles (McMahon and Hartman, 1989; Shirvell, 1990), which can cause fish displacement and adverse water turbidity (Gregory 1992); and extremely low flows in summer (Mathews and Olson, 1980; Quinn and Peterson, 1996). Details of these analyses follow in section, "Model Details."

The stock "escapement" represents the fish remaining after accounting for ocean mortality and harvest. Ocean mortality has been linked with indices of ocean conditions (Nickelson, 1986), which are related to ocean biological productivity. Ocean survival also may have a density-dependent component such that lower survival is associated with higher numbers of smolts (Emlen and others, 1990; Coronado and Hilborn, 1998). In this document, the terms spawners and escapement are used interchangeably because we do not have information regarding mortality between the last fishery interceptions and actual spawning. Ricker curve parameters describing productivity were developed for the number of smolts expected from total escapement rather than estimating the number of females.

The model includes a user-friendly interface to easily change certain model parameters and inputs. The interface allows users to conduct sensitivity analyses, incorporate future knowledge or changing conditions, and implement scenarios for various future conditions. The model can be initiated annually with number of spawners or it can use the number of spawners predicted from the last model run for subsequent generations. Environmental variables are provided by brood year (BY) rather than the calendar year. For example, summer flow in 1992 and ocean conditions in 1994 are associated with BY 1991, which is short for spawning that occurs in late 1991 and early 1992. Results can be viewed graphically or in a table in Stella Architect $1.1 .2^{\circledR}$, or results can be output to an Excel ${ }^{\circledR}$ spreadsheet; they also are represented by brood year rather than calendar year. Additionally, the user can choose between two flow gages and two alternative sets of ocean indices to drive the model. Definitions of model terms and detailed instructions for obtaining and running the model are in appendix A, section "Definitions of Model Terms" and appendix B, section "Running the Model." 


\section{Data Sources}

Fish-related data (for example, smolts, escapement, harvest; table 1) are compiled or calculated by Pete Kairis, resource manager for the Swinomish Indian Tribe on behalf of the Skagit Salmon Comanagers for use in influencing pre-terminal and terminal harvest levels and other management decisions (specific data used in model are excerpted in appendix C). These data are direct estimates or calculations from monitoring efforts of others. Smolt estimates and escapement are provided by Washington Department of Fish and Wildlife (WDFW). Pre-terminal harvest estimates are calculated based on expansions of coded wire tag data after accessing them from the Regional Mark Processing Center at the Pacific States Marine Fisheries Commission (http://www.rmpc.org, accessed June 2017). Results are updated regularly by the Skagit Salmon Co-managers as new records are added, sometimes several years after a given cohort has returned. Therefore, harvest estimates can change slightly over time. These data are preferred over pre-terminal harvest data produced in static annual reports by the Pacific Salmon Treaty Coho Technical Committee. Stock-specific terminal catch data are housed in the Treaty Online Catch Accounting System (TOCAS) database, serviced by the Skagit Salmon Comanagers.

Table 1. Data sources used to develop Skagit River coho salmon life history model.

\begin{tabular}{l|l|c}
\hline \multicolumn{1}{c|}{ Variable } & \multicolumn{1}{|c}{ Source } & Time series \\
\hline Smolt numbers & Washington Department of Fish and Wildlife & $1991-2014$ \\
\hline Smolt fork lengths & Washington Department of Fish and Wildlife & $1990-2015$ \\
\hline Escapement (spawners) & Skagit Salmon Co-managers (appendix C) & $1989-2016$ \\
\hline Harvest & Skagit Salmon Co-managers (appendix C) & $1992-2016$ \\
\hline Ocean Mortality & Skagit Salmon Co-managers (appendix C) & $1992-2016$ \\
\hline Flow & $\begin{array}{l}\text { U.S. Geological Survey streamgages: Sauk above White Chuck (12186000), } \\
\text { Sauk (12189500), Mount Vernon (12200500) }\end{array}$ & $1990-2013$ \\
\hline Turbidity & Anacortes Water Treatment Plant & $1998-2012$ \\
\hline Pacific Decadal & $\begin{array}{l}\text { http://research.jisao.washington.edu/pdo/PDO.latest.txt (accessed November, } \\
\text { Oscillation (PDO) }\end{array}$ & $1900-2015$ \\
\hline North Pacific Gyre & 2016) & \\
\hline Oscillation (NPGO) & $\begin{array}{l}\text { California Current Ecosystem Long-term Ecological Research, } \\
\text { http://www.o3d.org/nggo (accessed May 2017) }\end{array}$ & $1991-2014$ \\
\hline Chlorophyll-a & $\begin{array}{l}\text { Washington Department of Ecology Marine Waters Monitoring Program, } \\
\text { Saratoga Passage site (SAR003) }\end{array}$ & $2002-2014$ \\
& http://www.ecy.wa.gov/programs/eap/mar_wat/data.html (accessed May, & \\
\hline Sea level at Neah Bay & $\begin{array}{l}\text { Permanent service for Mean Sea Level, http://www.psmsl.org (accessed } \\
\text { November, 2016) }\end{array}$ & $1990-2013$ \\
\hline
\end{tabular}

\footnotetext{
${ }^{1}$ Sauk-Suiattle, Swinomish, and Upper Skagit Indian Tribes, and Washington Department of Fish and Wildlife.
} 


\section{Model Details}

\section{Modeling "Predicted Smolts"}

\section{Summary}

The model predicts annual smolt production based on the number of returning adults and presence of pink salmon in the juvenile year by using Ricker stock-recruitment curves estimated from years with and without pinks present during the coho juvenile stage (table 2). Changes in the abundance of rearing habitat can be incorporated by adjusting the carrying capacity parameter of the Ricker curves. The rationale for each of these factors and how they are parameterized in the model follows. Regression analyses for these and other relationships in the model were conducted using the statistical software $\mathrm{R}$ version 3.4.0 (R Core Team, 2013).

Table 2. Model relations to determine "predicted smolts."

\begin{tabular}{l|l}
\hline \multicolumn{1}{c|}{ Relation } & \multicolumn{1}{c}{ Function/process } \\
\hline Ricker initial slope parameter & Pink years, 4.292; non-pink years, 3.844 \\
\hline Ricker carrying capacity & Pink years, 1,460,832; non-pink years, 1,044,869 \\
\hline Stock recruitment with pinks & Predicted smolts = spawners x exp(4.29- 0.00001841 x spawners) \\
\hline Stock recruitment without pinks & Predicted smolts = spawners x exp(3.84- 0.00001643 x spawners) \\
\hline Habitat carrying capacity & 0.31 smolts per square meter $($ default $)$ \\
\hline $\begin{array}{l}\text { Effect of change in habitat on stock } \\
\text { recruitment — pink years }\end{array}$ & $\begin{array}{l}\text { Carrying capacity parameter is adjusted by }(4.292-1) /(\text { habitat change } \mathrm{x} \\
\text { habitat capacity }+1,460,832) \text { where habitat change is area of habitat } \\
\text { restored or lost }\end{array}$ \\
\hline $\begin{array}{l}\text { Effect of change in habitat on stock } \\
\text { recruitment - non-pink years }\end{array}$ & $\begin{array}{l}\text { Carrying capacity parameter is adjusted by }(3.844-1) /(\text { habitat change } \mathrm{x} \\
\text { habitat capacity }+1,044,869) \text { where habitat change is area of habitat } \\
\text { restored or lost }\left(\mathrm{m}^{2}\right)\end{array}$ \\
\hline
\end{tabular}

\section{Stock-Recruitment Curves}

Stock-recruitment relations are used by fisheries managers to predict the number of smolts expected from a given number of spawners in a particular area. Two commonly used relations are the Ricker (Ricker, 1954) and Beverton-Holt (Beverton and Holt, 1957) curves. Although they have different formulas and shapes, each has a parameter describing density-independent recruitment, which describes survival when densities are low, and a parameter describing density-dependent processes, which limits productivity with increasing numbers of spawners (Maceina and Pereira, 2007). The relations differ in that the Beverton-Holt curve approaches an asymptote of productivity with higher numbers of spawners, whereas the Ricker curve declines at higher spawner numbers, indicating overcompensation owing to processes such as cannibalism or predation. 
Choosing which stock-recruitment model is appropriate for a given species or stock is problematic. Zhou (2007) used artificially generated datasets with differing underlying stockrecruitment models to indicate that the correct model may not be distinguishable based on statistical methods or information criteria. Caution against using statistical inferences to evaluate spawnerrecruitment relations is advised (de Valpine and Hastings, 2002; Maceina and Pereira, 2007). Rather, knowledge of biology and behavior of specific species may provide insight into which model is appropriate (Zhou, 2007). It has been argued that that the Beverton-Holt relation is more appropriate to describe coho behavior than the Ricker curve (Barrowman and others, 2003). Specifically, little densitydependent mortality is expected until the habitat fills because coho juveniles are territorial (Sandercock, 1991); after habitat fills, productivity is expected to stabilize. However, coho are not territorial in winter (Sandercock, 1991), suggesting that populations that are more limited by winter habitat than summer habitat may show Ricker-type dynamics (Barrowman and Myers, 2000). Moreover, even if all stages of the lifecycle indicate compensatory dynamics (that is, Beverton-Holt dynamics), if density dependence from early stages also affects later stages (concurrent density dependence), the resulting dynamics will be over-compensatory (that is, Ricker dynamics, Bjorkstedt, 2000). Because concurrent density dependence is expected in salmon populations (Bjorkstedt, 2000), and coho biology does not necessarily support use of the Beverton-Holt equations, we based the coho model on the Ricker stock-recruitment curve (fig. 3).

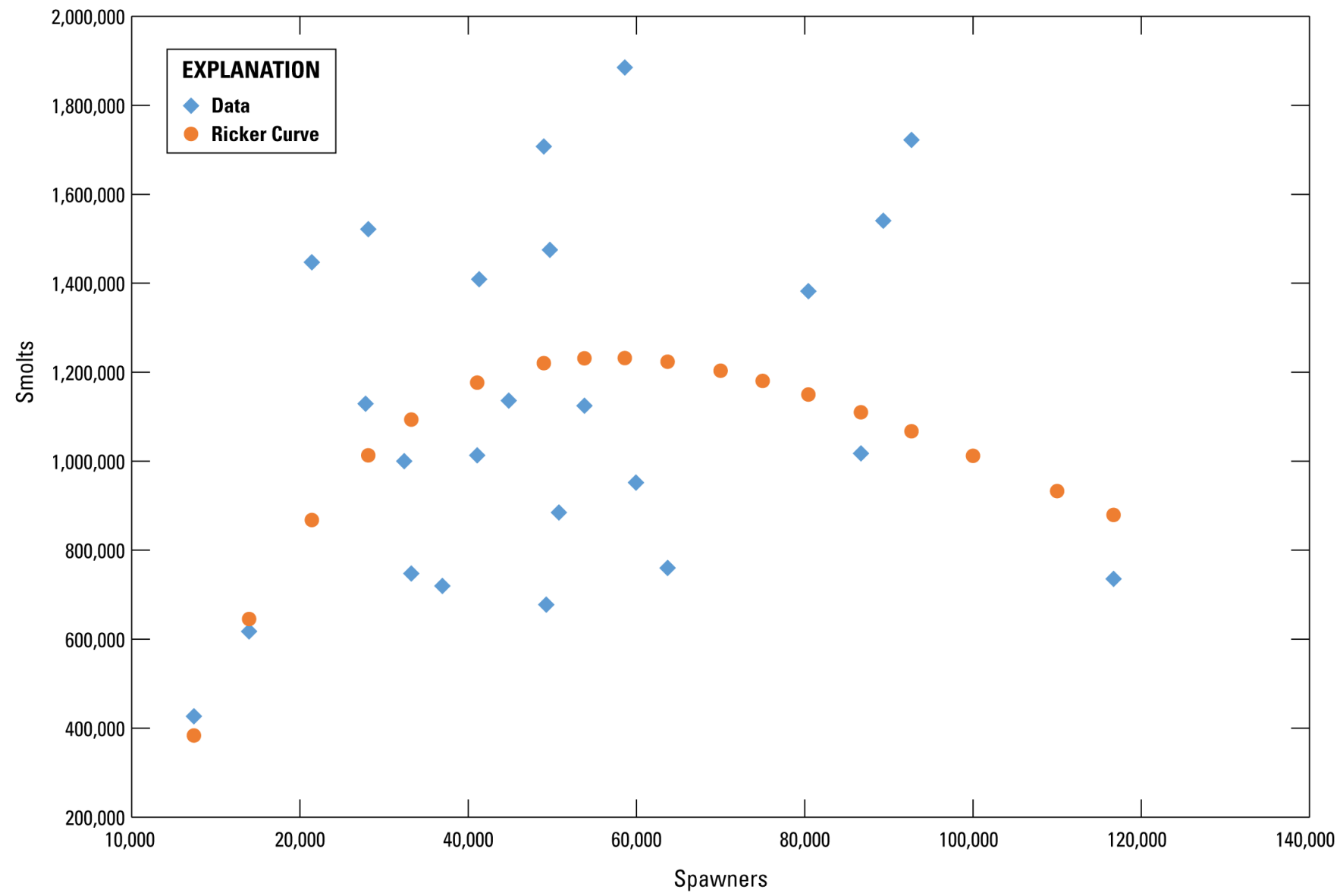

Figure 3. Ricker stock-recruitment curve calculated from smolt and spawner data collected on the Skagit River, northwestern Washington, brood years 1989-2012. 
The structure of this dataset is such that the year with highest escapement (2004; rightmost point in figure 3) also happens to have the lowest summer flow the and lowest number of pink salmon for a cohort with pinks present. Thus, there are multiple factors potentially lowering recruitment that year and perhaps exaggerating the downward curve of the Ricker curve, and, therefore, exaggerating typical density dependence. If the Ricker curve is estimated without that point, parameters describing initial recruitment rate and carrying capacity are 0.962 and 1.02 times those estimated from the entire dataset. We conclude that the Ricker curve calculated from the entire dataset is robust to the situation of this point.

Because most fish return to spawn 3 years after they hatch, there are three mostly distinct cohorts. However, some fish deviate from the 3-year cycle by remaining in freshwater for 30 months or returning from the ocean at age 2 (jacks) (Sandercock, 1991). These less common life histories are not considered in the model because they are relatively rare in the Skagit system. Jacks comprised on average 3 percent of the returns to the Marblemount hatchery from 1977 to 2012, in agreement with the observation that jacks become less common on a south-to-north gradient (18.4 percent, Wadell Creek, California; 0-2 percent, sites in British Columbia) in data compiled by Drucker (1972). Juveniles remaining in freshwater for 30 months also are most common in Alaska and are associated with colder water temperatures causing slower growth; very few 2-year-old coho smolts occur in the region south of British Columbia, including the Skagit River (Sandercock, 1991).

\section{Pink Salmon}

Pink salmon spawn in odd-number years in Puget Sound, numbering in the tens of thousands to over a million in the Skagit River. Pinks spawn in September-October then immediately migrate to saltwater upon fry emergence, usually in March-April (Heard, 1991; Michael, 1995). Coho production is greatly enhanced for cohorts that are juveniles during pink compared with non-pink years (Zimmerman, 2012) owing to several hypothesized mechanisms. These include disturbance of the stream bottom by spawning pinks to displace insects or previously spawned eggs, thereby creating easier prey; decomposing pink carcasses, eggs, and emerging fry as a direct food resource for juvenile coho; and general fertilization of the stream food web (Michael, 1995; Wipfli and others, 1999; Nelson and Reynolds, 2014). To account for the productivity disparity in pink compared with non-pink years, the coho model uses different curves to predict smolts from spawners in pink (odd-numbered) compared with non-pink (even-numbered) brood years (fig. 4). Estimated carrying capacity based on the Ricker model is more than 1.46 million coho smolts in pink years compared with about 1.04 million in nonpink years. Productivity in pink years was not significantly related to number of pinks (regression of smolts on pinks, coefficient of determination $\left.\left[r^{2}\right]=0.16, p>0.05\right)$ in this dataset where numbers of pinks always exceeded 60,000. If future pink runs are less than 60,000, number of pinks may need to be considered rather than simply presence-absence of pinks. A study of coastal streams in central British Columbia also showed juvenile coho abundance to be related to the number of pinks present just prior to coho spawning (Nelson and Reynolds, 2014). However, pink salmon returned to these small streams annually, so fish population dynamics were quite different than those on the Skagit River. 


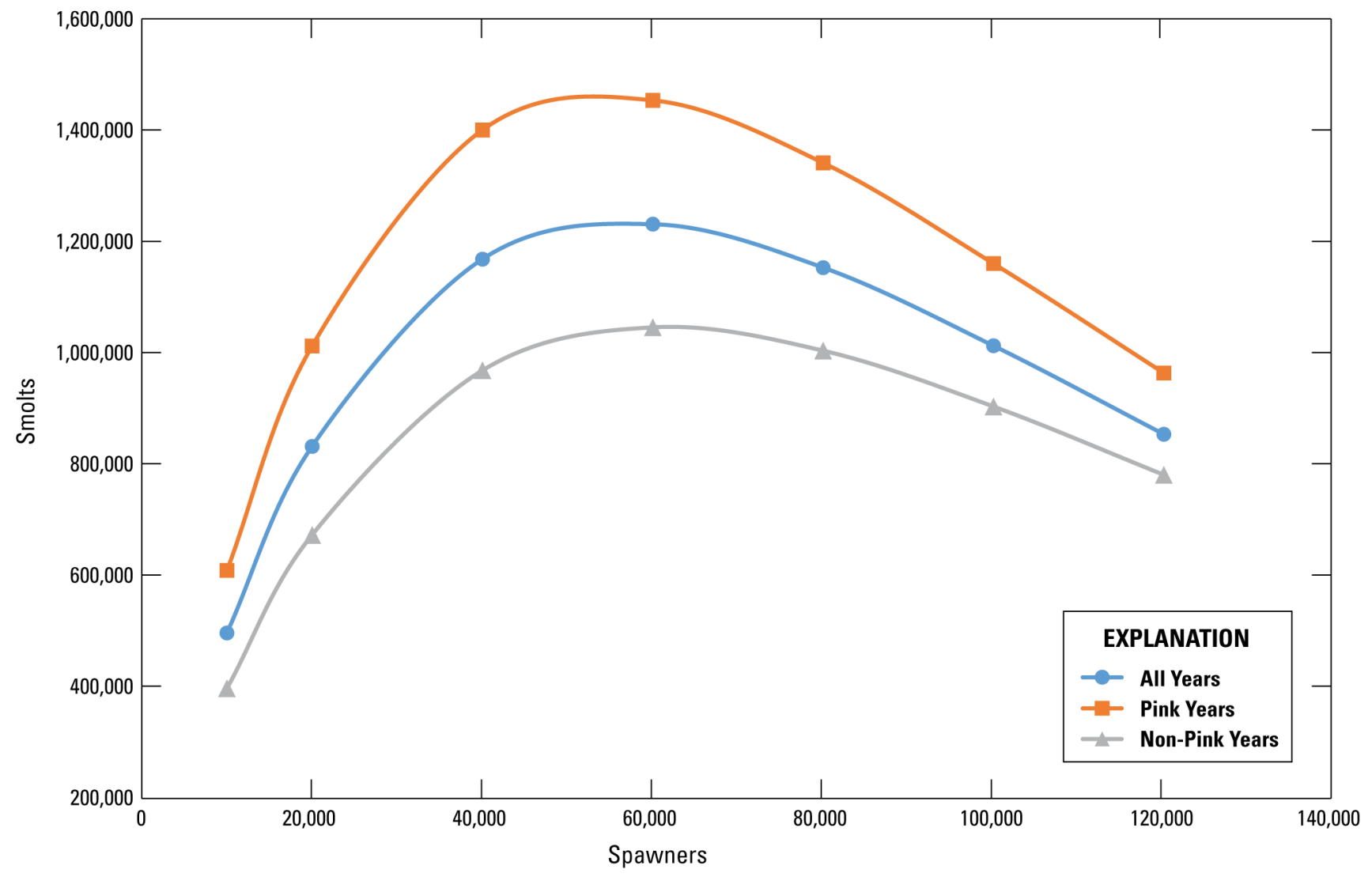

Figure 4. Comparison of smolt recruitment curves expected in years with and without spawning pink salmon, brood years 1989-2012. 


\section{Physical Habitat}

Coho are unusual among salmon species because they have an affinity for low-velocity habitat throughout their freshwater existence (Lestelle, 2007). Juvenile coho also prefer water depths of 0.46$1.2 \mathrm{~m}$ (Beecher and others, 2002). In the Skagit River basin, spawning occurs in tributaries upstream from Burlington (Washington Department of Fish and Wildlife, 2016), with about 12 percent of documented spawning occurring in the Sauk River Basin (Washington Department of Fish and Wildlife, 2017). Beechie and others (1994) estimate that spawning habitat in the Skagit River Basin is not limiting coho salmon abundance such that summer habitat can be fully seeded even if survival to emergence is low. Emergent fry typically stay in slow-velocity stream margins or backwaters of their natal stream (Sandercock, 1991) or move downstream to avoid competition (Chapman, 1962), owing to displacement by high flows (Hartman and others, 1982), or in search of more suitable habitat (Au, 1972). Even when present in the main stem Skagit River, coho occupy low-velocity habitats such as banks and backwaters (Beechie and others, 2005). In other systems, coho are known to move in order to avoid high $\left(>15^{\circ} \mathrm{C}\right.$ to $\left.19^{\circ} \mathrm{C}\right)$ stream temperatures or low flows (Konecki and others, 1995; Kruzic, 1998; Sutton and Soto, 2012), conditions that are not yet prevalent in the Skagit River but may become more common because of climate change (Mote and others, 2003; Mantua and others, 2010). Coho also may redistribute in autumn, sometimes great distances, to avoid areas with high flows and extremely cold water (Fedorenko and Cook, 1982; Scarlett and Cederholm, 1984). Their preferred winter habitats include off-channel ponds, beaver ponds, and side channels (Peterson and Reid, 1984; Scarlett and Cederholm, 1984), especially near complex wood cover (for example, rootwads) (Beechie and others, 2005).

Physical habitat for fish in rivers of the Pacific Northwest was greatly altered from 1880 to 1960 as settlers exploited natural resources for hydropower, forest products, and agriculture (Beechie and others, 1994). Activities included hydromodification (diking, ditching, dredging) associated with agriculture and urban lands, which accounts for 73 percent of coho summer habitat loss and 91 percent of winter habitat loss since before European settlement. Additionally, poorly functioning culverts on small tributaries have caused 13 percent loss of summer habitat and 6 percent loss of winter habitat, and forestry activities are responsible for 9 percent of summer habitat loss and 3 percent of winter habitat loss (Beechie and others, 1994). The large-scale activities have diminished since passage of the National Environmental Policy in 1970, but incremental losses continued (Beechie and others, 1994).

Changes in habitat availability should manifest as changes in ecosystem carrying capacity. Organized efforts to improve fish habitat in the Skagit River watershed began in 1990 with the establishment of the non-profit organization Skagit Fisheries Enhancement Group (Skagit Council of Governors, 2009). Momentum increased in 1997 with the formation of the Skagit Watershed Council, a consortium of private, county, State and Federal agencies (Skagit Council of Governors, 2009). Restoration in the Skagit River Basin was estimated as 590,733 m² in 2004 (Washington Department of Fish and Wildlife, 2004). If these areas were located in side channels and distributaries, they are expected to yield $0.391 \mathrm{smolts} / \mathrm{m}^{2}$ in summer (Beechie and others, 1994) or 0.141 million smolts. If they were located in tributaries, they are expected to yield $0.298 \mathrm{smolts} / \mathrm{m}^{2}$ in summer (Beechie and others, 1994) or 0.123 million smolts. Ricker curves calculated from data in the first one-third of the record compared with the last one-third indicate an increased carrying capacity (fig. 5). 


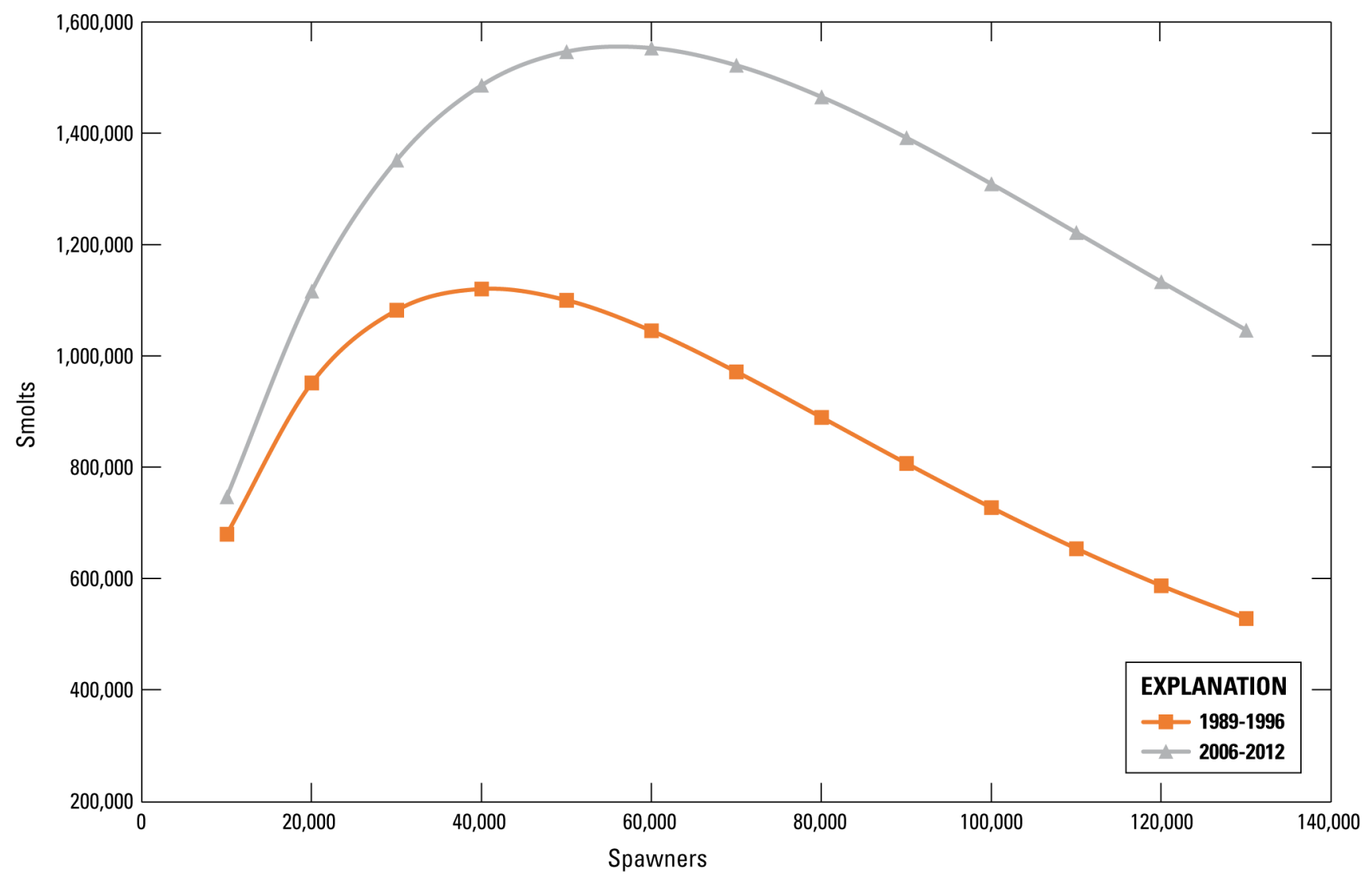

Figure 5. Comparison of Ricker stock-recruitment curves calculated for early and late in the period of record, brood years 1989-96 and 2006-12, respectively.

The model allows the user to increase or decrease available habitat to represent predicted or actual changes owing to habitat restoration or degradation, loss of habitat owing to sediment deposition, or exclusion of fish from areas owing to changes in water quality such as might result from climate change-caused increases in water temperature. Projections of future average August stream temperatures at the $1-\mathrm{km}$ scale owing to climate change can be obtained from the NorWeST project (http://www.fs.fed.us/rm/boise/AWAE/projects/NorWeST.html, accessed December 2016). Available coho habitat can be adjusted based on the range of observations of coho tolerance reported in the literature. Eaton and Sheller (1996) noted that coho avoid temperatures greater than $23.4{ }^{\circ} \mathrm{C}$. Frissell (1992) observed coho to be rare or absent where temperatures exceeded $21{ }^{\circ} \mathrm{C}$. Areas with maximum weekly maximum temperatures (MWMT) of $18{ }^{\circ} \mathrm{C}$ (Welsh and others, 2001) or those ranging from 23 to $27^{\circ} \mathrm{C}$ (Madej and others, 2006) also have been devoid of coho. Results from the NorWeST project for streams classified as "documented rearing habitat" (Washington Department of Fish and Wildlife, 2017) indicate that mean August stream temperature will be $18-20^{\circ} \mathrm{C}$ in $24 \mathrm{~km}$ of the South Fork Skagit and main-stem Skagit Rivers, in 2-3 km of lower Hansen Creek, in about $10 \mathrm{~km}$ of Day Creek, and in about $13 \mathrm{~km}$ of lower Finney Creek in the 2080s using the A1B climate-change scenario (Pachauri and Reisinger, 2008). At the same time, stream temperatures are projected to be $20-30{ }^{\circ} \mathrm{C}$ on about $5 \mathrm{~km}$ of the Nookachamps Creek. This is a small fraction of the estimated $756 \mathrm{~km}$ of river accessible to salmon in the Skagit system (Washington Department of Fisheries, 1975). 


\section{Modeling "Realized Smolts"}

\section{Summary}

The model determines "realized smolts" by adjusting the number of smolts predicted by the stock-recruitment relation to account for environmental conditions through the freshwater life stages (table 3). We tested the explanatory ability of several flow parameters and then developed relations for inclusion in the model. Summer low flow was used to determine the fraction of smolts predicted by Ricker curves that would actually be realized. Cumulative turbidity is used as a surrogate for high flows during the freshwater stage and as a direct stressor. Scouring flows are too infrequent to develop a statistical relation, so the basis for this relation primarily is anecdotal and it is modeled as a percentage decrease in smolt production in the case of a flow event exceeding a threshold. The rationale for and development of these relations follows.

Table 3. Model relations to determine "realized smolts."

\begin{tabular}{|c|c|}
\hline Relation & Function/process \\
\hline Summer low flow_-Sauk gage & $\begin{array}{l}\text { Fraction of Ricker prediction realized }=0.0001403 \times \text { average summer } \\
\text { flow April to Sept }+.3700\end{array}$ \\
\hline $\begin{array}{l}\text { Summer flow-Sauk above White Chuck } \\
\text { gage }\end{array}$ & $\begin{array}{l}\text { Fraction of Ricker prediction realized }=0.0004445 \text { x average summer } \\
\text { flow April to Sept }+.5054\end{array}$ \\
\hline Turbidity-Sauk gage & $\begin{array}{l}\text { Change fraction of Ricker expected to be realized by }-.000163 \times \text { (days } \\
\text { with turbidity }>30 \text { NTU during freshwater stage })^{2}+0.0070 \times(\text { days } \\
\text { with turbidity }>30 \text { NTU) }-0.0351\end{array}$ \\
\hline Turbidity_Sauk above White Chuck gage & $\begin{array}{l}\text { Change fraction of Ricker expected to be realized by }-0.000098 \times \text { (days } \\
\text { with turbidity }>30 \text { NTU during freshwater stage })^{2}+0.001308 \times \text { (days } \\
\text { with turbidity }>30 \text { NTU) }-0.2559\end{array}$ \\
\hline Scour threshold & Sauk gage: $50,000 \mathrm{ft}^{3} / \mathrm{s}$; Sauk above White Chuck gage: $20,000 \mathrm{ft}^{3} / \mathrm{s}$ \\
\hline Scour effect & Fraction of Ricker prediction expected to be realized is reduced by 0.2 \\
\hline
\end{tabular}

\section{Explanatory Flow Parameters}

Based on many years of forecasting coho returns to Puget Sound and Washington coastal rivers, Seiler and others (2003) observed that, in addition to the presence of pink salmon (accounted for in this model with choice of Ricker curve), inter-annual variation in coho productivity in the Skagit River primarily is driven by winter flows (affecting eggs), summer flows (determining summer rearing habitat), and autumn flows (determining spawner distribution). Seiler and others (2003) also anecdotally attributed high smolt production in 2002 to low flow during spawning, incubation, and early rearing beginning in autumn 2000. They postulated that higher-gradient streams in large systems, which yield low numbers of fry in normal years, could be more productive under lower, less disturbing flows. Unfortunately, the resolution of salmon abundance data does not allow for description and validation of the spatial complexity of fish response to changing flows. 
Potentially important flow variables were statistically tested for explanatory ability using the linear regression procedure ("lm") in R (R Core Team, 2013). Because the natural logarithm (ln) of smolts per spawner is a linear function of spawners, ln of number of smolts per spawner was regressed against number of coho spawners, pinks during brood and juvenile years, peak and mean flow during egg and alevin stage (October-March), 7-day averaged low, and mean flow during first summer (AprilSeptember). Predictor variables were normally distributed and correlations were not significantly different from zero $(\mathrm{p}<0.05)$. Regression models were evaluated using Akaike's Information Criterion for small samples (AICc; Hurvich and Tsai, 1989), and results indicate that numbers of pinks and spawners and the flow variables (mean summer flow and peak winter flow during the juvenile stage) were important (table 4).

Table 4. Best-ranked multiple regression models explaining smolt production.

[95-percent confidence set of best-ranked regression models (those with cumulative Akaike weight less than or equal to 0.95) examining effect of number of spawners, number of pinks, peak flow during egg and alevin stage (winter flow 1), 7-day averaged low and mean summer flow (summer flow), and peak and mean 7-day averaged winter flow (winter flow 2) on natural $\log$ of smolts per spawner. Abbreviations: $\mathrm{R}^{2}$, coefficient of multiple determination; df, degrees of freedom; logLik, logarithm of likelihood ; AICc, Akaike information criterion for small samples; delta, model AICc minus minimum AICc; weight, probability of being best model]

\begin{tabular}{lcccccr}
\hline \multicolumn{1}{c}{ Model } & $\mathbf{R}^{2}$ & df & logLik & AlCc & delta & weight \\
\hline Pinks, summer flow, winter flow 2, spawners & 0.931 & 6 & 9.300 & 0.40 & 0 & 0.616 \\
Pinks, summer flow, spawners, & 0.906 & 5 & 6.292 & 2.03 & 1.631 & 0.273 \\
Pinks, summer flow, winter flow 2, spawners, winter flow 1 & 0.937 & 7 & 10.18 & 3.82 & 3.482 & 0.111 \\
\hline
\end{tabular}

\section{Summer Low Flow}

Studies spanning many decades have documented that higher numbers of returning coho adults are associated with higher summer flows during freshwater rearing. The effect was reported for the Pacific Northwest by Neave (1949), for Puget Sound by Smoker (1955), and was reaffirmed by Hartman and Scrivener (1990) and Quinn and Peterson (1996). The positive effect of higher summer flows primarily is attributed to increased habitat availability (Zillges, 1977; Zimmerman, 2012). An estimated habitat loss for steelhead (Oncorhynchus mykiss) of 1-2 percent is associated with a 1-2 percent loss in streamflow from the 90 percent exceedance flow in several Puget Sound Basins (Caldwell, 1999). Other potential effects of low summer flow on juvenile fish include high stream temperature, low dissolved oxygen, disease, stranding, overcrowding (Mathews and Olson, 1980), higher predation, and loss of connectivity. Summer low flow is one parameter used by the WDFW to estimate freshwater productivity in rivers without smolt counts to forecast the number of returning coho adults to Puget Sound 2 years later (Zimmerman, 2012).

The Skagit River system has snow-dominated basins in the upper watershed where winter precipitation accumulates as snow (Hamlet and others, 2001; Mantua and others, 2010), causing summer flow to be sustained by melting snow. Climate change is projected to cause mixed rain and snow to fall in these basins in winter, resulting in lower summer flows (Mote and others, 2003; Mantua and others, 2010), and the duration of the summer low-flow period is projected to lengthen (Elsner and others, 2010). Specifically, the 7-day average low-flow magnitude with a 2-year return interval (7Q2) is projected to be 65-75 percent of historical levels (1970-99) for the Skagit by the 2080s using the A1B climate-change scenario (Mantua and others, 2010). 
The coho model uses mean summer flow (daily April-September) to refine the estimate for number of smolts calculated as the model stock "predicted smolts" (fig. 2). The fraction that the Rickerbased prediction represents of the actual number of smolts for each brood year was regressed against the mean daily summer flow (April-September) at the Sauk (U.S. Geological Survey [USGS] 12189500, fig. 6) and the Sauk above White Chuck (USGS 12186000) streamgages. Data from tributary streamgages are used in the model because they may better represent conditions experienced by coho than those on the main-stem Skagit River. Results show that productivity increases with increasing summer flow such that productivity may exceed the average capacity predicted from the Ricker curve. This relation is used in the coho model to adjust the number of smolts predicted by the Ricker curve to indicate summer flow.

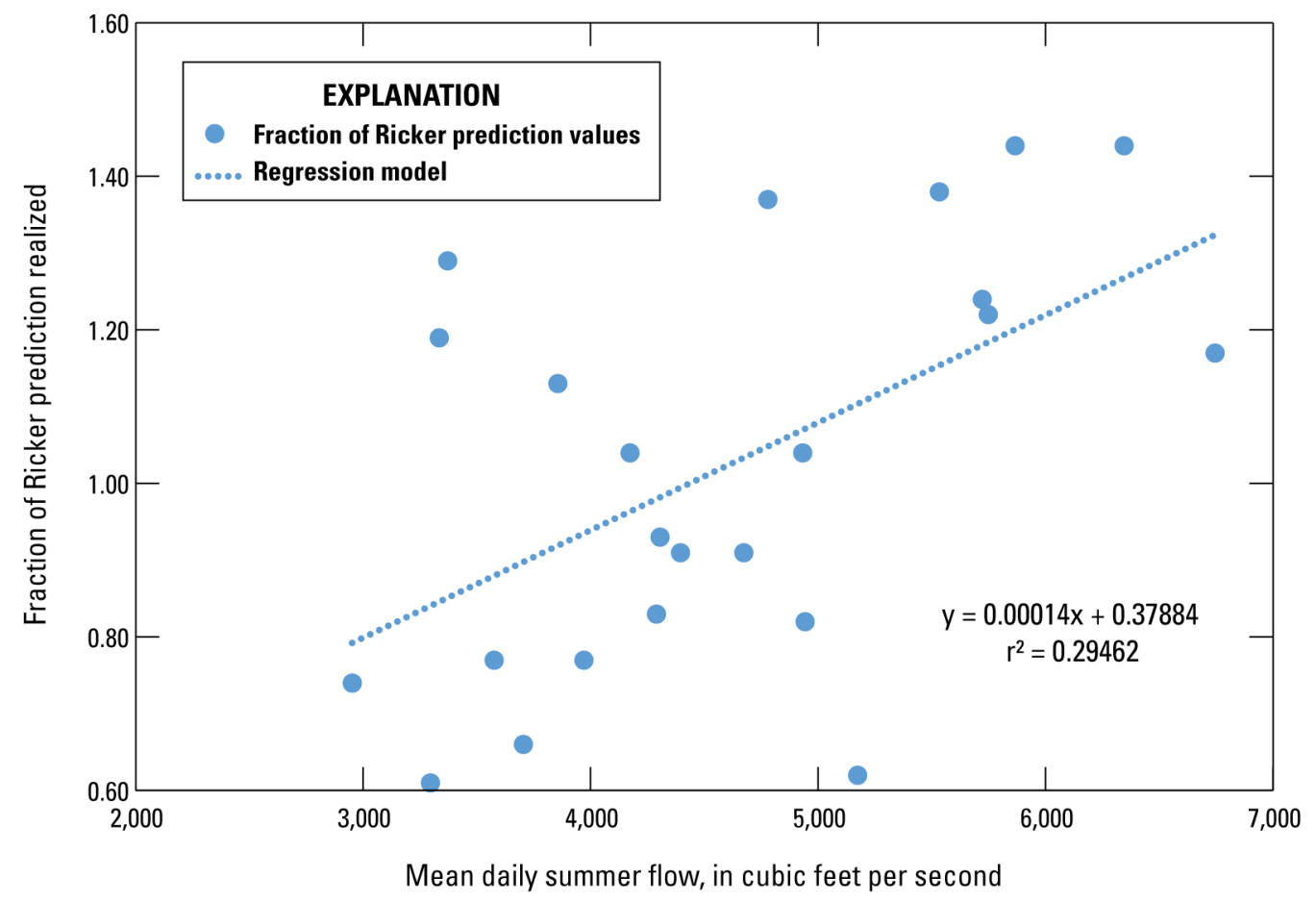

Figure 6. Regression showing fraction of smolt prediction from Ricker curve actually realized owing to summer flow conditions measured at Sauk River streamgage (USGS 12189500).

\section{Winter High Flow}

Coho are morphologically adapted to swimming in low-flow environments by having laterally compressed bodies and large median and paired fins (Bisson and others, 1988). Therefore, they are vulnerable to high flows, which normally occur in winter in the Pacific Northwest. Winter mortality can be substantial (Hartmann and others, 1987) and seems to be related to the availability of the sheltered habitat (Murphy and others 1984) that coho prefer in winter (McMahon and Hartmann, 1989; Shirvell, 1990). Winter rearing habitat has been identified by many authors as an important limiting factor for coho across the Pacific Northwest (Reeves and others, 1989; Nickelson, 1998; Lawson and others, 2004) and for the Skagit River Basin specifically (Beechie and others, 1994; Seiler and others, 2003). Adverse winter rearing conditions (that is, high flows and scouring) for coho are projected to become more frequent because of climate change (Mote and others, 2003). 
The visual comparison between the deviation of actual/predicted productivity predicted by the Ricker recruitment curve compared with high-flow events indicates a threshold relation where flows greater than about 30,000 $\mathrm{ft}^{3} / \mathrm{s}$ at the Sauk streamgage are associated with lower productivity (fig. 7). A breakpoint regression analysis using the "strucchange" package in R (Zeileis and others, 2003) confirmed evidence of a breakpoint at $31,000 \mathrm{ft}^{3} / \mathrm{s}$ (Sauk streamgage) and 7,000 $\mathrm{ft}^{3} / \mathrm{s}$ (Sauk above White Chuck streamgage) but not at the $\mathrm{p}<0.05$ significance level. This relation differs from the relation seen by Lawson and others (2004) in coastal systems, which seems to indicate that highest survival is associated with an intermediate flow that balances habitat availability with detrimental flows. Perhaps the different dynamics can be explained because compared with Puget Sound systems, coastal systems are smaller, lower-gradient, and rain-dominated, and likely have less in-stream large woody debris because of intensive logging. The effect of winter high flows was thought to be a component of the effect attributed to turbidity (see section "Turbidity") and was not modeled independently.

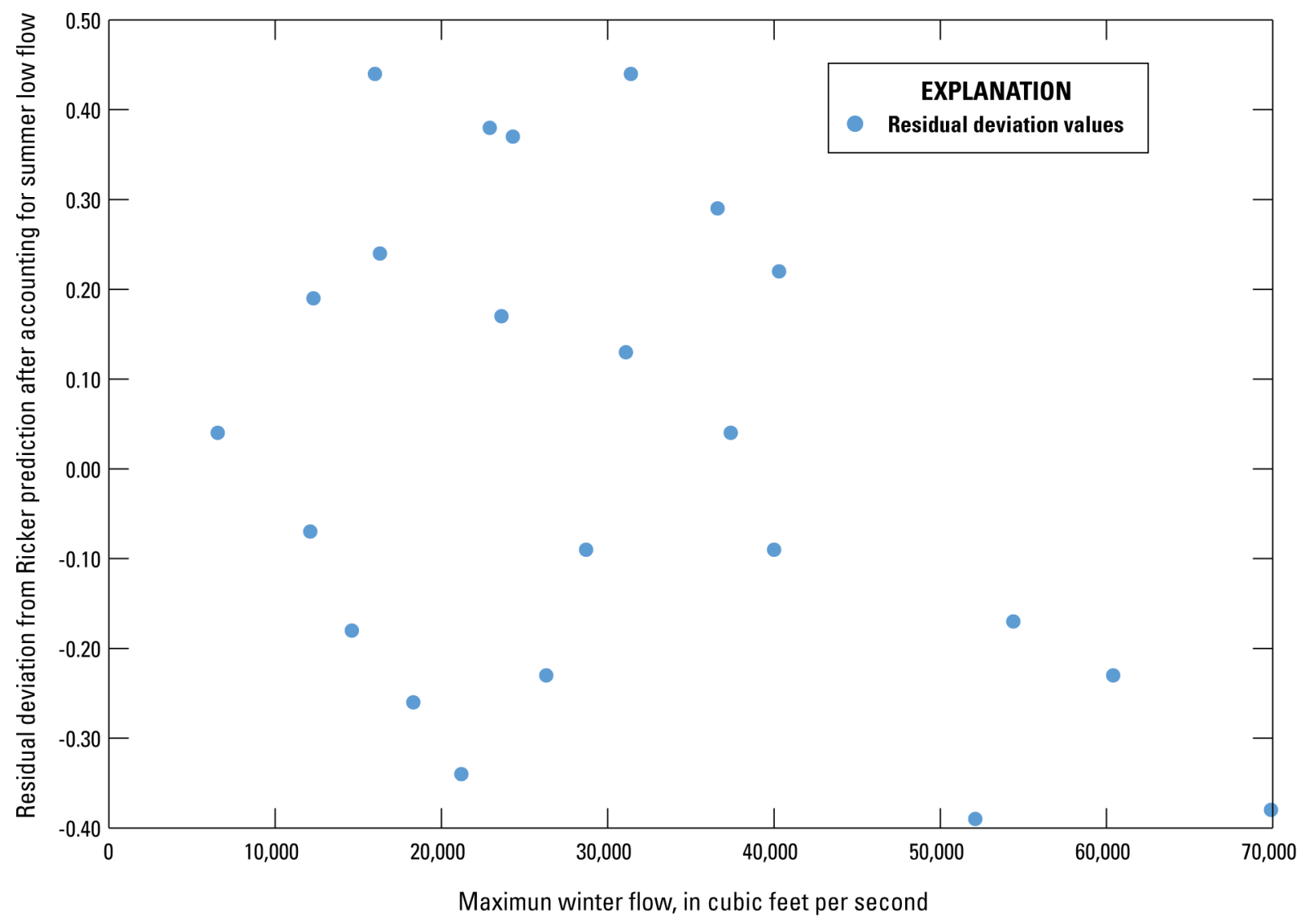

Figure 7. Graph showing effect of high flow during juvenile rearing period on residual deviation of smolt production from Ricker-based prediction after accounting for the effects of summer flow measured at Sauk gage (USGS 12186000). 


\section{Turbidity}

Many Pacific Northwest rivers naturally transport considerable amounts of suspended sediments, especially those fed by glacial meltwater (Lloyd and others, 1987). The most commonly used index of suspended sediment transport is turbidity, largely because of ease and low cost of measurement (DaviesColley and Smith, 2001). Because of inconsistent relations between turbidity and mass of suspended sediments as well as poor repeatability among turbidometers (Duchrow and Everhart, 1971), it would be better to use water clarity or actual measurement of suspended sediment mass to indicate the biological effect of suspended sediments (Henley and others, 2000; Davies-Colley and Smith, 2001). Nevertheless, turbidity is a relative measure and can be used as an index of suspended sediment concentration (Sigler and others, 1984; Davies-Colley and Smith, 2001).

Turbidity varies among and within watersheds based on geology and location in stream system, as well as seasonally in response to timing of precipitation and runoff (Servizi and Martens, 1987; Bash and others, 2001). Models of sediment supply and transport based on road density and natural and landuse-caused supply rates indicate that higher than natural levels exist in the Skagit because of clearcutting, road construction and clearing of log jams (Smith, 2003). Sediment loads are expected to further increase because of climate change effects on glacier retreat and flooding (Moore and others, 2009). The current sediment supply is estimated to be 1.5 times the natural rate in the Skagit River Basin in spite of the effect of dams on the upper Skagit River to trap sediment, with the greatest load on the lower Sauk River (Beamer and others, 2000). Sediment supply rate is of concern to the Sauk-Suiattle Tribe because of its potential effect on pocket estuaries, which are used as rearing habitat by Chinook salmon and to a lesser extent, coho salmon (Magnuson and Hilborn, 2003; Greene and Beamer, 2012). Therefore, the Sauk-Suiattle Tribe has partnered with USGS to monitor sediment at several places on the Sauk-Suiattle river system since 2006.

Turbidity can have diverse negative lethal, sublethal and behavioral effects on fish, even at relatively low values (18-70 Nephelometric Turbidity Units [NTU]; Gregory, 1992). Effects can be physiological (for example, gill trauma [Berg and Northcote, 1985], growth rate [Sigler and others, 1984]); behavioral (for example, avoidance of area [Berg, 1982; Servizi and Martens, 1987], loss of territoriality [Berg, 1982; Berg and Northcote, 1985], reduced ability to forage [Gregory and Northcote, 1993]); or habitat related (for example, smothering of redds [Cederholm and Salo, 1979], alterations of hyporheic flow [Sedell and others, 1990; Poole and Berman, 2001]). Effects seem to depend on level of exposure and duration (Newcombe and MacDonald, 1991). Alternatively, coho appear to prefer slightly to moderately turbid water for feeding (Sigler and others, 1984; Boehlert and Morgan, 1985; Gregory, 1993; Gregory and Northcote, 1993). It seems that turbidity can substitute for cover to protect fish from predation (Gregory and Levings, 1996). Therefore, there may be a tradeoff between reduced vulnerability to predation in clear water and inability to feed in very turbid water. 
Levels of turbidity observed to have deleterious effects for coho (including avoidance of habitat, slower growth rates, and reduced survival) vary among studies. These effects can be seen at relatively low turbidities (18-70 NTU; Lloyd and others, 1987; Gregory, 1992). Bisson and Bilby (1982) reported that fish are displaced by greater than ( $>$ ) 70 NTU. Gill flaring was seen at 60 NTU and ceased when levels decreased to 30 NTU (Gregory and Northcote, 1993). Berg (1982) reported that juvenile coho avoid areas with 60 NTU but return at 20 NTU. Sigler and others (1984) noted a significantly lower growth rate at 25 NTU compared with clear water, whereas newly emerged fry had a lower growth rate at 25-50 NTU. Determining harmful levels of turbidity is complicated by the need to incorporate duration of exposure as well as level (Newcombe and MacDonald, 1991). Effects also depend on the size and shape of particles and whether they are carrying pollutants (Lake and Hinch, 1999). Moreover, fish are adapted to survive in turbid waters at particular life stages (for example, migration though the estuary). Positive effects of turbidity to reduce predation on fish have been documented at $11-13$ NTU (Abrahams and Kattenfeld, 1997).

Turbidity is monitored by the City of Anacortes, Washington, at the Anacortes Water Treatment Plant located in Mount Vernon, Washington (river kilometer 25). Readings have been taken at 15minute intervals since 1999 and integrate sources of suspended sediment from most of the Skagit watershed upstream of the estuary. Considering turbidity values associated with harm to fish and the need to incorporate duration as well as level of exposure, the number of days with maximum turbidity $>30$ NTU during the freshwater life stages from alevin to smolt (February-April of the following year) was selected as an index of exposure to turbid conditions.

Usefulness of the index was determined by examining whether the index explained residual deviations of actual smolts from those predicted by spawners using the Ricker curve and after taking summer flow into consideration (fig. 6). Because collection of turbidity data began in BY 1998, the earlier turbidity regime was estimated based on the regression of daily average turbidity against daily average flow (USGS streamgage 12200500), both measured in Mount Vernon. We adopted a sequential approach by first predicting realized smolts expected from summer low flow (fig. 6). Next, the remaining deviation (actual smolts/corrected smolt prediction minus fraction predicted based on low flow) was regressed against turbidity (days with maximum turbidity $>30$ NTU). Results show a significant (model, $\mathrm{p}<0.05$ ) relation with a quadratic shape (fig. 8), in keeping with literature accounts that both low and high levels of turbidity can have adverse consequences for fish. 


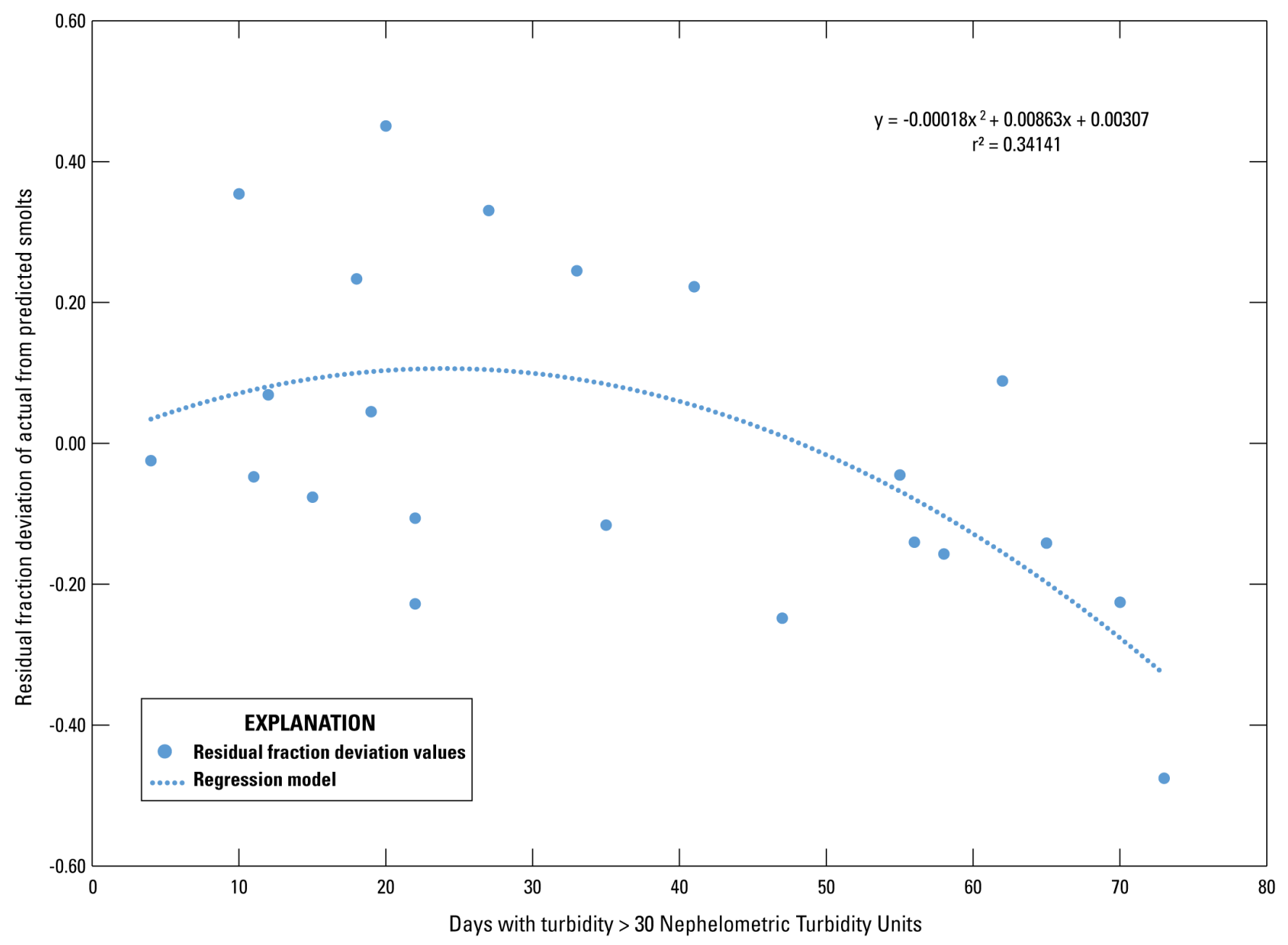

Figure 8. Regression showing relation of number of days with turbidity greater than $(>) 30$ Nephelometric Turbidity Units during the freshwater life stages of coho cohorts (February following spawning through April of following year) with residual deviation of actual from predicted smolts after summer low flow is accounted for.

Turbidity rather than winter high flow was used as a predictor in the coho model for several reasons. First, we considered the strong ability of days with turbidity $>30$ NTU to explain deviations of predicted smolt numbers from actual smolt numbers after summer low flow (fig. 8). Second, there is a poor association between flows in the overwinter rearing period and subsequent smolt abundance below a threshold (fig. 7), and few years in the record exceed the threshold flow where effects of higher flows can be detected. Finally, the relative strength of the relation between flow and turbidity indicates that they may include redundant information. Suspended sediment in streams, and, therefore, turbidity, naturally are a function of streamflow and resulting erosion and transport (Servizi and Martens, 1987). The relation between turbidity and flow (turbidity as a power function of flow) has an $\mathrm{r}^{2}$ of 0.77 at Anacortes (November through January for 1999 to 2009). Therefore, we use the relation between smolt abundance and turbidity in figure 8 to further modify the fraction of Ricker-predicted smolts already adjusted to account for summer flow. 


\section{Scouring Flow}

The Skagit River Basin is termed rain-dominated in lower elevations and either snow-dominated or transient (mixed rain and snow) at higher elevations (Mote and others; 2003; Beechie and others 2006; Mantua and others, 2010). Rain-dominated areas typically show peak flow coincident with highest precipitation, specifically early winter in the Pacific Northwest. Snow-dominated areas show a spring or early summer peak in flow coincident with snowmelt. Transient watersheds have both rain and snow during winter as well as two peaks in flow: early winter and spring/early summer (Hamlet and others, 2001). Climate change projections predict that the magnitude and frequency of flooding will increase most substantially in December and January for transient watersheds (Mote and others, 2003) because winter precipitation is projected to increase and more of it will fall as rain because of warmer air temperature. Climate projections also forecast that, by 2080, all snow-dominated basins in the Skagit watershed will become transient, thereby shifting peak flows from spring to winter (Mantua and others, 2010).

Greater magnitude and frequency of high flows lead to greater vulnerability of anadromous fish to scouring of redds (Mote and others, 2003; Goode and others, 2013) because of increased number and depth of scour events (Montgomery and others, 1999). This is especially true for autumn spawners such as coho in snow-dominated basins (Montgomery and others, 1999; Goode and others, 2013) because the timing of high flows is expected to become more coincident with incubating eggs. These effects may be somewhat mitigated if higher flows result in greater access to additional spawning habitat.

Scouring events occur relatively infrequently in the historical record and could not be detected as significant drivers using regression methods on this relatively short 24-year time series. Moreover, their effect may be obscured by other events during freshwater rearing. However, Tribal resource managers observed a scouring event in November 2006 (Scott Morris, Sauk-Suiattle Indian Tribe, oral commun.) when instantaneous peak flow at the Sauk above White Chuck streamgage (USGS 12186000) reached $33,600 \mathrm{ft}^{3} / \mathrm{s}$.

The effect of scour on egg mortality is a function of the magnitude and duration of peak discharge, grain size of bed-surface, and location in the channel (Holtby and Healey, 1986; Hassan, 1990; Montgomery and others, 1999). Without sufficient data to describe these relations in the Skagit River or its tributaries, the model uses a simple peak flow threshold to determine scour events and a simple fractional reduction of production to estimate effects. The threshold was estimated by first considering that bed mobility across the channel is thought to begin at bankfull flows (Carling, 1987). Bankfull flow has a recurrence interval of 1-2 years in the Pacific Northwest (Castro and Jackson, 2001). Using 92 years of annual instantaneous peak flow data from the Sauk above White Chuck streamgage, the flow frequency curve indicates that a recurrence interval of 2 years corresponds to peak flow of about $8,960 \mathrm{ft}^{3} / \mathrm{s}$. Holtby and Healey (1986) determined that 65-percent mortality of eggs owing to scour occurred at about 2.5 times bankfull flow at Carnation Creek on the west coast of Vancouver Island, British Columbia. Using 2.5 bankfull as a rough estimate of when significant mortality might occur, peak flows of $22,400 \mathrm{ft}^{3} / \mathrm{s}$ at the Sauk above White Chuck streamgage may pose a threat to salmon productivity. Instantaneous flow events greater than $22,400 \mathrm{ft}^{3} / \mathrm{s}$ during November-December in this dataset include water years ${ }^{4}$ (WYs) 1990, 1996, and 2007. The event in WY 1996 corresponds

${ }^{4} \mathrm{~A}$ water year is the 12-month period from October 1, for any given year, through September 30 of the following year. The water year is designated by the calendar year in which it ends. 
with an average daily peak flow of $18,900 \mathrm{ft}^{3} / \mathrm{s}$, which did not appear to affect smolt mortality, whereas an average daily peak of 22,000 $\mathrm{ft}^{3} / \mathrm{s}$ in WY 2007 was known to be a scouring flow (Scott Morris, SaukSuiattle Indian Tribe, oral commun., November 2016). Therefore, the threshold for scour effects was set at $20,000 \mathrm{ft}^{3} / \mathrm{s}$ for average daily peak flows occurring in November and December when spawning typically occurs. The same process applied to data from the Sauk streamgage (12189500) produces a threshold of $59,750 \mathrm{ft}^{3} / \mathrm{s}$. Because a flow of $54,400 \mathrm{ft}^{3} / \mathrm{s}$ in WY 2007 was known to be a scouring flow, the model uses $50,000 \mathrm{ft}^{3} / \mathrm{s}$ as the threshold for scour for the Sauk streamgage.

The fraction of salmon production lost because of scouring flows was modeled as a loss of 0.2 from the fraction of "predicted smolts" expected to be realized owing to other flow factors. This is based on unexplained, lower-than-predicted production following the one known scouring event in the dataset. Scour thresholds for flow at the Sauk and Sauk above White Chuck streamgages and the effect of scouring flow on smolt survival can be adjusted by the model user to test model response to alternative values.

The imposition of a fixed loss of productivity above a simple threshold during a discrete time interval certainly is an oversimplification of complex relations among timing of spawning, flow, and depth and geographic location of redds. Coho tend to spawn over a relatively long period from midautumn to early winter (Lestelle, 2007), and when scour occurs during the spawning period will determine the severity of effects. Spawning depth is partially determined by size of female (van den Berghe and Gross, 1984; Crisp and Carling 1989), which varies by individual and year. Scouring depth is linearly related to the logarithm of discharge (Moring and Lanz, 1975) and depth determines how many eggs are lost (Montgomery and others, 1999). Finally, the effects of an annual flow regime will vary across the Skagit River Basin, with some areas experiencing scour while others do not. Nevertheless, the model will enable users to experiment with the potential effects of more frequent high peak flows than represented in the data time-series.

\section{Modeling Escapement}

\section{Summary}

After considering smolt size, number of smolts (density dependence), and numerous ocean condition indices, we determined that ocean mortality was best explained by number of smolts and a quadratic relation with PDO index (table 5). Because WDFW and Skagit Salmon Co-managers are now (2017) using North Pacific Gyre Oscillation (NPGO) index and (or) chlorophyll-a monitoring in Puget Sound as predictors, these predictors also are provided as options in the model. The proportion of the coho population subject to harvest, as estimated from Skagit Salmon Co-managers data (appendix C), is subtracted in the model. Details regarding development of these relations follow.

Table 5. Model relations to determine "escapement."

\begin{tabular}{l|l}
\hline \multicolumn{1}{c|}{ Relation } & \multicolumn{1}{c}{ Function/process } \\
\hline Ocean survival—PDO and smolts & $\begin{array}{c}\text { Logit ocean survival }=(-0.00000038 \times \text { realized smolts })-0.1421 \times \text { PDO } \\
+0.1068 \times \text { PDO }^{2}-0.8007\end{array}$ \\
\hline $\begin{array}{l}\text { Ocean survival—NPGO and chlorophyll-a } \\
\text { density }\end{array}$ & $\begin{array}{l}\text { Logit ocean survival }=0.289 \times \mathrm{NGPO}+.0445 \times \text { chlorophyll-a density }- \\
1.691\end{array}$ \\
\hline Harvest & Fraction harvested $=1-$ estimated escapement/estimated OA3 \\
\hline
\end{tabular}




\section{Ocean Survival}

Marine survival of coho has been in decline in the Salish Sea (Puget Sound, Strait of Juan de Fuca, and Strait of Georgia) since estimates using wild indicator stocks began in the mid-1970s, although declines have been less in Puget Sound than other regions (Shaul and others, 2007; Beamish and others, 2010; Zimmerman and others, 2015). Determining the factors that influence ocean survival of salmon has not been successfully accomplished (Dorner and others, 2013; Zimmerman and others, 2015). Candidate parameters include salmon population characteristics such as smolt size and numbers; and physical and biological ocean condition indicators such as sea-surface temperature and pressure indices (for example, PDO, NPGO, Oceanic Nino Index [ONI]), timing and strength of upwelling, and various chemical and food web constituents) (Scarnecchia, 1981; Nickelson, 1986; Zimmerman, 2012; Araujo and others, 2013; Burke and others, 2013). Because salmon range widely through spatially and temporally dynamic, complex ecological environments and cannot feasibly be tracked, survival is unlikely to relate to single metrics in any one environment (Burke and others, 2013).

Size. It makes intuitive sense that larger smolts should have an advantage over smaller ones for ocean survival. However, in several studies, large smolt size was not consistently associated with greater survival of coho among years or sites (Mathews and Ishida, 1989; Holtby and others, 1990; Tschaplinski, 2000, Irvine and others, 2013). Within individual years, larger size may confer greater survival, especially in years when ocean conditions are relatively poor (Mathews and Ishida, 1989; Holtby and others, 1990). Survival also may be related to time of ocean entry (Bilton and others, 1982; Thedinga and Koski, 1984; Morley and Station, 1988). Time of entry is indirectly related to smolt size because larger smolts tend to emigrate from freshwater to the marine environment earlier than smaller ones (Seiler and others, 1981, 1984). The size that fish attain during early ocean residence is correlated with ocean survival (Holtby and others, 1990).

Density dependence. Ocean survival also may be subject to density dependence (Peterman, 1982; Clark and McCarl, 1983; McCarl and Rettig, 1983; Coronado and Hilborn, 1998; Emlen and others, 1990), perhaps especially in years with low upwelling (Peterman and Routledge, 1983; McGie, 1984). Others reported no density dependence for ocean survival (Peterman, 1981; Nickelson, 1986; Holtby and others 1990) or questioned whether the experimental designs used by others are sufficient to detect density dependence (Nickelson, 1986; Peterman, 1989; Pearcy, 1992). Hypothesized mechanisms for density-dependent mortality include increased predation of coho in the nearshore caused by large numbers of coho training piscine and avian predators to exploit the coho search image (Emlen and others, 1990), lower marine food supplies, faster spread of diseases and parasites in dense populations (Peterman, 1978), and larger numbers of fish owing to hatchery production.

Ocean conditions. Many studies have reported correlations between marine survival of Pacific Northwest salmon and ocean conditions thought to indicate habitat quality in the Pacific Ocean. Relations with sea-surface temperature as described by various indices (Nickelson, 1986; Francis and Hare, 1994; Peterman and others, 1998, Di Lorenzi and others, 2008), upwelling parameters (Nickelson, 1986; Scarnecchia, 1981; Ryding and Skalski, 1999), salinity, dissolved oxygen, and biological properties such as chlorophyll-a density and copepod richness and abundance (Zimmerman, 2012; Araujo and others 2013) showed no consistent result. It also seems that important factors also might be operating at various spatial and temporal scales, whether annual (Ryding and Skalski, 1999; Teo and other 2009) or decadal (Beamish and Bouillon, 1993; Mantua and others, 1997), by ocean basin or subbasin (Francis and others, 1998; Hare and others, 1999; Teo and others, 2009; Zimmerman and others, 2015) or individual stream (Ryding and Skalski, 1999; Mueter and others, 2002), and that groups of sites with coherent survival patterns have shifting membership through time (Zimmerman and others, 2015). Moreover, some time periods in the marine life stage may be more critical than others. Specifically, several authors have reported that ocean conditions at the time of ocean entry or for several 
months thereafter are particularly important (Hobday and Boehlert, 2001; Beamish and others, 2010; Zimmerman and others, 2015), perhaps determining early ocean growth, which is associated with ocean survival (Holtby and others, 1990).

The need for more accurate forecasts of coho returns has motivated analyses to identify predictive indicators of ocean condition even though functional understanding is lacking. Although multivariate indices may be most appropriate representations of the complex marine environment (Burke and others, 2013), efforts to find relations predicting survival of Puget Sound, Strait of Juan de Fuca, and Skagit coho have focused until recently on univariate models or have found univariate models to be best (Zimmerman, 2012). Sea-surface temperature anomalies, such as PDO and ONI, generally are associated with ocean survival of salmon. PDO describes monthly sea-surface temperature (SST) anomalies in the northeastern Pacific Ocean, north of $20^{\circ} \mathrm{N}$ latitude, an area closer to the Pacific Northwest than ONI, which describes the 3-month running mean of SST anomalies in the east-central Pacific Ocean $\left(5^{\circ} \mathrm{S}\right.$ to $5^{\circ} \mathrm{N}$ latitude, $170^{\circ} \mathrm{W}$ to $120^{\circ} \mathrm{W}$ longitude).

The focus since 2015 has shifted to multi-variate predictions, specifically using NPGO, a seasurface pressure anomaly measured in the same region as PDO, and chlorophyll-a density measured in Saratoga Passage for Skagit coho. We used these findings of others (table 6) to justify investigating PDO (May-September), ONI (January-June), sea level at Neah Bay, and chlorophyll-a density averaged over the top $20 \mathrm{~m}$ of water depth in Saratoga Passage as indicators of marine conditions. We excluded mixed layer depth because data are difficult to obtain. We did not consider sea-surface temperature off the Oregon coast because it is highly correlated with PDO. We considered both linear and quadratic relations because Ryding and Skalski (1999) noted concave and convex relations between ocean mortality and condition indicators.

Table 6. Indicators of ocean condition determined to be associated with ocean mortality of coho salmon in geographic areas near to or including the Skagit River, northwestern Washington.

\begin{tabular}{|c|c|c|}
\hline Geographic region & Indicator & Source \\
\hline Strait of Juan de Fuca & $\begin{array}{l}\text { June sea-surface temperature off Washington coast } \\
\text { Spring transition } \\
\text { Upwelling } 48^{\circ} \mathrm{N}\end{array}$ & Ryding and Skalski, 1999 \\
\hline Puget Sound & $\begin{array}{l}\text { Sea level } \\
\text { Mixed layer depth }\end{array}$ & Hobday and Boehlert, 2001 \\
\hline Baker River (Skagit) & $\begin{array}{l}\text { Sea-surface temperature at station NH } 05 \\
\text { (nearshore buoy, Oregon coast) } \\
\text { Pacific Decadal Oscillation (May-September) } \\
\text { Oceanic Niño Index (January-June) }\end{array}$ & Zimmerman, 2012 \\
\hline Baker River (Skagit) & Oceanic Niño Index (January-June) & $\begin{array}{l}\text { https://data.noaa.gov/dataset/climate- } \\
\text { orediction-center-cpcoceanic-nino- } \\
\text { index (accessed September 2017) }\end{array}$ \\
\hline Baker River (Skagit) & $\begin{array}{l}\text { North Pacific Gyre Oscillation, chlorophyll-a } \\
\text { density in Saratoga Passage }\end{array}$ & Zimmerman, 2017 \\
\hline
\end{tabular}


To identify indicators of coho ocean success, logit-transformed ocean survival estimates (appendix C) were regressed against individual predictors describing ocean conditions (PDO, ONI, NPGO, and sea level), smolt abundance (number of smolts), and smolt size (fork length at smolt trap) from BY 1989 to 2012. Missing values of ocean survival for BY 2006 and 2007 were estimated by regression against ocean survival estimated for Skykomish River coho. As a result, fork length, NPGO, ONI, and sea level were eliminated from consideration for having no significant $(p<0.05)$ explanatory value. A multiple regression of transformed ocean survival against the remaining predictors (PDO and smolts) resulted in a model where coefficients for smolts and linear and quadratic terms for PDO were significant $(\mathrm{p}<0.05)$. Using the shorter time series for which chlorophyll-a data were available (BY 2001-12), a multiple regression of transformed ocean survival on NGPO and chlorophyll-a produced significant $(\mathrm{p}<0.05)$ coefficients for both.

A quadratic relation between coho ocean survival and sea-surface temperature (monthly averages from buoy off Washington coast) has been seen by others for fish originating in the Strait of Juan de Fuca but not for coastal Washington and Columbia River coho (Ryding and Skalski, 1999), however the result was not explained. Salmon generally show better survival when sea-surface temperatures are cool (cool phase of PDO; Mantua and others, 1997). Because Skagit coho appear to rear primarily near the southwestern tip of Vancouver Island, Puget Sound and the Strait of Georgia (Weitkamp and Neely, 2002), they normally inhabit the California Current. However, they also may have access to the cooler water of the Alaska Current, which flows just north of Vancouver Island, when the California Current is adversely warm. The potential for coho to demonstrate interannual variability in spatial patterns of ocean use was hypothesized by Hobday and Boehlert (2001). Moreover, a quadratic relation may be more generally applicable because it also was seen to explain ocean survival of coho returning to Oregon coastal rivers (Rupp and others, 2012).

Based on these analyses, the coho model predicts ocean survival from a multiple regression that includes the number of smolts, and linear and quadratic terms for PDO. Note that the relation describing ocean survival using smolts and PDO is based on data mostly post-1990 when productivity in the Salish Sea experienced a major shift to lower ecosystem productivity (Zimmerman and others, 2015). Perhaps density dependence is less important when productivity of the Salish Sea is higher, as it was in the 1970s and 1980s. The user also is given the option to use NPGO and chlorophyll-a density as predictors of ocean survival to correspond with latest practices of WDFW and Skagit Salmon Co-managers.

Harvest

The proportion of the coho population lost to harvest is simply modeled by subtracting the harvest percentage from fish surviving the marine environment (column "Total wild OA3", appendix C). Harvest percentage was calculated by dividing estimated escapement by estimated survival to ocean age 3 (OA3), which represents ocean survival prior to commercial and recreational harvest. 


\section{Model Validation}

The model was validated by asking two questions-(1) How well do model results reproduce the data that were used to generate the model (descriptive ability; Shmueli, 2010)?, and (2) how well does the model predict new data (predictive ability)? The first question was asked of model results when spawner numbers were generated from actual escapement estimates at the beginning of each brood year ("non-cycling"), and also when the first three brood years were initialized with data and then the model results were initialized in subsequent years ("cycling"). Results from the non-cycling model indicate how well the model predicts each year individually based on initial spawners; results from the cycling version indicate how well the model predicts multiple lifecycles based on a single initiation of each cohort. The second question was answered using leave-one-out cross-validation (LOOCV; Geisser, 1993) where model parameters were generated using all years but one, and then results from the missing year were generated from the model. This process was repeated for all years, and the error rate from the entire model was compared with the error rate when each year was predicted from the other years.

When the model is initiated annually with estimated escapement (model does not "cycle"), it generally reproduces the pattern of smolt production over time $\left(\mathrm{r}^{2}=0.7747\right)$, although some points are outside the 95-percent confidence intervals (CIs) around the data (fig. 9A) and the 95-percent CI of the regression slope of the actual smolt data against predicted smolts does not include 1.0, meaning that the model tends to over-estimate smolt production (slope, 1.1143; 95-percent CI, 1.03-1.19; fig. 9B). There is no pattern in the residuals (fig. $9 \mathrm{C}$ ), suggesting that the errors are random.

Because of an inadequate understanding of key factors affecting marine survival and potentially incomplete harvest data, results for escapement predicted using smolts and PDO from the annually initiated model $\left(\mathrm{r}^{2}=0.3259\right.$; fig. $\left.10 \mathrm{~B}\right)$ are weaker than results for smolts. The model does not explain some years with poor returns (notably BYs 2003 and 2012) and one year with very high production (BY 2001) (fig. 10A). The 95-percent CI of the slope of the regression of escapement data against modeled escapement includes 1 (slope, 0.72; CI, 0.28-1.16; fig. 10B). Residuals from the model prediction tend to be negative at high numbers of predicted escapement (fig. 10C). Escapement is better predicted using NPGO and chlorophyll-a (fig. 11; $\mathrm{r}^{2}=0.8203$ ) than using PDO and smolts (fig. $10 ; \mathrm{r}^{2}=0.3259$ ) and NPGO and chlorophyll-a density to explain the high escapement observed in BY 2001. The 95-percent $\mathrm{CI}$ of the regression slope of actual against predicted escapement includes 1 (slope, 0.7593; CI; 0.511.0; fig. 11B). Again, the residuals from the model prediction are most negative at high numbers of predicted escapement. 

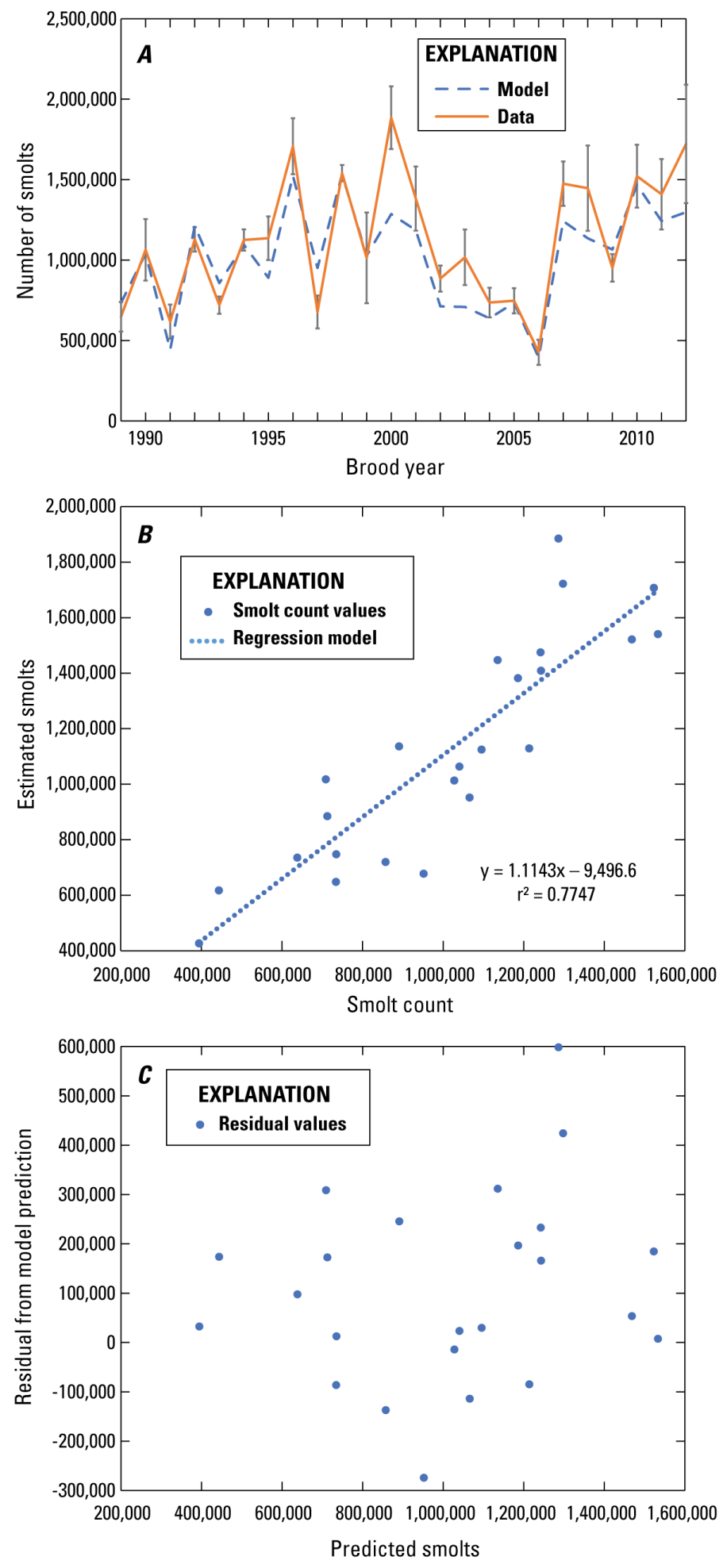

Figure 9. Comparison of model results with estimated number of smolts from counts at smolt trap when each year is initialized with estimated number of spawners (escapement), 1989-2012. (A) Times series of predicted smolts and smolt counts. Error bars indicate 95-percent confidence intervals around smolt estimates (data and confidence intervals provided by Joe Anderson and Clayton Kinsel, Washington Department of Fish and Wildlife, January 2017). (B) Regression of smolt counts against predicted smolts. (C) Graph of residuals (difference) of predicted smolts from smolt counts. 

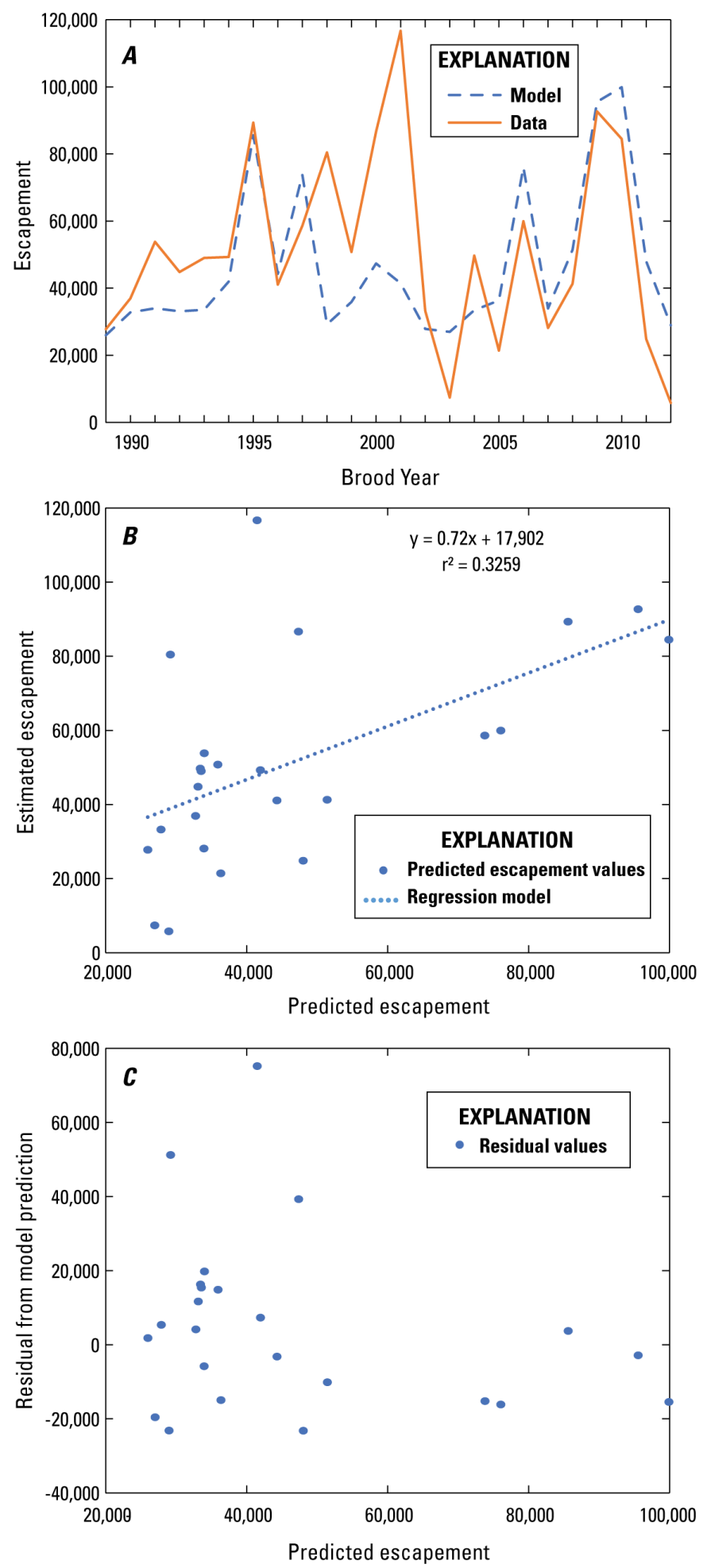

Figure 10. Comparison of model results for estimated escapement predicted using Pacific Decadal Oscillation and smolts compared with data-based estimates when each year is initialized with estimated number of spawners (escapement), 1989-2012. (A) Times series of predicted escapement and estimated escapement. (B) Regression of estimated escapement against predicted escapement. (C) Graph of residuals (difference) of predicted escapement from estimated escapement. 

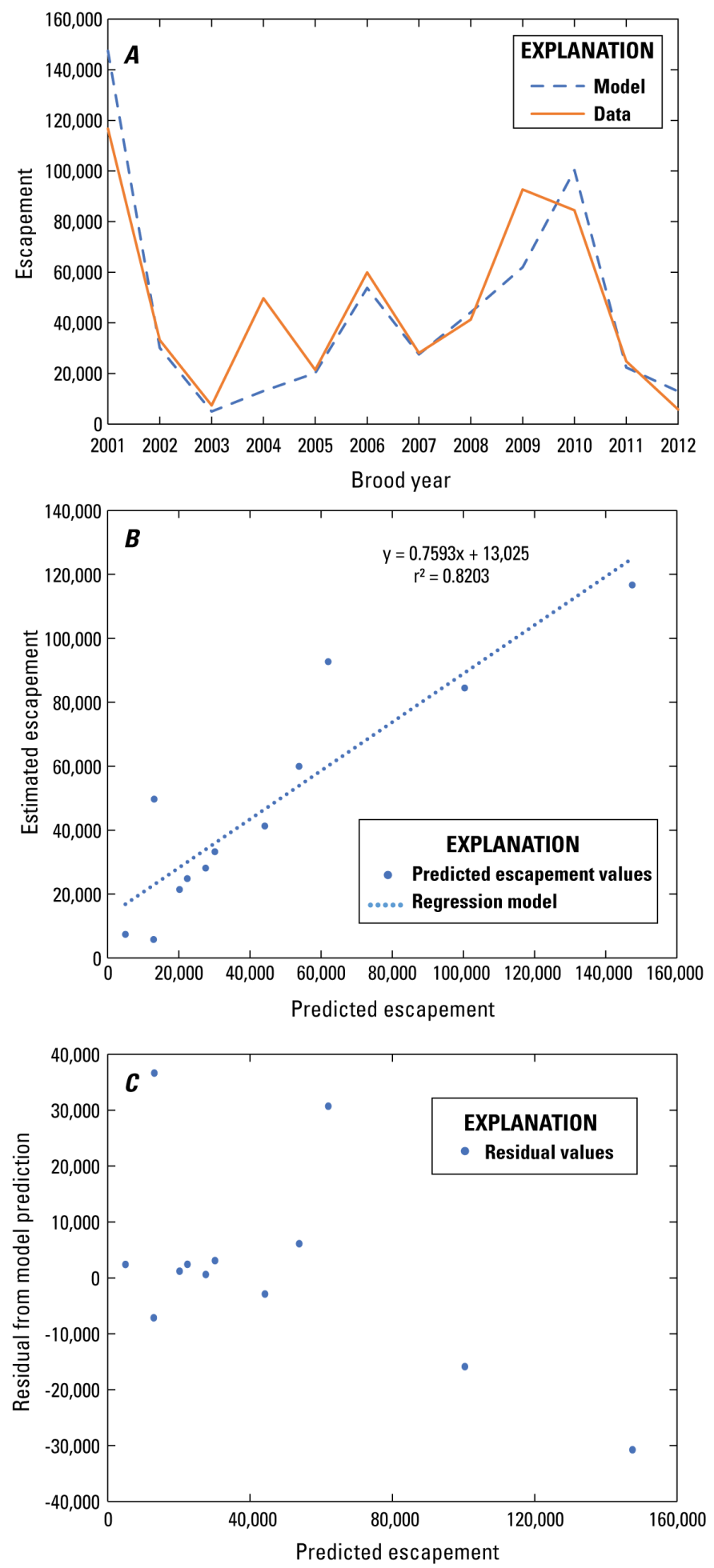

Figure 11. Comparison of model results for estimated escapement predicted using North Pacific Gyre Oscillation and chlorophyll-a compared with data-based estimates when each year is initialized with estimated number of spawners (escapement), 2001-12. (A) Times series of predicted escapement and estimated escapement. (B) Regression of estimated escapement against predicted escapement. (C) Graph of residuals (difference) of predicted escapement from estimated escapement. 
When escapement for each cohort is initialized based on actual estimates for the first three brood years and subsequent escapement values are generated by the model (the model "cycles"), performance at predicting smolts is inferior to the non-cycling version (fig. 12A). This is likely owing to prediction errors propagating to the next generation of fish. The regression of actual smolt data against modeled smolt results (fig. $12 B$ ) shows a weaker association between data and the model $\left(\mathrm{r}^{2}=0.7747\right.$, noncycling, compared to 0.5899 , cycling), but a slope close to 1 (slope, 0.9978; 95-percent CI, 0.90-1.09, fig. 12B). The residual plot (fig. 12C) shows no pattern, suggesting there no systematic source of error. Results for escapement predicted by PDO and smolts also are inferior in the cycling $\left(\mathrm{r}^{2}, 0.2317\right.$; fig. $13 B)$ compared to the non-cycling model $\left(\mathrm{r}^{2}, 0.3259\right.$; fig. $\left.10 B\right)$. The slope of the regression of actual against predicted escapement is low (slope, 0.5248; 95-percent CI, 0.34-0.71; fig. 13B), indicating that the model underestimates escapement. The residuals show increasing negative deviations, with higher predicted escapement, and may indicate a linear effect that is missing from the model (fig. $13 C$ ). Escapement is better predicted using NPGO and chlorophyll-a than using PDO and smolts in the cycling model ( $\mathrm{r}^{2}, 0.7114$; fig. 14), but not a good as for the non-cycling model $\left(\mathrm{r}^{2}, 0.8203\right.$; fig. 11). The 95percent $\mathrm{CI}$ for the slope of the regression of actual compared to predicted escapement includes 1 (slope, 0.7675; 95-percent CI, 0.42-1.11; fig. 14B). Residuals of actual from predicted escapement show no pattern, with the exception of the most negative residual occurring with the highest predicted escapement. 

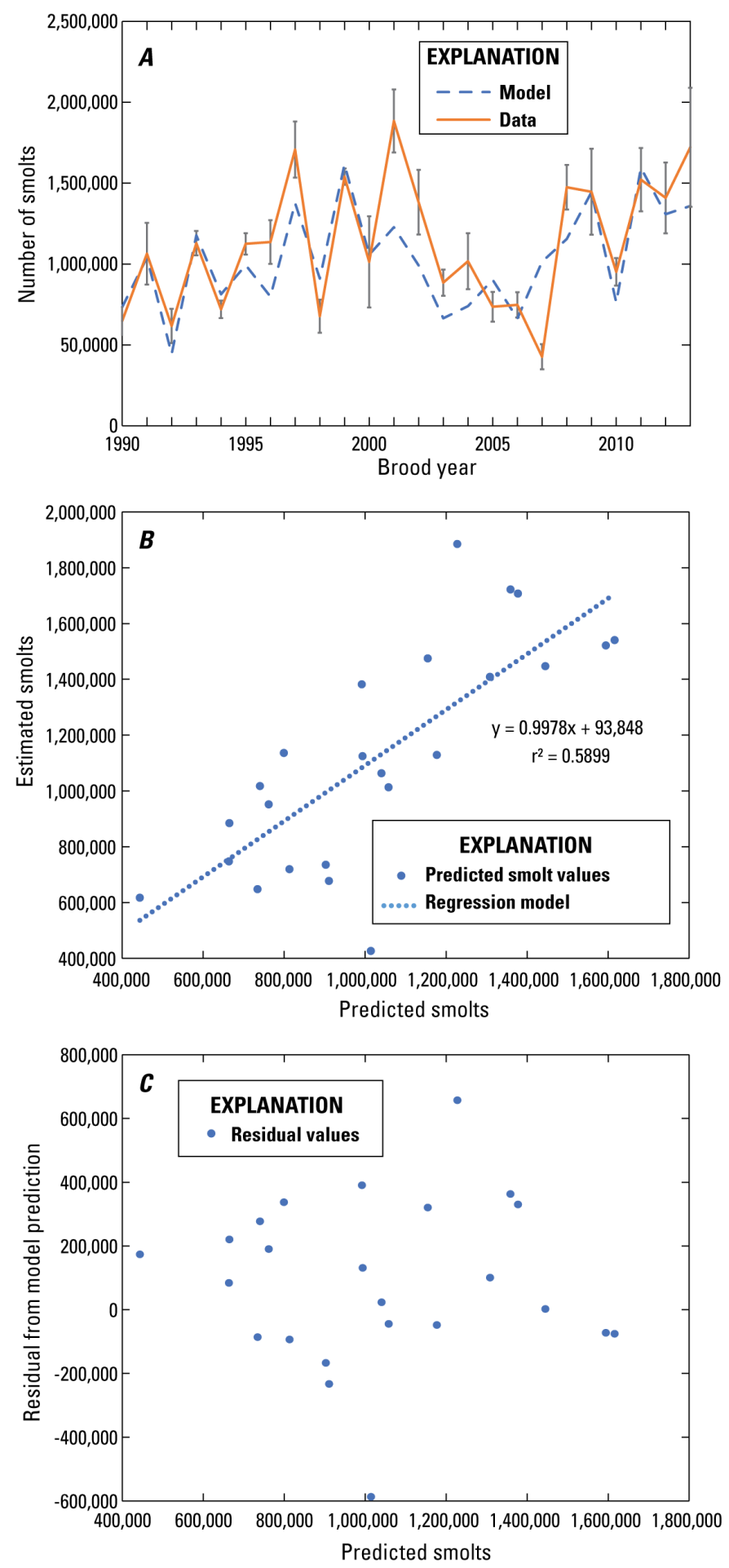

Figure 12. Comparison of model results with estimated number of smolts based on counts at smolt trap when the first 3 years of the model run are initialized with estimated number of spawners (escapement) and subsequently by model results. (A) Times series of predicted smolts and smolt counts. Error bars indicate 95-percent confidence intervals around smolt estimates (data and confidence intervals provided by Joe Anderson and Clayton Kinsel, Washington Department of Fish and Wild life, January 2017). (B) Regression of smolt counts against predicted smolts. (C) Graph of residuals (difference) of predicted smolts from smolt counts. 

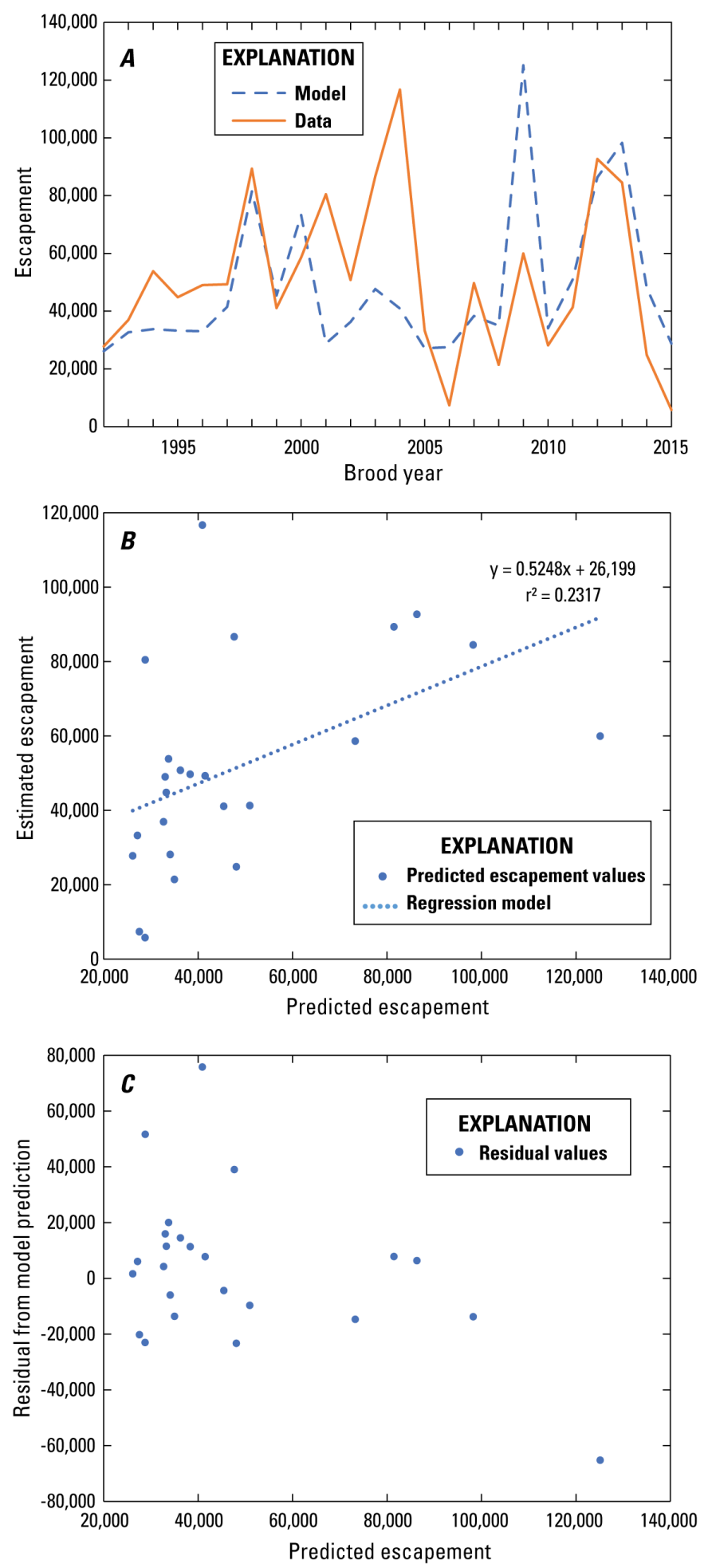

Figure 13. Comparison of model results for estimated escapement predicted using Pacific Decadal Oscillation and smolts compared with data-based estimates when the first 3 years of the model run are initialized with estimated number of spawners (escapement) and subsequently by model results. (A) Times series of predicted escapement and estimated escapement. (B) Regression of estimated escapement against predicted escapement. (C) Graph of residuals (difference) of predicted escapement from estimated escapement. 

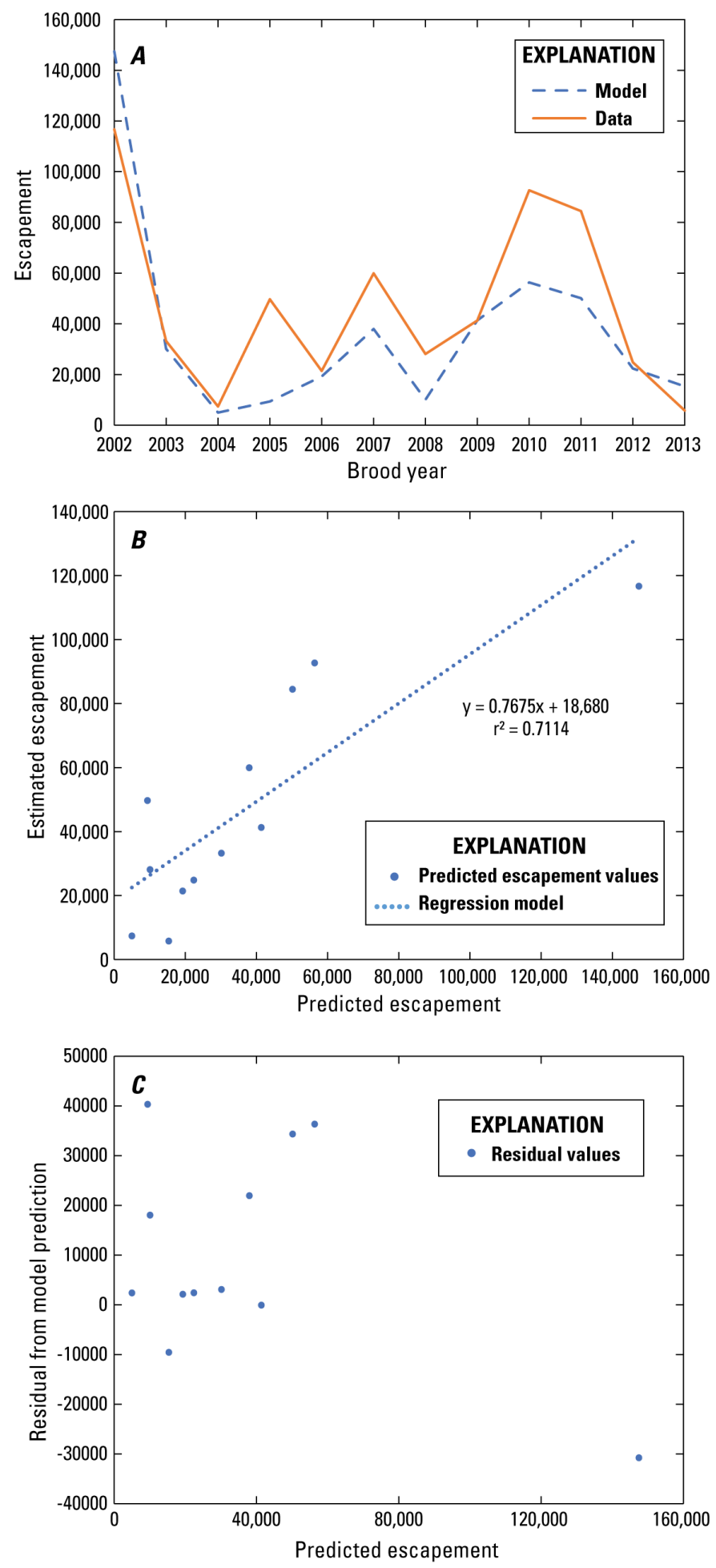

Figure 14. Comparison of model results for estimated escapement predicted using NPGO and chlorophyll-a compared with data-based estimates when the first 3 years of the model run are initialized with estimated number of spawners (escapement) and subsequently by model results. (A) Times series of predicted escapement and estimated escapement. (B) Regression of estimated escapement against predicted escapement. (C) Graph of residuals (difference) of predicted escapement from estimated escapement. 
The LOOCV predicts results for individual years based on a model developed from all other years. After this is repeated for all years, the error between observed and predicted values for results generated by omitting years is compared with results for the whole model using parameters based on all years. This analysis was run for the non-cycling (escapement initialized from actual estimates for each brood year) version of the model and for escapement predicted from PDO and smolts.

The LOOCV results for smolts show that the error for the full model is greater than the error from cross-validation predictions (table 7). These results indicate that the results from the validation runs are not significantly $(\mathrm{p}<0.05)$ different than results from the whole model. This can be interpreted to show that the model has similar ability to fit the data used to create as it has to fit new data. For escapement, LOOCV results show a slightly higher error for the cross-validation predictions compared with the full model (table 7). A possible cause of the greater error in the cross-validation results is that the model includes more parameters than can be estimated by the relatively small dataset; hence, the model fits the data very well but is not as good at predicting the results of new data. One solution for this situation is to simplify the model. Another interpretation is that each year of data provides important information to the model and the model can best be improved by obtaining more years of data. Given the simplicity of the model, the complexity of the system it attempts to describe, and the small difference between the estimated errors, accumulating more data may be the most productive means to improve the model.

Results from model-validation analyses indicate that the model does a good job of predicting smolts, both when cohorts are initialized annually and to a lesser extent when the model results are used to initialize subsequent life cycles. In both cases, the regression of actual smolts against predicted smolts is close to 1 (although not within the 95-percent CI for the annually initiated version) and residual plots do not show a pattern that would indicate exclusion of a systematic factor. The cross-validation exercise (conducted only for the non-cycling version) also indicates that the model structure does not include extra parameters.

Results of model validation are not as strong for escapement as for smolts, especially when PDO and number of smolts are used to predict ocean survival. Although most 95-percent CIs of regression slopes of actual escapement against predicted escapement include 1, the slope estimates themselves are uniformly less than one. Residual plots indicate that this is due to an underestimate of production during highly productive years for all versions of the escapement model. Performance of the escapement model that uses NPGO and chlorophyll-a density to predict ocean survival is much superior to using PDO and smolts but can only be evaluated for the years when chlorophyll-a density is available. The crossvalidation analysis for escapement indicates that the model may benefit from future incorporation of a longer time-series of data.

Table 7. Results from leave-one-out cross-validation analysis.

[Abbreviations: LOOCV, leave-one-out cross validation; RMSE, root mean square error]

\begin{tabular}{l|c|l|c}
\hline \multicolumn{1}{c|}{ Life stage } & Years & \multicolumn{1}{c|}{ RMSE model } & RMSE LOOCV \\
\hline Smolts & $1991-2010$ & 280,833 & 233,067 \\
\hline & & & \\
\hline Escapement & $1991-2009$ & 27,002 & 27,967 \\
\hline
\end{tabular}




\section{Potential Uses of Model}

This system dynamics model of coho in the Skagit River is a synthesis of available data based on current hypotheses regarding interactions between salmon and their environment. It is built to be easily manipulated by tribal staff and others, and could be used for the following purposes:

- Determining relative differences between climatic regimes and (or) management actions. In an era of potentially greatly changing climate and given the possibility that restoration activities can improve salmon habitat, the model provides an opportunity to experiment with combinations of actions and climate scenarios to evaluate the relative importance of specific changes in each. Although the model was developed using flow values from specific time periods (for example, March-October for low flow), the user is nevertheless able to experiment with changing the hydrologic regime. Advantageous or adverse events can simply be added to the appropriate hydrograph that represents a particular life stage.

- Showing how much of annual variation can be explained and how much is not understood. Years when model predictions and reality diverge are years when new hypotheses about system drivers can be developed to explain why the model, which describes what we think we understand, is not correct. The model is expected to become obsolete as novel drivers owing to changing climate and other ecosystem stressors come to dominate. We may already be seeing this as PDO becomes less explanatory of ocean mortality than NPGO and chlorophyll-a density.

- Validating model with future data. As monitoring data continue to accumulate, they will represent a wider range of environmental conditions, including new combinations of average events as well as more extreme events. By comparing modeled survival with monitored survival, the veracity of the model can be tested.

- Testing sensitivity of results to parameter values. Parameters in the model are based on relations developed from relatively short time series of data, literature values, or expert opinion. By changing parameters and re-running the model, the user can determine the sensitivity of model outcomes. Eventually, a formal sensitivity analysis could be conducted to determine which parameters have the greatest influence on fish survival.

- Public outreach. The model could be used as a teaching tool with various audiences to explain how various factors interact to affect fish survival.

- Improving monitoring program and restoration activities. Outcomes from model validation and tests of sensitivity to parameters likely will suggest additional data needs, data that may not need to be collected, or more effective ways to collect data. Ultimately, the model could be used to redirect monitoring and restoration efforts and as a tool to test potential scenarios for improving growth, survival, and production of juvenile salmon. There is an obvious need to effectively monitor habitat and understand the potential for habitat availability to mitigate adverse flow conditions. 


\section{Model Limitations}

All models necessarily simplify reality. Users of this model should be aware of its limitations and consider them when evaluating model outcomes.

- Limits of conceptual model. The model represents the current thinking of researchers and resource managers regarding factors limiting coho production. Although this conceptual model is based on direct experience and scientific evidence, the system is not perfectly understood and the model may need to be modified as more information accumulates.

- Short time series. The model is based on data collected over a very short period of time, which did not include the full range and combination of possible environmental conditions. Therefore, many relations (for example, smolt productivity when pink returns are less than 60,000 or the effect of the "blob" of anomalously warm water in the eastern Pacific that formed in late 2013 and persisted until late 2016) could not be described because these conditions did not occur during the sampled time period. Additionally, the short time series constrains even parameterized relations to be based on few observations.

- Not all important factors were measured. Datasets were not available to describe the condition of environmental factors suspected to be important. Examples include predation pressure in the freshwater and marine environments. Some of these cases were addressed using literature values (for example, identifying limiting levels of turbidity).

- Interaction terms were not included. For example, the effects of flow depend on the availability of refugia created by large woody debris. Future versions of the model would benefit from adding this complexity.

- Unforeseen or unpredictable changes. Unforeseen limiting factors are likely to arise as the environment changes and produces novel combinations of conditions or conditions more extreme than expected. Changes in abundance and distribution of invasive species and exotic diseases are other potential ecosystem stressors. Moreover, many assumptions may not hold in the future. For example, we do not know how fish may alter their life cycle to adapt to future environments or whether the hierarchy of life history bottlenecks will change under future hydrologic and temperature conditions. A small fraction of the coho population already do not adhere to the 3-year life cycle.

- Simplistic representation of ocean conditions. Factors determining ocean survival are the least understood part of the coho life cycle, which comprises one-half of the time frame for each generation. Fish spend about 18 months in the ocean, during which time their migratory dynamics are only known from point interceptions of coded, wire-tagged fish in ocean fisheries, and monitoring of environmental conditions other than sea-surface temperature that may affect their survival also is primarily based on point measurements.

- Spatial resolution is crude. Elevation range, land use patterns, geology, and other factors create substantial diversity among sub-basins of the Skagit River. However, the availability of longterm fish production data from only one smolt trap eliminates our ability to describe productivity owing to differing environmental conditions at the sub-basin scale, yet these differences likely will counter or exacerbate climate change. 
- Temporal resolution is crude. Although the model considers some drivers relative to the periods in which they are relevant (for example, scouring flows are only considered during November and December), other drivers are summarized over long periods of time (for example days having turbidity over a threshold are summarized for most of the freshwater stage of the lifecycle). This approach does not capture the variation in outcome that the same event might have on fish of different ages. Moreover, the temporal duration of events is not considered when looking at merely a maximum or threshold value.

- Deterministic model. The model does not describe the stochasticity of the real world. Therefore, it does not describe the variation in outcome that results from the natural variation that is represented by a deterministic parameter value in the model. The user does not see the confidence interval that exists around the model prediction. However, features of the model software enable the user to vary individual parameters according to a selected range and distribution to see the distribution of predictions that would result (see appendix B, section "Running the Model").

\section{Acknowledgments}

The authors thank members of the Sauk-Suiattle Indian Tribe, including Russell Hornback, Jason Joseph, Norma Joseph, Jan Mabee, Kathy Misanes, and Ray Misanes, who discussed the cultural and economic importance of salmon species to the Tribe and Tribal natural resource management, and helped to determine the topic of the model. Eric Beamer and Casey Ruff of the Skagit River System Cooperative engaged in several fruitful discussions throughout the development of the model, and Casey provided R code and some analytical results. Pete Kairis (Swinomish Indian Tribe) provided fish data and feedback on parts of the model. We also discussed the model with Joseph Anderson (Washington Department of Fish and Wildlife), Robert Black (USGS), Chris Curran (USGS), Correigh Greene (National Oceanic and Atmospheric Administration), Clay Kinsel (Washington Department of Fish and Wildlife), and Corey Phillis (National Oceanic and Atmospheric Administration). Joseph Anderson and Clay Kinsel provided fish data collected by Washington Department of Fish and Wildlife, and Chris Curran provided turbidity data. Finally, we thank Mara Zimmerman (Washington Department of Fish Wildlife) and an anonymous reviewer for great suggestions for improving the manuscript and the model.

\section{References Cited}

Abrahams, M.V., and Kattenfeld, M.G., 1997, The role of turbidity as a constraint on predator-prey interactions in aquatic environments: Behavioral Ecology and Sociobiology, v. 40, p. 169-174.

Araujo, H.A., Holt, C., Curtis, J.M., Perry, R.I., Irvine, J.R., and Michielsens, C.G., 2013, Building an ecosystem model using mismatched and fragmented data-A probabilistic network of early marine survival for Coho Salmon Oncorhynchus kisutch in the Strait of Georgia: Progress in Oceanography, v. 115, p. 41-52.

Au, D.W.K., 1972, Population dynamics of the coho salmon and its response to logging in three coastal streams: Corvallis, Oregon State University, Ph.D. thesis.

Barrowman, N.J., and Myers, R.A., 2000, Still more spawner-recruit curves-The hockey stick and its generalizations: Canadian Journal of Fisheries and Aquatic Science, v. 57, p. 665-676.

Barrowman, N.J., Myers, R.A., Hilborn, R., Kehler, D.G., and Field, C.A., 2003, The variability among populations of coho salmon in the maximum reproductive rate and depensation: Ecological Applications, v. 13, p. 784-793. 
Bash, J., Berman, C., and Bolton, S., 2001, Effects of turbidity and suspended solids on salmonids: Olympia, Washington, Washington State Transportation Commission, Final Research Report, Research Project T1803, Task 42, 74 p.

Beamer, E., Beechie, T., Perkowski, B., and Klochak, J., 2000, Application of the Skagit Watershed Council's strategy_-River basin analysis of the Skagit and Samish Basins-Tools for salmon habitat restoration and protection: Mount Vernon, Washington, Skagit Watershed Council, 80 p.

Beamish, R.J., and Bouillon, D.R., 1993, Pacific salmon production trends in relation to climate: Canadian Journal of Fisheries and Aquatic Sciences, v. 50, p. 1,002-1,016.

Beamish, R.J., Sweeting, R.M., Lange, K.L., Noakes, D.J., Preikshot, D., and Neville, C.M., 2010, Early marine survival of coho salmon in the Strait of Georgia declines to very low levels: Marine and Coastal Fisheries, Dynamics, Management and Ecosystem Science, v. 2, p. 424-439.

Beecher, H.A., Caldwell, B.A., and DeMond, S.B., 2002, Evaluation of depth and velocity preferences of juvenile coho salmon in Washington streams: North American Journal of Fisheries Management, v. 22, p. 785-795.

Beechie, T., Beamer, E., and Wasserman, L., 1994, Estimating coho salmon rearing habitat and smolt production losses in a large river basin, and implications for habitat restoration: North American Journal of Fisheries Management, v. 14, p. 797-811.

Beechie, T.J., Buhle, E.R., Ruckelshaus, M.H., Fullerton, A.H., and Holsinger, L., 2006, Hydrologic regime and the conservation of salmon life history: Biological Conservation, v. 130, p. 560-572.

Beechie, T.J., Liermann, M., Beamer, E.M., and Henderson, R., 2005, A classification of habitat types in a large river and their use by juvenile salmonids: Transactions of the American Fisheries Society, v. 134, p. 717-729.

Berg, L., 1982, The effect of exposure to short-term pulses of suspended sediment on the behavior of juvenile salmonids, in Proceedings of the Carnation Creek workshop - A ten-year review: Nanaimo, Canada, Department of Fisheries and Oceans, Pacific Biological Station, p. 177-196.

Berg, L., and Northcote, T.G., 1985, Changes in territorial, gill-flaring, and feeding behaviour in juvenile coho salmon (Oncohynchus kisutch) following short-term pulses of suspended sediment: Canadian Journal of Fisheries and Aquatic Sciences, v. 42, p. 1,410-1,417.

Beverton, R.J.H., and Holt, S.J., 1957, On the dynamics of exploited fish populations: London, United Kingdom Ministry of Agriculture and Fisheries, Fisheries Investigations Series 2, v. 19.

Bilton, H.T., Alderdice, D.F., and Schnute, J.T., 1982, Influence of time and size at release of juvenile coho salmon (Oncorhynchus kisutch) on returns at maturity: Canadian Journal of Fisheries and Aquatic Sciences, v. 39, p. 426-447.

Bisson, P.A., and Bilby, R.E., 1982, Avoidance of suspended sediment by juvenile coho salmon: North American Journal of Fisheries Management, v. 4, p. 371-374.

Bisson, P.A., Sullivan, K., and Nielsen, J.L., 1988, Channel hydraulics, habitat use, and body form of juvenile coho salmon, steelhead, and cutthroat trout in streams: Transactions of the American Fisheries Society, v. 117, p. 262-273.

Bjorkstedt, E.P., 2000, Stock-recruitment relationships for life cycles that exhibit concurrent density dependence: Canadian Journal of Fisheries and Aquatic Sciences, v. 57, p. 459-467.

Boehlert, G.W., and Morgan, J.B., 1985, Turbidity enhances feeding abilities of larval Pacific herring, Clupea harengus pallasi: Hydrobiologia, v. 123, p. 161-170.

Burke, B.J., Liermann, M.C., Teel, D J., and Anderson, J.J., 2013, Environmental and geospatial factors drive juvenile Chinook salmon distribution during early ocean migration: Canadian Journal of Fisheries and Aquatic Sciences, v. 70, p. 1,167-1,177.

Caldwell, B., 1999, Big Quilcene River fish habitat analysis under the instream flow incremental methodology: Washington Department of Ecology, Open File Technical Report 99-05, 49 p. 
Carling, P.A., 1987, Bed stability in gravel streams, with reference to stream regulation and ecology, in River channels_-Environment and process: Oxford, United Kingdom, Blackwell Scientific Publications Ltd., p. 321-347.

Castro, J.M., and Jackson, P.L., 2001, Bankfull discharge recurrence intervals and regional hydraulic geometry relationships_-Patterns in the Pacific Northwest: Journal of the American Water Resources Association, v. 37, p. 1,249-1,262.

Cederholm, C.J., and Salo, E.O., 1979, The effects of logging road landslide siltation on the salmon and trout spawning gravels of Stequaleho Creek and the Clearwater River Basin, Jefferson County, Washington, 1972-1978: Seattle, University of Washington, Fisheries Research Institute, FRI-UW7915, $99 \mathrm{p}$.

Chapman, D.W., 1962, Aggressive behavior in juvenile coho salmon as a cause of emigration: Journal of the Fisheries Research Board of Canada, v. 19, p. 1,047-1,080.

Clark, J., and McCarl, B., 1983, An investigation of the relationship between Oregon coho salmon (Oncorhynchus kisutch) hatchery releases and adult production utilizing law of the minimum regression: Canadian Journal of Fisheries and Aquatic Sciences, v. 40, p. 516-523.

Coronado, C., and Hilborn, R., 1998, Spatial and temporal factors affecting survival in coho salmon (Oncorhynchus kisutch) in the Pacific Northwest: Canadian Journal of Fisheries and Aquatic Sciences, v. 55, p. 2,067-2,077.

Crisp, D.T., and Carling, P.A., 1989, Observations on siting, dimensions and structure of salmonid redds: Journal of Fish Biology, v. 34, p. 119-134.

Davies-Colley, R.J., and Smith, D.G., 2001, Turbidity, suspended sediment, and clarity of water-A review: Journal of the American Water Resources Association, v. 37, p. 1,085-1,101.

de Valpine, P. and Hastings, A., 2002, Fitting population models incorporating process noise and observation error: Ecological Monographs, v. 72, p. 57-76.

Di Lorenzi, E., Schneider, N., Cobb, K.M., Franks, P.J.S., Chhak, K., Miller, A.J., McWilliams, J.C., Bogard, S.J., Arango, H., Curchister, E., Powell, T.M., and Riviere, P., 2008, North Pacific Gyre Oscillation links ocean climate and ecosystem change: Geophysical Research Letters, v. 35, p. L08607.

Dorner, B., Holt, K.R., Peterman, R.M., Jordan, C., Larsen, D.P., Olsen, A.R., and Abdul-Aziz, O.I., 2013, Evaluating alternative methods for monitoring and estimating responses of salmon productivity in the North Pacific to future climatic change and other processes - A simulation study: Fisheries Research, v. 147, p. 10-23.

Drucker, B., 1972, Some life history characteristics of coho salmon of the Karluk River system, Kodiak Island, Alaska: Fishery Bulletin, v. 70, p. 79-94.

Duchrow, R.M., and Everhart, W.H., 1971, Turbidity measurement: Transactions of the American Fisheries Society, v. 4, p. 682-690.

Eaton, J.G., and Scheller, R.M., 1996, Effects of climate warming on fish thermal habitat in streams of the United States: Limnological Oceanography, v. 41, p. 1,109-1,115.

Elsner, M.M., Cuo, M., Voisin, N., Deems, J.S., Hamlet, A.F., Vano, J.A., Mickelson, K.E.B., Lee, S.Y., and Lettenmaier, D.P., 2010, Implications of 21st century climate change for the hydrology of Washington State: Climate Change, v. 102, p. 225-260.

Emlen, J.M., Reisenbichler, R.R., McGie, A.M., and Nickelson, T.E., 1990, Density-dependence at sea of coho salmon (Oncorhynchus kisutch): Canadian Journal of Fisheries and Aquatic Science, v. 47, p. $1,765-1,772$.

Fedorenko, A.Y., and Cook, R.J., 1982, Trapping and coded wire tagging of wild coho juveniles in the Vedder-Chilliwack River, 1976 to 1979: Canadian Manuscript Report of Fisheries and Aquatic Sciences 1678, 79 p. 
Ford, F.A., 1999, Modeling the environment — An introduction to system dynamics models of environmental systems: Washington, D.C., Island Press, 401 p.

Francis, R.C., and Hare, S.R., 1994, Decadal-scale regime shifts in the large marine ecosystems of the north-east Pacific - A case for historical science: Fisheries Oceanography, v. 3, p. 279-291.

Francis, R.C., Hare, S.R., Hollowed, A.B., and Wooster, W.S., 1998, Effects of interdecadal climate variability on the oceanic ecosystems of the NE Pacific: Fisheries Oceanography, v. 7, p. 1-21.

Franklin, J.F., and Dyrness, C.T., 1973, Natural vegetation of Oregon and Washington: Portland, Oregon, U.S. Forest Service, Pacific Northwest Forest and Range Experiment Station, General Technical Report PNW-GTR-008, 427 p.

Frissell, C.A., 1992, Cumulative effects of land use on salmon habitat in southwest Oregon coastal streams: Corvallis, Oregon State University, Ph.D. thesis, 227 p.

Gallagher, S.P., and Wright, D.W., 2012, Coastal Mendocino County salmonid life cycle and regional monitoring-Monitoring status and trends for 2011: Fortuna, California State Department of Fish and Wildlife, Coastal Watershed Planning and Assessment Program, 49 p.

Geisser, S., 1993, Predictive inference: New York, Chapman and Hall, 240 p.

Goode, J.R., Buffington, J.M., Tonina, D., Isaak, D.J., Thurow, R.F., Wenger, S., Nagel, D., Luce, C., Tetzlaff, D., and Soulsby, C., 2013, Potential effects of climate change on streambed scour and risks to salmonid survival in snow-dominated mountain basins: Hydrological Processes, v. 27, p. 750-765.

Greene, C.M., and E.M. Beamer, 2012, Monitoring population responses to estuary restoration by Skagit River Chinook salmon: National Oceanic and Atmospheric Administration, Intensively Monitored Watershed Project, Annual Report 2011, 19 p.

Gregory, R.S., 1992, The influence of ontogeny, perceived risk of predation, and visual ability on the foraging behavior of juvenile chinook salmon: Theory and Application of Fish Feeding Ecology, v. 18, p. 271-284.

Gregory, R.S., 1993, Effect of turbidity on the predator avoidance behaviour of juvenile chinook salmon (Oncorhynchus tshawytscha): Canadian Journal of Fisheries and Aquatic Sciences, v. 50, p. 241-246.

Gregory, R.S., and Levings, C.D., 1996, The effects of turbidity and vegetation on the risk of juvenile salmonids, Oncorhynchus spp., to predation by adult cutthroat trout, O. clarkia: Environmental Biology of Fishes, v. 47, p. 279-288.

Gregory, R.S., and Northcote, T.G., 1993, Surface, planktonic, and benthic foraging by juvenile chinook salmon (Oncorhynchus tshawytscha) in turbid laboratory conditions: Canadian Journal of Fisheries and Aquatic Sciences, v. 50, p. 233-240.

Groot, C., and Margolis, L., 1991, Pacific salmon life histories: Vancouver, Canada, University of British Columbia Press, 393 p.

Hamlet, A.F., Fluharty, D., Lettenmaier, D.P, Mantua, N., Miles, E., Mote, P., Whitely Binder, L., 2001, Effects of climate change on water resources in the Pacific Northwest - Impacts and policy implications: Seattle, University of Washington, Climate Impacts Group Publication 145, 16 p.

Hare, S.R., Mantua, N.J., and Francis, R C., 1999, Inverse production regimes-Alaska and West Coast Pacific salmon: Fisheries, v. 24, p. 6-14.

Hartman, G.F., Andersen, B.C., and Scrivener, J.C., 1982, Seaward movement of coho salmon (Oncorhynchus kisutch) fry in Carnation Creek, an unstable coastal stream in British Columbia: Canadian Journal of Fisheries and Aquatic Science, v. 39, p. 588-597.

Hartman, G.F., and Scrivener, J.C., 1990, Impacts of forestry practices on a coastal stream ecosystem, Carnation Creek, British Columbia: Canadian Bulletin of Fisheries and Aquatic Sciences, v. 223, 148 p. 
Hartman, G., Scrivener, J.C., Holtby, L.B., and Powell, L., 1987, Some effects of different streamside treatments on physical conditions and fish population processes in Carnation Creek, a coastal rain forest stream in British Columbia, in Streamside management-Forestry and fishery interactions:

Seattle, University of Washington, Institute of Forest Resources, p. 330-372.

Hassan, M., 1990, Scour, fill, and burial depth of coarse material in gravel bed streams: Earth Surface Processes and Landforms, v. 15, p. 341-356.

Heard, W.R., 1991, Life history of pink salmon (Oncorhynchus gorbuscha), in Pacific salmon life histories: Vancouver, Canada, University of British Columbia Press, p. 121-222.

Henley, W.F., Patterson, M.A., Neves, R.J., and Lemly, A.D., 2000, Effects of sedimentation and turbidity on food webs-A concise review for natural resource managers: Reviews in Fisheries Science, v. 8, p. 125-139.

Hobday, A.J., and Boehlert, G.W., 2001, The role of coastal ocean variation in spatial and temporal patterns in survival and size of coho salmon (Oncorhynchus kisutch): Canadian Journal of Fisheries and Aquatic Sciences, v. 58, p. 2,021-2,036.

Holtby, L.B., Andersen, B.C., and Kadowaki, R.K., 1990. Importance of smolt size and early ocean growth to interannual variability in marine survival of coho salmon (Oncorhynchus kisutch): Canadian Journal of Fisheries and Aquatic Sciences, v. 47, p. 2,181-2,194.

Holtby, L.B., and Healey, M.C., 1986, Selection for adult size in female coho salmon (Oncorhynchus kisutch): Canadian Journal of Fisheries and Aquatic Sciences, v. 43, p. 1,946-1,959.

Hurvich, C.M., and Tsai, C.-L., 1989, Regression and time series model selection in small samples: Biometrika, v. 76, p. 297-307.

Irvine, J.R., O’Neill, M., Godbout, L., and Schnute, J., 2013, Effects of smolt release timing and size on the survival of hatchery-origin coho salmon in the Strait of Georgia: Progress in Oceanography, v. 115, p. 111-118.

Konecki, J. T., and Woody, C. A., and Quinn, T. P., 1995, Temperature preference in two populations of juvenile coho salmon, Oncorhynchus kisutch: Environmental Biology of Fishes, v. 44, p. 417-421.

Kruzic, L.M., 1998, Ecology of juvenile coho salmon within the upper south Umpqua Basin, Oregon: Moscow, University of Idaho, Master's thesis, 97p.

Lake, R.G., and Hinch, S.G., 1999, Acute effects of suspended sediment angularity on juvenile coho salmon (Oncorhynchus kisutch): Canadian Journal of Fisheries and Aquatic Science, v. 56, p. 862867.

Lawson, P.W., Logerwell E.A., Mantua, N.J., Francis, R.C., and Agostini, V.N., 2004, Environmental factors influencing freshwater survival and smolt production in Pacific Northwest coho salmon (Oncorhynchus kisutch): Canadian Journal of Fisheries and Aquatic Sciences, v. 61, p. 360-373.

Lestelle, L.C., 2007, Coho salmon (Oncorhynchus kisutch) life history patterns in the Pacific Northwest and California: Report prepared for Bureau of Reclamation, Klamath Area Office, Arcata, California, $122 \mathrm{p}$.

Lloyd, D.S., J.P. Koenings, and J.D. LaPerriere, 1987, Effects of turbidity in fresh waters of Alaska: North American Journal of Fisheries Management, v. 7, p. 18-33.

Maceina, M.J., and Pereira, D.L., 2007, Recruitment, in Analysis and interpretation of freshwater fisheries data: Bethesda, Maryland, American Fisheries Society, p. 121-185.

Madej, M.A., Currens, C., Ozaki, V., Yee, J., and Anderson, D.G., 2006, Assessing possible thermal rearing restrictions for juvenile coho salmon (Oncorhynchus kisutch) through thermal infrared imaging and in-stream monitoring, Redwood Creek, California: Canadian Journal of Fisheries and Aquatic Sciences, v. 63, p. 1,384-1,396. 
Magnuson, A., and R. Hilborn, 2003, Estuarine influence on survival rates of coho (Oncorhynchus kisutch) and Chinook salmon (Oncorhynchus tshawytscha) released from hatcheries on the U. S. Pacific Coast: Estuaries, v. 26, p. 1,094-1,103.

Mantua, N.J., Hare, S R., Zhang, Y., Wallace, J M., and Francis, R.C., 1997, A Pacific interdecadal climate oscillation with impacts on salmon production: Bulletin of the American Meteorological Society, v. 78, p. 1,069-1,079.

Mantua, N., Tohver, I., and Hamlet, A., 2010, Climate change impacts on streamflow extremes and summertime stream temperature and their possible consequences for freshwater salmon habitat in Washington State: Climatic Change, v. 102, p. 187-223.

Mathews, S.B., and Ishida, Y., 1989, Survival, ocean growth, and ocean distribution of differentially timed releases of hatchery coho salmon (Oncorhynchus kisutch): Canadian Journal of Fisheries and Aquatic Sciences, v. 46, p. 1,216-1,226.

Mathews, S.B., and Olson, F.W., 1980, Factors affecting Puget Sound coho salmon (Oncorhynchus kisutch) runs: Canadian Journal of Fisheries and Aquatic Sciences, v. 37, p. 1,373-1,378.

McCarl, B.A., and Rettig, R.B., 1983, Influence of hatchery smolt releases on adult salmon production and its variability: Canadian Journal of Fisheries and Aquatic Sciences, v. 11, p. 1,880-1,886.

McGie, A.M., 1984, Commentary-Evidence for density dependence among coho salmon stocks in the Oregon Production Index area, in The influence of ocean conditions on the production of salmonids in the North Pacific-A workshop: Corvallis, Oregon State University Press, p. 37-49.

McMahon, T.E., and Hartman, G.F., 1989, Influence of cover complexity and current velocity on winter habitat use by juvenile coho salmon (Oncorhynchus kisutch): Canadian Journal of Fisheries and Aquatic Sciences, v. 46, p. 1,551-1,557.

Michael, J.H. Jr., 1995, Enhancement effects of spawning pink salmon on stream rearing juvenile coho salmon-Managing one resource to benefit another: Northwest Science, v. 69, p. 228-232.

Montgomery, D.R., Beamer, E.M., Pess, G.R., and Quinn, T.P., 1999, Channel type and salmonid spawning distribution and abundance: Canadian Journal of Fisheries and Aquatic Sciences, v. 56, p. 377-387.

Moore, R.D., Fleming, S.W., Menounos, B., Wheate, R., Fountain, A., Stahl, K., Holm, K., and Jakob, M., 2009, Glacier change in western North America-Influences on hydrology, geomorphic hazards and water quality: Hydrological Processes, v. 23, p. 42-61.

Moring, J.R., and Lanz, R.L., 1975, The Alsea watershed study_Effects of logging on the aquatic resources of three headwater streams of the Alsea River, Oregon-Part I, Biological studies: Corvallis, Oregon Department of Fish and Wildlife Research Report, Fishery Research Report Number 9, 66 p.

Morley, R.B., and Station, P.B., 1988, The influence of time and size at release of juvenile coho salmon (Oncorhynchus kisutch) on returns at maturity-Results of studies on three brood years at Quinsam hatchery, B.C.: Nanaimo, British Columbia, Canada, Department of Fisheries and Oceans, Fisheries Research Branch, Pacific Biological Station, 126 p.

Mote, P.W., Parson, E.A., Hamlet, A.F., Keeton, W.S., Lettenmaier, D., Mantua, N., Miles, E.L., Peterson, D.W., Peterson, D.L., Slaughter, R., and Snover, A.K., 2003, Preparing for climatic change-The water, salmon, and forests of the Pacific Northwest: Climate Change, v. 61, p. 45-88.

Mueter, F.J., Ware, D.M., and Peterman, R.M., 2002, Spatial correlation patterns in coastal environmental variables and survival rates of salmon in the north-east Pacific ocean: Fisheries and Oceanography, v. 11, p. 205-218. 
Murphy, M.L., Thedinga, J.F., Koski, K.V., and Grette, G.B., 1984, A stream ecosystem in an oldgrowth forest in Southeast Alaska-Part V, Seasonal changes in habitat utilization by juvenile salmonids, in Fish and wildlife relationships in old growth forests-Proceedings of a symposium, April 12-15, 1982, Juneau, Alaska: American Institute for Fishery Research Biologists, p. 89-98.

National Oceanographic and Atmospheric Administration, 2014, Oceanic Nino Index data, accessed June 2014, at http://www.cpc.ncep.noaa.gov/products/analysis_monitoring/ensostuff/ensoyears.shtml.

Neave, F., 1949, Game fish populations of the Cowichan River: Bulletin No. 84 of the Fisheries Research Board of Canada, $32 \mathrm{p}$.

Nelson, M.C., and Reynolds, J.D., 2014, Time-delayed subsidies-Interspecies population effects in salmon: PLOS One, v. 9, p. 1-9.

Newcombe, C.P., and MacDonald., D.D., 1991, Effects of suspended sediments on aquatic ecosystems: North American Journal of Fisheries Management, v. 11, p. 72-82.

Nickelson, T.E., 1986, Influences of upwelling, ocean temperature, and smolt abundance on marine survival of coho salmon (Oncorhynchus kisutch) in the Oregon Production Area: Canadian Journal of Fisheries and Aquatic Sciences, v. 43, p. 527-535.

Nickelson, T.E., 1998, A habitat-based assessment of coho salmon production potential and escapement need for Oregon coastal streams: Portland, Oregon Department of Fish and Wildlife, Information Reports Number 98-4, 15 p.

Pauchauri, R. K. and Reisinger, A. (editors), 2008, IPCC 2007: Climate change 2007 synthesis reportContribution of working groups I, II and III to the Fourth Assessment Report of the Intergovernmental Panel on Climate Change: Geneva, Intergovernmental Panel on Climate Change, 104 p.

Pearcy, W.G., 1992, Ocean ecology of North Pacific salmonids-Books in recruitment fishery oceanography: Seattle, Washington Sea Grant Program, 190 p.

Peterman, R.M., 1978. Testing for density-dependent marine survival in Pacific salmonids: Journal of the Fisheries Board of Canada, v. 35, p.1,434-1,450.

Peterman, R.M., 1981, Form of random variation in salmon smolt-to-adult relations and its influence on production estimates: Canadian Journal of Fisheries and Aquatic Sciences, v. 38, v. 1,113-1,119.

Peterman, R.M., 1982, Model of salmon age structure and its use in preseason forecasting and studies of marine survival: Canadian Journal of Fisheries and Aquatic Sciences, v. 39, p. 1,444-1,452.

Peterman, R.M., 1989, Application of statistical power analysis to the Oregon coho salmon (Oncorhynchus kisutch) problem: Canadian Journal of Fisheries and Aquatic Sciences, v. 46, p. $1,183-1,187$.

Peterman, R.M., Pyper, B.J., Lapointe, M.F., Adkison, M.D., and Walters, C.J., 1998, Patterns of covariation in survival rates of British Columbian and Alaskan sockeye salmon (Oncorhynchus nerka) stocks: Canadian Journal of Fisheries and Aquatic Sciences, v. 55, p. 2,503-2,517.

Peterman, R.M., and Routledge, R.D., 1983, Experimental management of Oregon coho salmon (Oncorhynchus kisutch)_Designing for yield of information: Canadian Journal of Fisheries and Aquatic Sciences, v. 40, p. 1,212-1,223.

Peterson, N.P., and Reid, L.M., 1984, Wall-base channels - Their evolution, distribution, and use by juvenile coho salmon in the Clearwater River, Washington, in Proceedings of the Olympic Wild Fish Conference, Peninsula College and Olympic National Park, Port Angeles, Washington, p. 215-225.

Poole, G.C., and Berman, C.H., 2001, An ecological perspective on in-stream temperature-Natural heat dynamics and mechanisms of human-caused thermal degradation: Environmental Management, v. 27, p. 787-802.

Quinn, T.P., and Peterson, N.P., 1996, The influence of habitat complexity and fish size on over winter survival and growth of individually marked juvenile coho salmon (Oncorhynchus kisutch) in Big Beef Creek, Washington: Canadian Journal of Fisheries and Aquatic Sciences, v. 53, p. 1,555-1,564. 
R Core Team, 2013, R: A language and environment for statistical computing: Vienna Austria, R Foundation for Statistical Computing, accessed November 2016, at http://www.R-project.org/.

Reeves, G.H., Everest, F.H., and Nickelson, T.E., 1989, Identification of physical habitats limiting the production of coho salmon in western Oregon and Washington: Portland, Oregon, U.S. Forest Service, Pacific Northwest Research Laboratory, Technical Report PNW-GTR-245, 18 p.

Ricker, W.E., 1954, Stock and recruitment: Journal of the Fisheries Research Board of Canada, v. 11, p. 559-623.

Rupp, D.E., Wainwright, T.C., Lawson, P.W., and Peterson, W.T., 2012, Marine environment-based forecasting of coho salmon (Oncorhynchus kisutch) adult recruitment: Fisheries and Oceanography, v. 21, p. 1-19.

Ryding, K.E., and Skalski, J.R., 1999, Multivariate regression relationships between ocean conditions and early marine survival of coho salmon (Oncorhynchus kisutch): Canadian Journal of Fisheries and Aquatic Sciences, v. 56, p. 2,374-2,384.

Sandercock, F.K., 1991, Life history of coho salmon (Oncorhynchus kisutch), in Pacific salmon life histories: Vancouver, Canada, University of British Columbia Press, p. 395-446.

Scarlett, W.J., and Cederholm, C.J., 1984, Juvenile coho salmon fall-winter utilization of two small tributaries of the Clearwater River, Jefferson County, Washington, in Proceedings of the Olympic Wild Fish Conference, Peninsula College and Olympic National Park, Port Angeles, Washington, p. 227-242.

Scarnecchia, D.L., 1981, Effects of streamflow and upwelling on yield of wild coho salmon (Oncohynchus kisutch): Canadian Journal of Fisheries and Aquatic Science, v. 38, p. 471-475.

Sedell, J.R., Reeves, G.H., Hauer, F.R., Stanford, J.A., and Hawkins, C.P., 1990, Role of refugia in recovery from disturbance-Modern fragmented and disconnected river systems: Environmental Management, v. 14, p. 711-724.

Seiler, D., Neuhauser, S., and Ackley, M., 1981, Upstream/downstream salmonid trapping project, 1977-1980: Olympia, Washington Department of Fisheries, Progress Report No. 144, 197 p.

Seiler, D., Neuhauser, S., and Ackley, M., 1984, Upstream/downstream salmonid trapping project, 1980-1982: Olympia, Washington Department of Fisheries, Progress Report No. 200.

Seiler, D., Neuhauser, S., and Kishimoto, L., 2001, 2000 Skagit River wild 0+ chinook salmon evaluation-Annual project report: Olympia, Washington Department of Fish and Wildlife, $50 \mathrm{p}$.

Seiler, D., Volkhardt, G., Neuhauser, S., Hanratty, P., Kishimoto, L., Topping, P., and Ackley, M., 2003, 2003 wild coho forecasts for Puget Sound and Washington coastal systems: Olympia,

Washington Department of Fish and Wildlife Science Division, 24 p.

Servizi, J.A., and Martens, D.W., 1987, Some effects of suspended Fraser River sediments on sockeye salmon (Oncorhynchus nerka), in Sockeye salmon (Oncorhynchus nerka) population biology and future management: Canadian Special Publication on Fisheries and Aquatic Sciences, v. 96, p. 254 264.

Shapovalov, L., and Taft, A.C., 1954, The life histories of the steelhead rainbow trout (Salmo gairdneri gairdneri) and silver salmon (Oncorhynchus kisutch) with special reference to Waddel Creek, California, and recommendations regarding their management: Sacramento, State of California, Department of Fish and Game, Fish Bulletin No. 98.

Shaul, L., Weitkamp, L., Simpson, K., and Sawada, J., 2007, Trends in abundance and size of coho salmon in the Pacific Rim: North Pacific Anadromous Fish Commission Bulletin, v. 4, p. 93-104. Shirvell, C.S., 1990, Role of instream rootwads as juvenile coho salmon (Oncorhynchus kisutch) and steelhead trout $(O$. mykiss) cover habitat under varying streamflows: Canadian Journal of Fisheries and Aquatic Sciences, v. 47, p. 852-861.

Shmueli, G., 2010, To explain or predict?: Statistical Science v. 2,. p. 289-310. 
Sigler, J.W., Bjornn, T.C., and Everest, F.H., 1984, Effects of chronic turbidity on density and growth of steelhead and coho salmon: Transactions of the American Fisheries Society, v. 113, p. 142-150.

Skagit Council of Governors, 2009, Skagit countywide UGA open space concept plan: Skagit County

Planning and Development Services website, accessed May 17, 2016, at

http://www.skagitcounty.net/Departments/PlanningAndPermit/openspace.htm.

Smith, C. J., 2003, Salmon and steelhead habitat limiting factors-Water resource inventory areas 3 and 4, Skagit watershed: Olympia, Washington State Conservation Commission.

Smoker, W.A., 1955, Effects of stream flow on silver salmon production in western Washington: Seattle, University of Washington, Ph.D. dissertation, 175 p.

Sutton, R., and Soto, T., 2012, Juvenile coho salmon behavioural characteristics in Klamath River summer thermal refugia: River Research and Applications, v. 28, p. 338-346.

Teo, S.L., Botsford, L.W., and Hastings, A., 2009, Spatio-temporal covariability in coho salmon (Oncorhynchus kisutch) survival, from California to southeast Alaska: Deep Sea Research Part IITopical Studies in Oceanography, v. 56, p. 2,570-2,578.

Thedinga, J.F., and Koski, K.V., 1984, A stream ecosystem in an old-growth forest in southeast Alaska, Part VI-The production of coho salmon, Oncorhynchus kisutch, smolts and adults from Porcupine Creek, in Fish and wildlife relationships in old growth forests: Proceedings of a Symposium, April 12-15, 1982: Juneau, Alaska, American Institute for Fishery Research Biologists, p. 99-108.

Tschaplinski, P.J., 2000, The effects of forest harvesting, fishing, climate variation, and ocean conditions on salmonid populations of Carnation Creek, Vancouver Island, British ColumbiaSustainable fisheries management_-Pacific salmon: Boca Raton, Florida, CRC Press, p. 297-327. van den Berghe, E.P., and Gross, M.R., 1984, Female size and nest depth in coho salmon

(Oncorhynchus kisutch): Canadian Journal of Fisheries and Aquatic Sciences, v. 41, p. 204-206.

Washington Department of Fish and Wildlife, 2004, 2003 Annual report, Environmental Restoration Technical Assistance Section, Technical Application Division, Habitat Program: Washington Department of Fish and Wildlife, Olympia, Washington, 31 p., accessed June 2016, at http://wdfw.wa.gov/publications/00580/wdfw00580.pdf.

Washington Department of Fish and Wildlife, Salmonscape: Washington Department of Fish and Wildlife website, accessed June 2016, at http://apps.wdfs.wa.gov/salmonscape.

Washington Department of Fisheries, 1975, A catalog of Washington streams and salmon utilization: Washington Department of Fisheries, Seattle, Washington, accessed April 2017, at http://www.streamnetlibrary.org/?page_id $=95$.

Weitkamp, L., and Neely, K., 2002, Coho salmon (Oncorhynchus kisutch) ocean migration patternsInsight from marine coded-wire tag recoveries: Canadian Journal of Fisheries and Aquatic Sciences, v. 59, p. 1,100-1,115.

Welsh, H.H., Jr., Hodgson, G. R., Harvey, B. C., and Roche, M. F., 2001, Distribution of juvenile coho salmon in relation to water temperatures in tributaries of the Mattole River, California: North American Journal of Fisheries Management, v. 21, p. 464-470.

Wipfli, M.S., Hudson, J.P., Chaloner, D.T., and Caouette, J.P., 1999, Influence of salmon spawner densities on stream productivity in Southeast Alaska: Canadian Journal of Fisheries and Aquatic Sciences, v. 56, p. 1,600-1,611.

Zeileis, A., Kleiber, C., Krämer, W. and Hornik, K., 2003, Testing and dating of structural changes in practice: Computational Statistics and Data Analysis, v. 44, p. 109-123.

Zhou, S., 2007, Discriminating alternative stock-recruitment models and evaluating uncertainty in model structure: Fisheries Research, v. 86, p. 268-279. 
Zillges, G., 1977, Methodology for determining Puget Sound coho escapement goals, escapement estimates, 1977 preseason run size prediction and in-season run assessment: Olympia, Washington, Washington Department of Fisheries, Technical Report 28.

Zimmerman, M.S., 2012, 2012 wild coho forecasts for Puget Sound, Washington Coast, and Lower Columbia: Olympia, Washington, Washington Department of Fish and Wildlife, 47 p., accessed November 2016, at http://wdfw.wa.gov/publications/01404.

Zimmerman, M.S., Irvine, J.R., O’Neill, M., Anderson, J.H., Greene, C.M., Weinheimer, J., Trudel, M., and Rawson, K., 2015, Spatial and temporal patterns in smolt survival of wild and hatchery coho salmon in the Salish Sea: Marine and Coastal Fisheries-Dynamics, Management, and Ecosystem Science, v. 7, p. 116-134. 


\section{Appendix A. Definitions of Model Terms}

Table A1. Definitions of names of stocks (S), flows (F), and converters (C).

\begin{tabular}{|c|c|c|}
\hline Term & Type & Definition \\
\hline AvgQAprSeptSauk & $\mathrm{C}$ & $\begin{array}{l}\text { Average daily flow during April-September of juvenile year measured at Sauk } \\
\text { streamgage (in cubic feet per second) }\end{array}$ \\
\hline AvgQAprSeptSaukWC & $\mathrm{C}$ & $\begin{array}{l}\text { Average daily flow during April-September of juvenile year measured at Sauk above } \\
\text { White Chuck streamgage (in cubic feet per second) }\end{array}$ \\
\hline Chlor & $\mathrm{C}$ & Time series of chlorophyll-a densities \\
\hline Cycle & $\mathrm{C}$ & $\begin{array}{l}\text { Information from switch on model interface used to choose whether model output is } \\
\text { used to initiate escapement }\end{array}$ \\
\hline empty & $\mathrm{F}$ & Flow used to empty Escapement stock after each cohort is calculated \\
\hline Escapement & $\mathrm{S}$ & Fish returning to spawn (no distinction is made between escapement and spawners) \\
\hline Fraction harvested & $\mathrm{C}$ & Total harvest of adult fish \\
\hline Fraction ocean survival & $\mathrm{C}$ & Converter used to calculate fraction ocean survival from logit ocean survival \\
\hline Fraction predicted & $\mathrm{C}$ & $\begin{array}{l}\text { Fraction of smolt numbers predicted by Ricker curve that is realized owing to } \\
\text { environmental conditions }\end{array}$ \\
\hline FractionScour & $\mathrm{C}$ & Fraction of smolt population lost to scouring flow events \\
\hline FractionSummerFlow & $\mathrm{C}$ & $\begin{array}{l}\text { Fraction of smolt numbers predicted by Ricker curve that is realized owing to low } \\
\text { summer flow }\end{array}$ \\
\hline FractionTurbidity & $\mathrm{C}$ & $\begin{array}{l}\text { Fraction of smolt numbers predicted by Ricker curve that is realized owing to stream } \\
\text { turbidity after accounting for summer flow }\end{array}$ \\
\hline Habitat capacity & $\mathrm{C}$ & Smolt production per square meter of habitat \\
\hline Habitat change & $\mathrm{C}$ & Area of habitat gained or lost from current baseline (in square meters) \\
\hline Initial cohort & $\mathrm{C}$ & Time series of total number of spawners ( both males and females) \\
\hline $\begin{array}{l}\text { Logit Fraction ocean } \\
\text { survival }\end{array}$ & $\mathrm{C}$ & $\begin{array}{l}\text { Converter used to calculate logit of fraction of ocean survival based on indices of ocean } \\
\text { condition }\end{array}$ \\
\hline MaxQNovDecSauk & $\mathrm{C}$ & $\begin{array}{l}\text { Maximum daily flow during November and December during brood year measured at } \\
\text { Sauk streamgage }\end{array}$ \\
\hline MaxQNovDecSaukWC & $\mathrm{C}$ & $\begin{array}{l}\text { Maximum daily flow during November and December during brood year measured at } \\
\text { Sauk above White Chuck streamgage }\end{array}$ \\
\hline NPGO & $\mathrm{C}$ & Time series of North Pacific Gyre Oscillation (NPGO) values \\
\hline ocean mortality & $\mathrm{F}$ & $\begin{array}{l}\text { Flow that removes fish from Realized Smolts stock owing to ocean conditions and } \\
\text { harvest }\end{array}$ \\
\hline ocean survival & $\mathrm{F}$ & $\begin{array}{l}\text { Flow that transfers fish from Realized Smolts stock to Escapement stock to represent } \\
\text { ocean survival }\end{array}$ \\
\hline PDO & $\mathrm{C}$ & Time series of Pacific Decadal Ocillation (PDO) values \\
\hline Pinks & $\mathrm{C}$ & $\begin{array}{l}\text { Time series of number of pink salmon during juvenile year; determines which Ricker } \\
\text { curve to use }\end{array}$ \\
\hline Predicted Smolts & $\mathrm{S}$ & Stock of number of smolts predicted by Ricker curve based on escapement \\
\hline Realized Smolts & $\mathrm{S}$ & $\begin{array}{l}\text { Stock of number of smolt production actually realized owing to environmental } \\
\text { conditions }\end{array}$ \\
\hline Ricker Capacity & $\mathrm{C}$ & Parameter of Ricker equation describing density-dependent capacity \\
\hline Ricker Initial Slope & $\mathrm{C}$ & Parameter of Ricker equation describing non-density-dependent population growth \\
\hline SaukScourThreshold & $\mathrm{C}$ & Flow that results in redd scour measured at Sauk streamgage \\
\hline SaukWCScourThreshold & $\mathrm{C}$ & Flow that results in redd scour measured at Sauk above White Chuck streamgage \\
\hline ScourEffect & $\mathrm{C}$ & Fraction of smolt population lost to scouring flow events \\
\hline smolt mortality & $\mathrm{F}$ & $\begin{array}{l}\text { Flow that removes fish from Predicted Smolts stock if environmental conditions } \\
\text { indicate that the prediction will not be realized }\end{array}$ \\
\hline smolt supplement & $\mathrm{F}$ & $\begin{array}{l}\text { Flow that adds fish to Realized Smolts stock if environmental conditions indicate that } \\
\text { more fish than predicted will be realized }\end{array}$ \\
\hline smolt survival & $\mathrm{F}$ & Flow transferring fish from Predicted Smolts stock to Realized Smolts stock \\
\hline
\end{tabular}




\begin{tabular}{|l|l|l|}
\hline \multicolumn{1}{|c|}{ Term } & Type & \multicolumn{1}{|c|}{ Definition } \\
\hline spawn & F & $\begin{array}{l}\text { Flow adding fish to Predicted Smolts for each cohort based on escapement and Ricker } \\
\text { curve }\end{array}$ \\
\hline Turbid30 & C & $\begin{array}{l}\text { Time series of the number of days with average turbidity greater than 30 Formazin } \\
\text { Nephelometric Units measured at the Anacortes Water Treatment Plant from } \\
\text { February of brood year through smolting }\end{array}$ \\
\hline UseNPGOChlor & C & $\begin{array}{c}\text { Converter containing information from switch on interface used to determine whether to } \\
\text { use NPGO and chlorophyll-a density or PDO to describe ocean conditions }\end{array}$ \\
\hline UsePDO & C & $\begin{array}{c}\text { Converter containing information from switch on interface used to determine whether to } \\
\text { use Oceanic Nino Index (ONI) or PDO to describe ocean conditions }\end{array}$ \\
\hline UseSauk & C & $\begin{array}{c}\text { Converter containing information from switch on interface used to determine whether to } \\
\text { use flow data from Sauk or Sauk above White Chuck streamgages }\end{array}$ \\
\hline UseSaukWC & C & $\begin{array}{c}\text { Converter containing information from switch on interface used to determine whether to } \\
\text { use flow data from Sauk or Sauk above White Chuck streamgages }\end{array}$ \\
\hline
\end{tabular}




\section{Appendix B. Accessing and Running the Model}

\section{Accessing the Model}

The Skagit River coho system dynamics simulation model can be run by accessing it using the isee ${ }^{\circledR}$ Exchange site at https://exchange.isee.systems.com/public/andreawoodward/skagit-coho. The model is set up to run using data from brood years (BYs) 1989-2012. The user can use alternative data by adjusting the inputs on the interface shown on the website and described in section, "Running the Model". The online version of the software will not allow the user to modify the model structure or change parameters of equations. Equations used by the model are available in appendix D.

\section{Running the Model}

The isee ${ }^{\circledR}$ Exchange website provides an interface that enables the user to run a model without a personal copy of Stella Architect version 1.1.2 ${ }^{\circledR}$. The title page opens first and includes buttons to access the users' guide (this document) and a description of model structure and elements (fig. B1). Paging down using the down arrow on the keyboard leads to the dashboard (fig. B2).

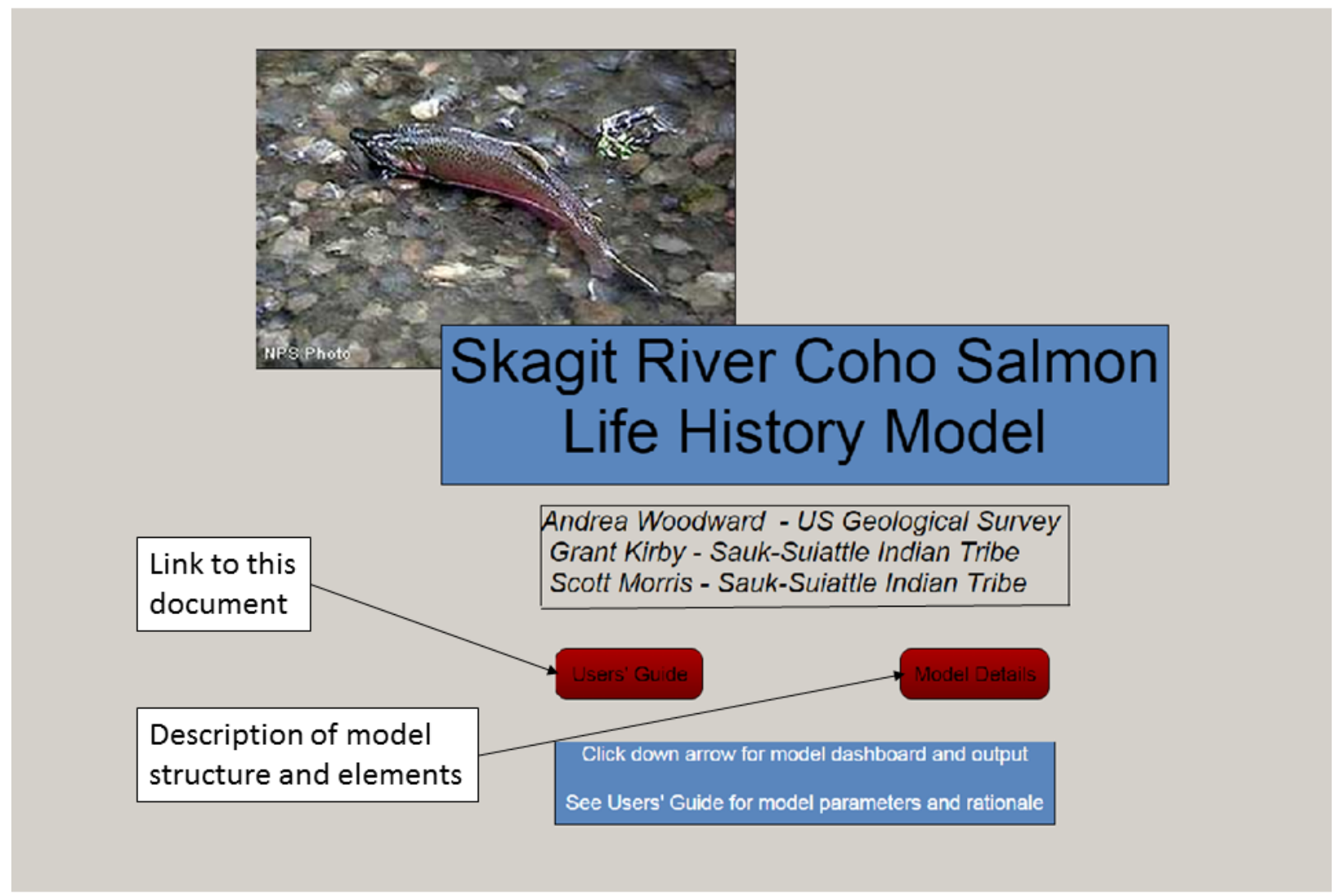

Figure B1. Screen capture showing title page of model in interface and buttons for accessing the users' guide (this document), and a detailed description of model elements. 


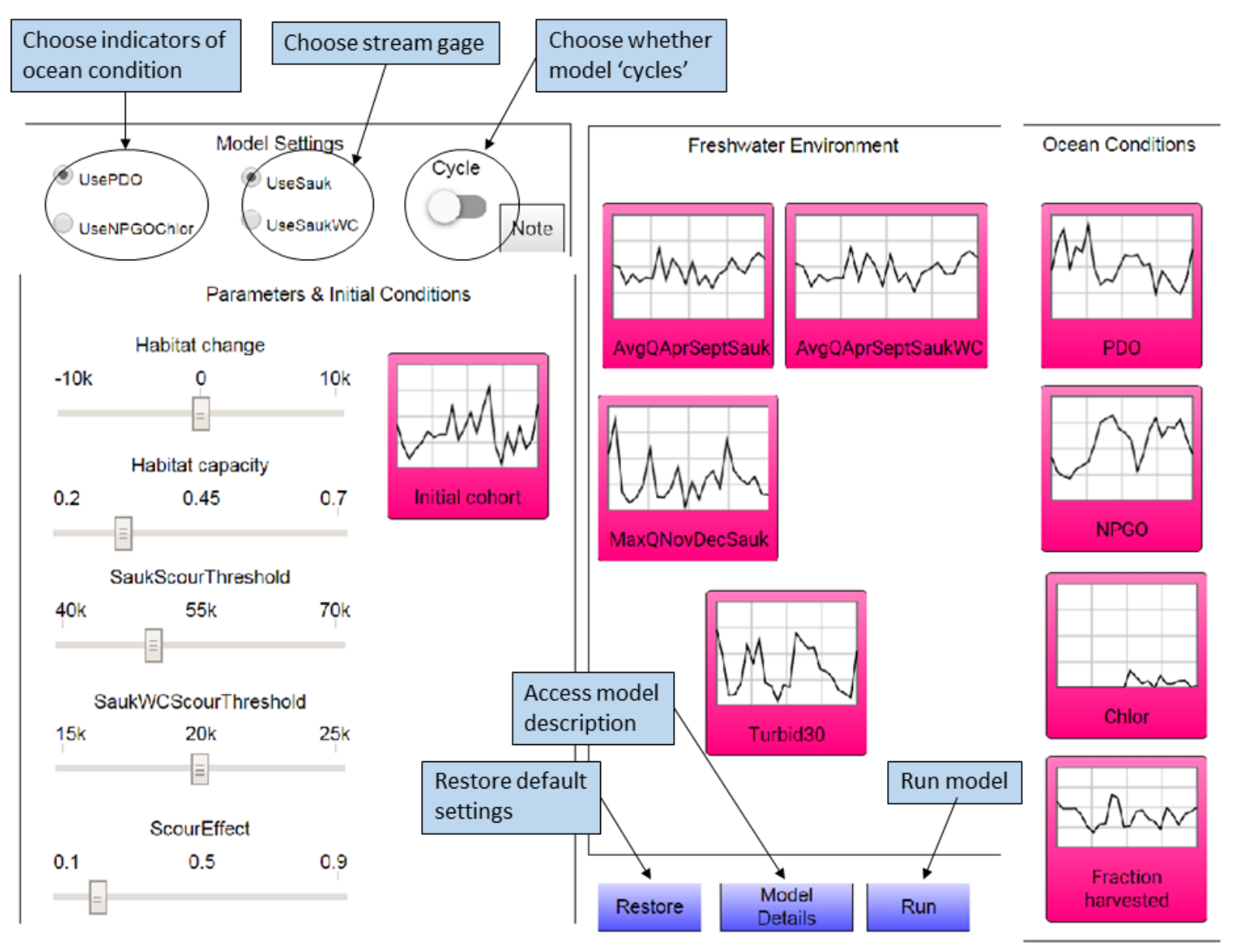

Figure B2. Screen capture showing dashboard for running model.

The dashboard enables the user to set model conditions and run the model (fig. B2). The user can decide whether to use PDO or NGPO and chlorophyll-a density as indicators of ocean conditions by clicking on the appropriate radio button. The same is true for selection of streamgage. The user also can decide whether the model will be initiated each year with observed estimates of escapement (model does not "cycle") or whether the model will use its own output for subsequent escapement after each cohort has been initialized (model "cycles").

Important Note (available from "Note" button next to "Cycle" switch): Because the time series of chlorophyll-a density is not as long as the rest of the time series, the model will give spurious results if "UseNPGOChlor" and "Cycle" are used together. Results also are not legitimate for years that do not have chlorophyll-a data when "Cycle" is turned off (that is, first 13 years of the time series).

Default escapement and environmental data for the model are from BYs 1989 to 2012, and are the data used to develop the model. The user can change these data to represent actual data collected in other years, to experiment with novel conditions, or to investigate the sensitivity of the model to changes in a single variable (fig. B3). 


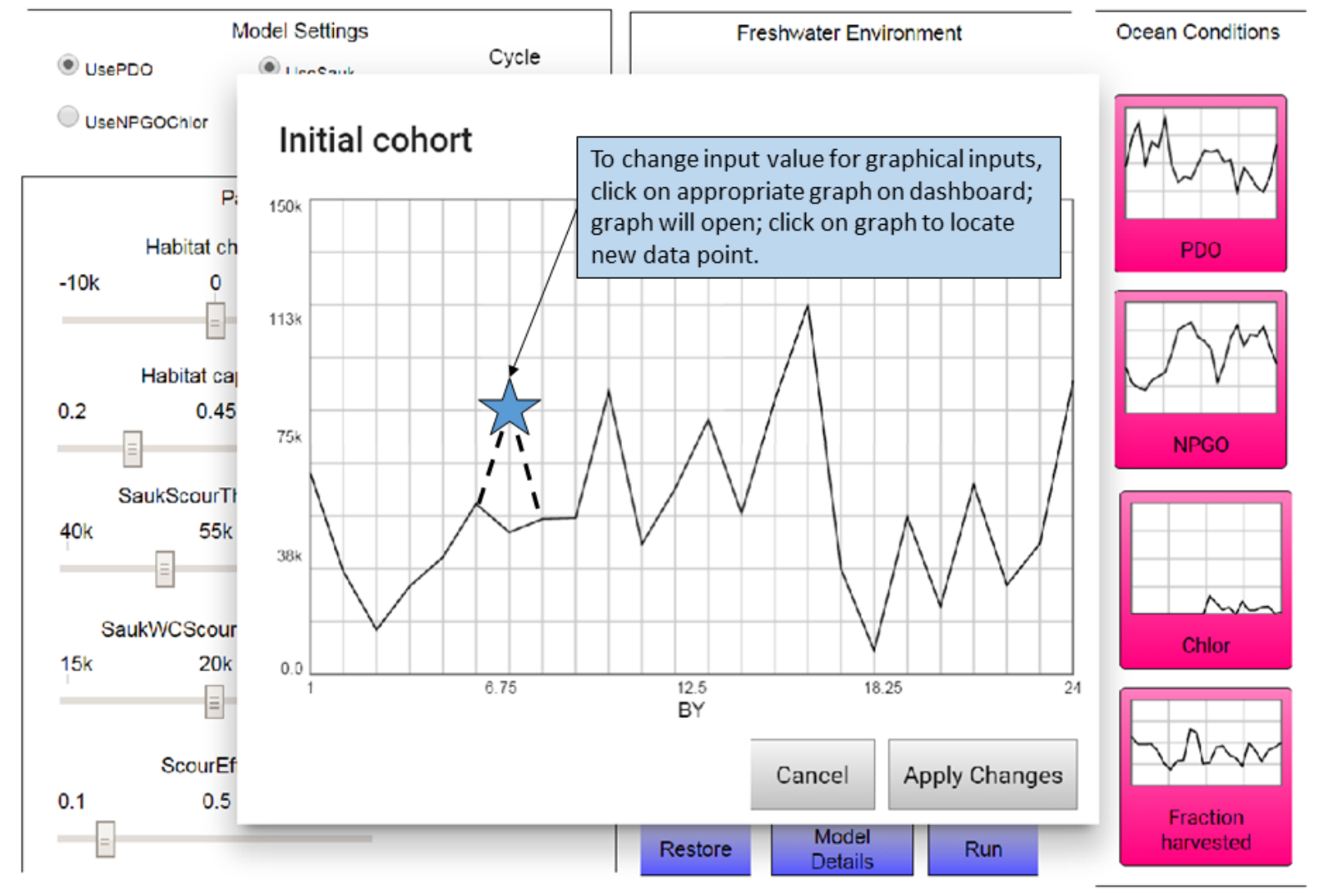

Figure B3. Screen capture showing how to change data for graphical inputs.

Changing data using the slider bars requires simply dragging the bar to the desired value. Changing graphical data requires first clicking on the appropriate graph. The graph will enlarge (fig. B3), and the data can be changed by clicking on the graph at the desired new value and then clicking on "Apply Changes".

After the data have been changed, clicking on "Run" will run the model. To reset the original, default values, click on "Restore".

Output from the model displays on the third page of the model interface (fig. B4). It can be saved to an Excel ${ }^{\circledR}$ spreadsheet by right-clicking on the output table, and then clicking on the sign that reads "Copy Data". Next, click Paste in an open spreadsheet. The model is set up to indicate annual results for the stocks Realized Smolts and Escapement. 


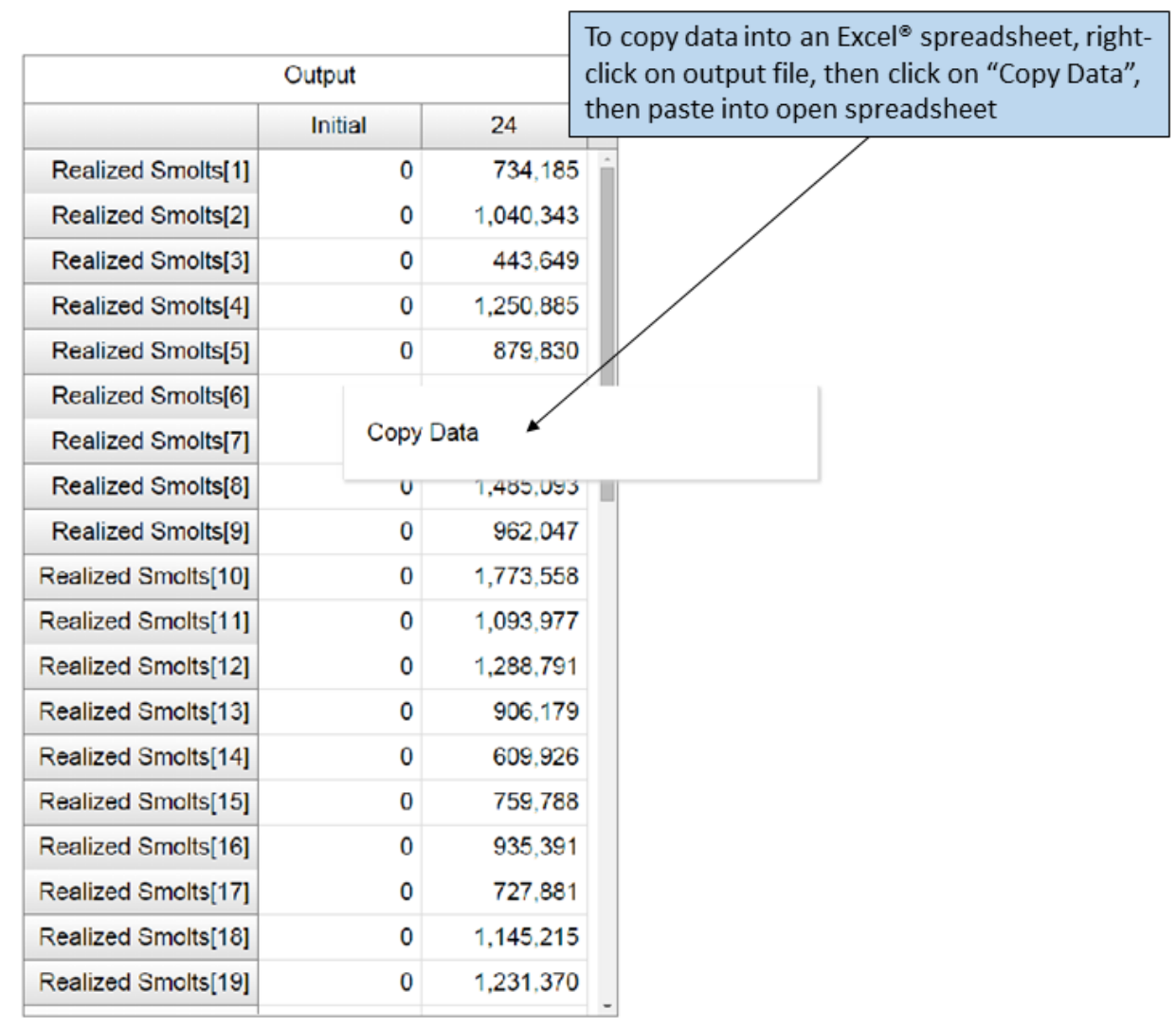

Figure B4. Screen capture showing model output page and opportunity to copy output to a spreadsheet.

Clicking on "Model Details" on the title page or dashboard takes the user to an image of the entire model structure followed by pages that define individual model elements (fig. B5). The full background on methods and rationale for model development is only available in the users' guide (this document), which can be accessed from a button on the title page.

Stella version 1.1. $2^{\circledR}$ software has many more features and capabilities than described here, but they are available only with the purchase of the software. 


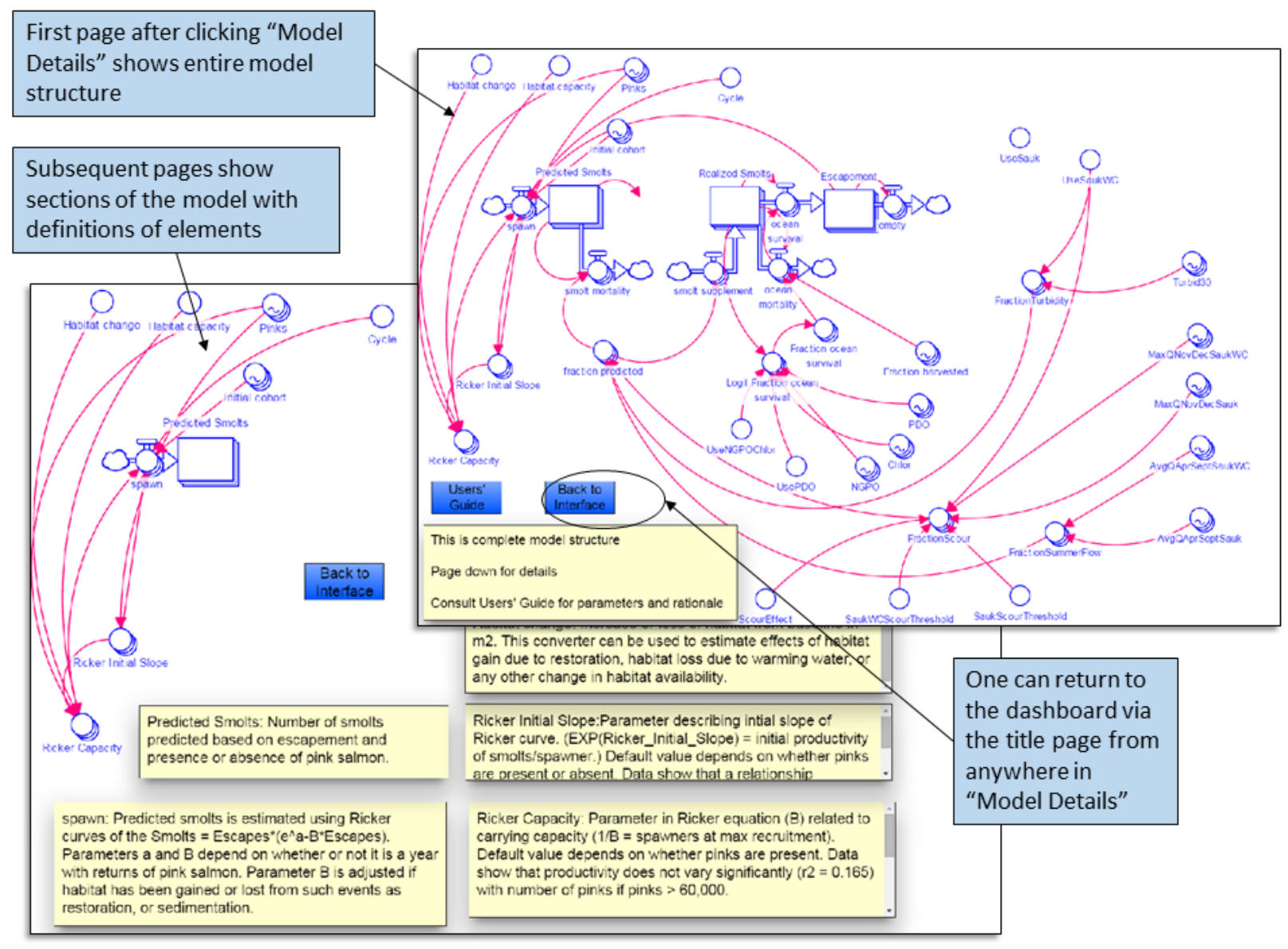

Figure B5. Screen capture showing the first two pages of "Model Details." 


\section{Appendix C. Skagit Salmon Co-Managers Data Used in Model Development}

[This dataset is maintained by Pete Kairis, resource manager for the Swinomish Indian Tribe. Data in bold font are preliminary. Abbreviations: BY, brood year; RY, run year; OA3, estimated survival to ocean age 3; NA, not available]

\begin{tabular}{|c|c|c|c|c|c|c|}
\hline \multirow[b]{2}{*}{$\begin{array}{l}\text { Brood } \\
\text { year }\end{array}$} & \multirow[b]{2}{*}{$\begin{array}{l}\text { Migration } \\
\text { year }\end{array}$} & \multirow[b]{2}{*}{$\begin{array}{c}\text { Return } \\
\text { year }\end{array}$} & \multicolumn{4}{|c|}{ Total wild (Skagit + Baker) } \\
\hline & & & $\begin{array}{l}\text { Total wild BY } \\
\text { smolts }\end{array}$ & $\begin{array}{l}\text { Total wild RY } \\
\text { esc }\end{array}$ & Total wild OA3 & $\begin{array}{c}\text { Total wild smolt- } \\
\text { to-OA3 survival } \\
\text { (percentage) }\end{array}$ \\
\hline 1989 & 1991 & 1992 & 587,000 & 27,793 & 64,860 & 11.05 \\
\hline 1990 & 1992 & 1993 & $1,073,200$ & 36,939 & 71,338 & 6.65 \\
\hline 1991 & 1993 & 1994 & 619,868 & 53,815 & 103,715 & 16.73 \\
\hline 1992 & 1994 & 1995 & $1,129,000$ & 44,817 & 87,037 & 7.71 \\
\hline 1993 & 1995 & 1996 & 720,000 & 48,997 & 82,922 & 11.52 \\
\hline 1994 & 1996 & 1997 & $1,125,000$ & 49,289 & 66,550 & 5.92 \\
\hline 1995 & 1997 & 1998 & $1,136,268$ & 89,338 & 109,911 & 9.67 \\
\hline 1996 & 1998 & 1999 & $1,707,625$ & 41,082 & 57,636 & 3.38 \\
\hline 1997 & 1999 & 2000 & 677,779 & 58,600 & 83,480 & 12.32 \\
\hline 1998 & 2000 & 2001 & $1,540,590$ & 80,442 & NA & NA \\
\hline 1999 & 2001 & 2002 & $1,013,523$ & 50,774 & NA & NA \\
\hline 2000 & 2002 & 2003 & $1,884,772$ & 86,672 & 116,325 & 6.17 \\
\hline 2001 & 2003 & 2004 & $1,382,479$ & 116,706 & 158,950 & 11.5 \\
\hline 2002 & 2004 & 2005 & 885,082 & 33,236 & 59,985 & 6.78 \\
\hline 2003 & 2005 & 2006 & $1,017,519$ & 7,392 & 13,736 & 1.35 \\
\hline 2004 & 2006 & 2007 & 735,876 & 49,708 & 77,315 & 10.51 \\
\hline 2005 & 2007 & 2008 & 747,491 & 21,408 & 31,610 & 4.23 \\
\hline 2006 & 2008 & 2009 & 426,963 & 59,935 & 77,562 & 18.17 \\
\hline 2007 & 2009 & 2010 & $1,475,065$ & 28,134 & 56,233 & 3.81 \\
\hline 2008 & 2010 & 2011 & $1,447,110$ & 41,297 & 69,891 & 4.83 \\
\hline 2009 & 2011 & 2012 & 951,990 & 92,687 & 128,837 & 13.53 \\
\hline 2010 & 2012 & 2013 & $1,237,000$ & 84,479 & 144,380 & 11.67 \\
\hline 2011 & 2013 & 2014 & $1,409,000$ & 24,820 & 44,788 & 3.18 \\
\hline 2012 & 2014 & 2015 & $1,722,084$ & 5,794 & 11,587 & 0.67 \\
\hline 2013 & 2015 & 2016 & 665,087 & 35,080 & 41,901 & 6.30 \\
\hline 2014 & 2016 & 2017 & 729,392 & & & \\
\hline
\end{tabular}




\section{Appendix D. Model Equations}

Model equations as shown on the 'Equation' tab in Stella Architect version 1.1.2 ${ }^{\circledR}$ software:

Escapement $[\mathrm{BY}](\mathrm{t})=$ Escapement $[\mathrm{BY}](\mathrm{t}-\mathrm{dt})+($ ocean_survival[BY] - empty[BY] $) * d t$

INIT Escapement[BY] $=0$

INFLOWS:

ocean_survival[BY] $=($ Realized_Smolts $(B Y)$-ocean_mortality $(B Y))$

OUTFLOWS:

empty $[\mathrm{BY}]=$ Escapement(BY)

Predicted_Smolts[BY] $(\mathrm{t})=$ Predicted_Smolts[BY] $(\mathrm{t}-\mathrm{dt})+(\operatorname{spawn}[\mathrm{BY}]-$ smolt_mortality[BY] smolt_survival[BY] $* \mathrm{dt}$

INIT Predicted_Smolts[BY] $=0$

INFLOWS:

spawn[BY] $=$ if Cycle $=0$ then Initial_cohort(BY)*EXP(Ricker_Initial_Slope(BY)-

Ricker_Capacity(BY)*Initial_cohort(BY)) else (if BY>3 then Escapement(BY-

3)*EXP(Ricker_Initial_Slope(BY)-Ricker_Capacity(BY)*Escapement(BY-3))

else (Initial_cohort(BY)*EXP(Ricker_Initial_Slope(BY)-

Ricker_Capacity(BY)*Initial_cohort(BY))))

OUTFLOWS:

smolt_mortality[BY] $=$ if fraction_predicted $<1$ then (Predicted_Smolts(BY) * $(1$ -

fraction_predicted)) else 0

smolt_survival[BY] $=$ Predicted_Smolts(BY) -smolt_mortality(BY)

Realized_Smolts $[\mathrm{BY}](\mathrm{t})=$ Realized_Smolts $[\mathrm{BY}](\mathrm{t}-\overline{\mathrm{d} t})+($ smolt_survival $[\mathrm{BY}]+$

smolt_supplement[BY] - ocean_survival[BY] - ocean_mortality[BY]) $* d t$

INIT Realized_Smolts[BY] $=0$

INFLOWS:

smolt_survival[BY] $=$ Predicted_Smolts(BY) - smolt_mortality $(B Y)$

smolt_supplement $[\mathrm{BY}]=$ if fraction_predicted(BY) $>1$ then $(\operatorname{Predicted}$ SSmolts(BY) *

(fraction_predicted(BY) - 1)) else 0

OUTFLOWS:

ocean_survival[BY] $=($ Realized_Smolts(BY)-ocean_mortality $(B Y))$

ocean_mortality $[\mathrm{BY}]=($ Realized_Smolts $(\mathrm{BY}) *(1$-Fraction_ocean_survival $))+$

$($ Realized_Smolts $(\mathrm{BY}) *($ Fraction_ocean_survival) $*$ fraction_harvested(BY))

AvgQAprSeptSauk[BY] = GRAPH(BY)

AvgQAprSeptSaukWC[BY] = GRAPH(BY)

Chlor $[\mathrm{BY}]=\mathrm{GRAPH}(\mathrm{BY})$

Cycle $=0$

FractionScour[BY] $=$ if $($ UseSaukWC $=1)$ then (if

MaxQNovDecSaukWC $>$ SaukWCScourThreshold then -ScourEffect else 0) else (if

MaxQNovDecSauk>SaukScourThreshold then - ScourEffect else 0)

FractionSummerFlow[BY] = if $($ UseSaukWC $=1)$ then $0.0004445 *$ AvgQAprSeptSaukWC $(B Y)+$ .505373 else $0.00014034 *$ AvgQAprSeptSauk(BY) +0.37 
FractionTurbidity[BY] $=$ if $($ UseSaukWC $=1)$ then $-.000098 *$ Turbid30(BY)^2+ $.001308 *$ Turbid30(BY) -0.255861 else $-0.000163 *$ Turbid30(BY)^2 $+0.007 *$ Turbid30(BY) 0.03507

Fraction_harvested[BY] $=$ GRAPH(BY)

Fraction ocean survival[BY] =

$10^{\wedge}$ Logit_Fraction_ocean_survival/(1+10^Logit_Fraction_ocean_survival)

fraction_predicted[BY] $=$ FractionSummerFlow + FractionTurbidity+ FractionScour

Habitat_capacity $=0.31$

Habitat_change $=0$

Initial_cohort[BY] $=$ GRAPH(BY)

Logit_Fraction_ocean_survival[BY] $=$ If $(\mathrm{UsePDO}=1)$ then $(-$

$.0000003844 *$ Realized_Smolts(BY)-0.1431*PDO+.1057*PDO(BY)*PDO(BY)-0.7959) else if $($ UseNGPOChlor=1) then $(.28874 * \mathrm{NGPO}(\mathrm{BY})+.04462 *$ Chlor(BY) -1.69135$)$ else 0

MaxQNovDecSauk[BY] = GRAPH(BY)

MaxQNovDecSaukWC[BY] = GRAPH(BY)

$\mathrm{NGPO}[\mathrm{BY}]=\mathrm{GRAPH}(\mathrm{BY})$

Ricker_Capacity[BY] $=$ IF $($ Pinks $(\mathrm{BY})>0)$

THEN EXP(Ricker_Initial_Slope(BY) - 1)/(Habitat_change*Habitat_capacity+1460832)

ELSE EXP(Ricker_Initial_Slope(BY) - 1)/(Habitat_change*Habitat_capacity+1044869)

Ricker_Initial_Slope[BY] $=$ if Pinks(BY) $>0$ then 4.2919 else 3.8436

SaukScourThreshold $=50000$

SaukWCScourThreshold $=20000$

ScourEffect $=0.2$

UseNGPOChlor $=0$

$\mathrm{UsePDO}=0$

UseSauk $=0$

UseSaukWC $=0$ 

Publishing support provided by the U.S. Geological Survey Science Publishing Network, Tacoma Publishing Service Center

For more information concerning the research in this report, contact the Director, Forest and Rangeland Ecosystem Science Center U.S. Geological Survey

777 NW 9th St., Suite 400

Corvallis, Oregon 97330

http://fresc.usgs.gov 
